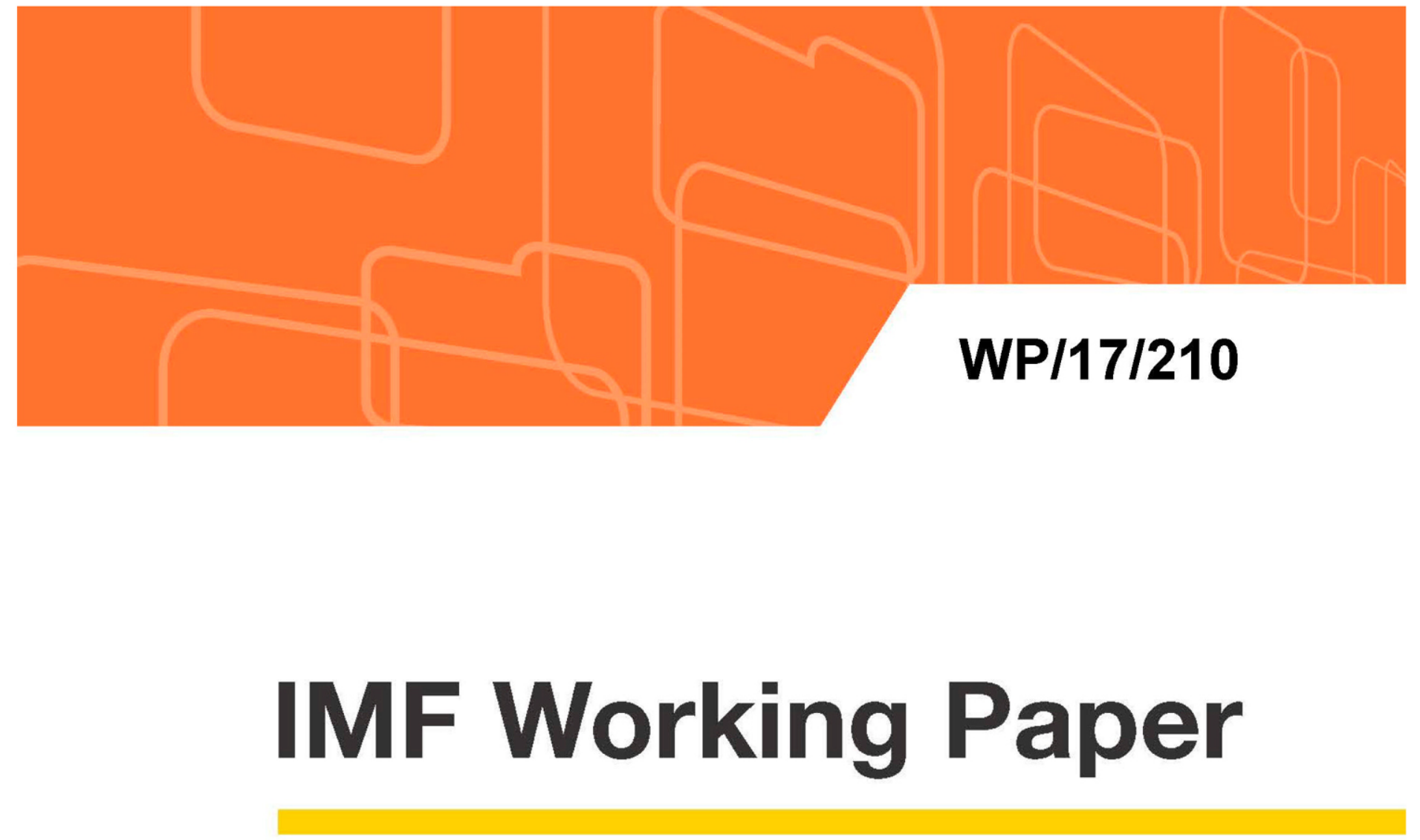

\title{
Interconnectedness of Global Systemically-Important Banks and Insurers
}

by Sheheryar Malik and TengTeng Xu

IMF Working Papers describe research in progress by the author(s) and are published to elicit comments and to encourage debate. The views expressed in IMF Working Papers are those of the author(s) and do not necessarily represent the views of the IMF, its Executive Board, or IMF management. 


\section{WP/17/210}

\section{IMF Working Paper}

\section{Interconnectedness of Global Systemically-Important Banks and Insurers}

by Sheheryar Malik and TengTeng Xu

IMF Working Papers describe research in progress by the author(s) and are published to elicit comments and to encourage debate. The views expressed in IMF Working Papers are those of the author(s) and do not necessarily represent the views of the IMF, its Executive Board, or IMF management.

I N T E R N A T I O N A L M O N E T A R Y F U N D 


\title{
IMF Working Paper
}

Monetary and Capital Markets Department

\section{Interconnectedness of Global Systemically Important Banks and Insurers \\ Prepared by Sheheryar Malik and TengTeng $\mathrm{Xu}^{1}$}

Authorized for distribution by Udaibir S. Das

September 2017

\section{IMF Working Papers describe research in progress by the author(s) and are published to elicit comments and to encourage debate. The views expressed in IMF Working Papers are those of the author(s) and do not necessarily represent the views of the IMF, its Executive Board, or IMF management.}

\begin{abstract}
Interconnectedness among global systemically important banks (GSIBs) and global systemically important insurers (GSIIs) has important financial stability implications. This paper examines connectedness among United States, European and Asian GSIBs and GSIIs, using publicly-available daily equity returns and intra-day volatility data from October 2007 to August 2016. Results reveal strong regional clusters of return and volatility connectedness amongst GSIBs and GSIIs. Compared to Asia, selected GSIBs and GSIIs headquartered in the United States and Europe appear to be main sources of market-based connectedness. Total system connectedness - i.e., among all GSIBs and GSIIs - tends to rise during financial stress, which is corroborated by a balance sheet oriented systemic risk measure. Lastly, the paper demonstrates significant influence of economic policy uncertainty and U.S. long-term interest rates on total connectedness among systemically important institutions, and the important role of bank profitability and asset quality in driving bank-specific return connectedness.
\end{abstract}

JEL Classification Numbers: G21, G22 and C32.

Keywords: Global systemically important banks and insurers, connectedness, equity prices, volatility, vector autoregression.

Authors’ E-Mail Addresses: smalik2@imf.org and txu@imf.org

\footnotetext{
${ }^{1}$ We are grateful to Apostolos Apostolou, Udaibir S. Das, Daniel Hardy, Paul Hiebert, Tadeusz Galeza, Gee Hee Hong, Peter Lindner, Steven Phillips and Nobu Sugimoto and participants in the MCM Policy Forum, for helpful insights and comments. All remaining errors are our own.
} 


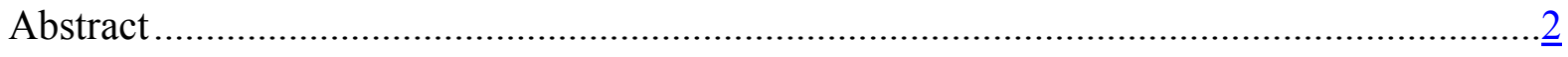

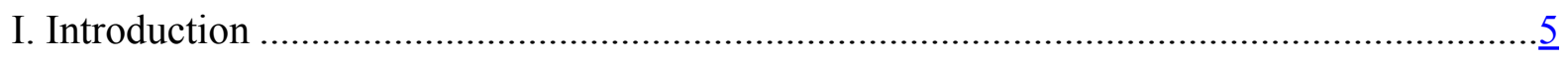

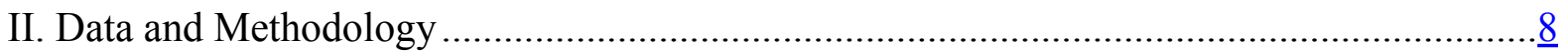

A. Data and Stylized Facts ...........................................................................

B. Methodology and Measure of Connectedness ................................................11

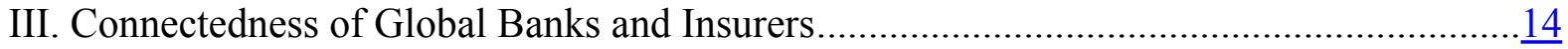

A. Global Connectedness Among GSIBs and GSIIs ....................................... $\frac{14}{20}$

B. Global Connectedness Among GSIBs ........................................................ $\frac{20}{\underline{20}}$

C. Global Connectedness Among GSIIs........................................................... $\frac{24}{24}$

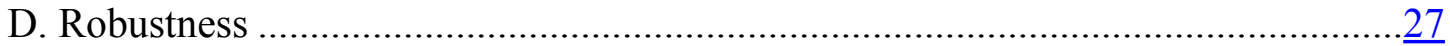

E. Connectedness Compared with a Balance Sheet-oriented Systemic Risk Measure-

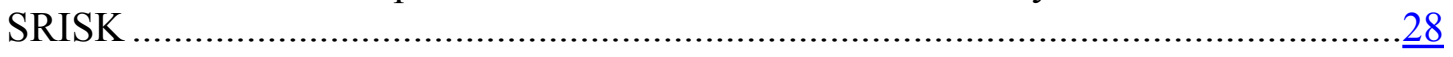

IV. Investigation Into Factors Influencing Connectedness.............................................. $\underline{30}$

A. Common Factors and Global Connectedness …............................................ $\frac{30}{36}$

B. Predicting Connectedness via Common Factors .............................................. $\frac{36}{41}$

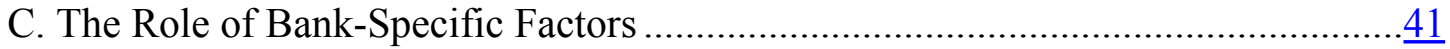

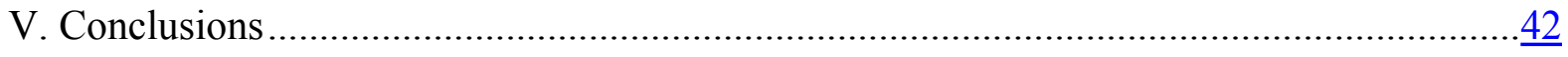

Tables

1. Sample of Global Systemically Important Banks and Insurers …................................... $\underline{8}$

2. Predictive Regression: Global Connectedness......................................................... $\frac{37}{40}$

3. Predictive Regression: Total Directional Connectedness - To- and From-Degrees ........... $\underline{40}$

4. Panel Regression Controlling for Bank-Specific and Global Factors .............................. 42

Figures

1. Assets of Global Systemically Important Banks ....................................................... 9

2. Assets of Global Systemically Important Insurers..................................................... $\underline{9}$

3. Average Daily Returns of Equity Prices for GSIBs and GSIIs ...................................10

4. Intra-Day Volatility of Equity Prices for GSIBs and GSIIs ........................................11

5. Global Dynamic Connectedness among GSIBs and GSIIs …................................... 15

6. Equity Return Connectedness among GSIBs and GSIIs ........................................... 17

7. Net Directional Connectedness in the System of GSIBs and GSIIs ................................18

8. Net Dynamic Return Connectedness in the System of GSIBs and GSIIs .........................19

9. Net Dynamic Volatility Connectedness in the System of GSIBs and GSIIs ......................20

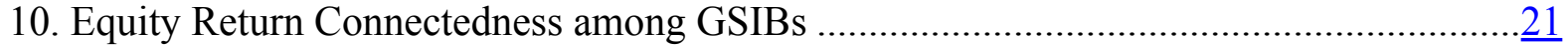

11. Net Directional Connectedness in the System of GSIBs ..........................................22

12. Net Dynamic Return Connectedness in the System of GSIBs .....................................23 
13. Net Dynamic Volatility Connectedness in the System of GSIBs ................................24

14. Equity Return Connectedness Among GSIIs.........................................................25

15. Net Directional Connectedness in the System of GSIIs ..............................................

16. Net Dynamic Return and Volatility Connectedness in the System of GSIIs....................27

17. Global Connectedness vs. SRISK ......................................................................29

18. Global Connectedness vs. Selected Risk Indicators: July 2008-August 2016 ..................

19. Global Connectedness vs. Selected Bond Yields ..................................................... 33

20. U.S.10-year Yield vs. Common Factor...................................................................... $\frac{34}{38}$

21. Within-sample Predictive Accuracy ....................................................................... $\frac{38}{38}$

22. Out-of-Sample Predictive Accuracy ........................................................................ $\frac{38}{38}$

23. Out-of-Sample Predictions and Counterfactuals ...........................................................

Boxes

1. Dynamic Responses of Global Connectedness to Selected Shocks.................................. $\underline{35}$

2. Projecting Global Connectedness Conditional on a U.S. Growth Scenario .......................44 


\section{INTRODUCTION}

The Global Financial Crisis of 2007-2009 highlighted the role of global systemically important banks and insurers in the transmission of financial shocks across countries and markets. Given their size, complexity and systemic interconnectedness, distress or disorderly resolution of these financial institutions has caused significant disruptions in the wider financial system and economic activity, and have at times required public sector bailouts. Starting in 2011, the Financial Stability Board (FSB) has maintained a list of global systemically important banks (GSIBs), and global systemically important insurers (GSIIs), as part of an integrated set of policy measures to address systemic and moral hazard risks associated with systemically important financial institutions. Judgments of such systemic importance may reflect not only size and complexity but also a high degree of interconnectedness.

Motivated by such considerations, this paper examines interconnectedness among GSIBs and GSIIs, a crucial element in understanding the transmission and evolution of financial stress. We analyze and quantify connectedness among U.S., European, and Asian GSIBs and GSIIs - as identified by the FSB - using the Diebold and Yilmaz (2014 and 2015) approach, applied to publicly-available daily equity return and intra-day equity volatility data. ${ }^{2} \mathrm{We}$ focus on the list of GSIBs and GSIIs identified by the FSB in the past three years, which was published by the FSB in 2016, 2015 and 2014 available in the public domain. ${ }^{3}$

The span for this analysis runs from October 2007 to August 2016, and considers: (i) static (average) connectedness over the full sample; and (ii) dynamic connectedness, capturing its evolution over time. In addition, we compare the market connectedness measure with SRISK, a balance-sheet based systemic risk measure put forth by Acharya et al. $(2010,2012)$ that has been gaining in popularity recently. Furthermore, we explore and examine factors that influence global and regional connectedness using linear and quantile regression frameworks. In particular, we analyze risk indicators including global economic policy uncertainty, computed based on the methodology put forth in Baker, Bloom, and Davis (2016), and the role of short-term and long-term government bond yields. We also conduct scenario analysis to project connectedness going forward based on these factors. Finally, we examine the role of bank-specific balance sheet factors such as asset quality and profitability (publicly available data) in driving return connectedness for GSIBs based on panel data analysis.

\footnotetext{
${ }^{2}$ Proceeding with a market-based approach - applied to publicly-available data -is in part because cross-entity and cross-border exposure data for GSIBs and GSIIs are typically confidential and not accessible.

${ }^{3}$ See for example http://www.fsb.org/2016/11/2016-list-of-global-systemically-important-banks-g-sibs/ and http://www.fsb.org/2015/11/fsb-publishes-the-2015-update-of-the-g-sii-list/
} 
While this paper's attention focuses on the methodology of Diebold and Yilmaz, there are alternative approaches aimed at quantifying interconnectedness which have been proposed in the literature. Leading examples are inter alia, CoVaR by Adrian and Brunnermeier (2016), SRISK by Acharya et al. (2010, 2012) and SyRIn by Segoviano et al. (2017, forthcoming). Our motivation for focusing on Diebold and Yilmaz here is to be able to extract measures of connectedness, which are intimately-related to key measures of connectedness used in the network literature - interest in which has grown significantly in recent years. ${ }^{4}$ Overall, as will be described subsequently, this approach effectively marries VAR variance-decomposition theory and network topology theory, recognizing that variance decompositions of VARs form weighted directed networks, characterizing connectedness in those networks, and in turn characterizing connectedness among GSIBs and GSIIs based on the VAR. ${ }^{5}$

This paper contributes to the existing empirical literature on financial connectedness in four main dimensions. First, we attempt to estimate market-based interlinkages among GSIBs and GSIIs, in order to better understand the connections among financial intermediaries. Regarding the insurance sector, specifically, the global financial crisis has highlighted the role it can play in propagating systemic financial risks. ${ }^{6}$ Second, we examine the relationship between the market-based connectedness measure - implied by the Diebold and Yilmaz approach - and a widely-used systemic risk measure that draws on balance sheet-based information. Third, we examine the extent which market-based connectedness can be explained by risk indicators such as economic policy uncertainty, VIX, as well as short and long maturity bond yields. In noting that measurement of economic policy uncertainty based on qualitative underlying data has been proposed by Baker, Bloom, and Davis (2016), this paper also adds to the literature by quantifying the relevance of this novel measure for interconnectedness among GSIBs and GSIIs. Finally, the paper examines the role of bank balance sheet variables such as profitability and asset quality in driving bank-specific return connectedness.

The main findings of the paper are as follows. First, there is evidence of strong regional clusters in returns and volatility connectedness among GSIBs and GSIIs. The strongest pairwise linkages are found among GSIBs and GSIIs within each region, namely, Asia, the

\footnotetext{
${ }^{4}$ Research on networks has grown rapidly in recent years. Newman (2010) and Jackson (2008) provide good general and economic introductions, respectively. Seminal contributions to the characterization, detection, and estimation of causal links in networks range from the early work of Pearl (2000) to the more recent work of White and Chalak (2009). Furthermore, Diebold and Yilmaz (2014) show that connectedness measures based on variance decompositions are closely related to the CoVaR measure. Other applications of network mappings include Ohnsorge et al (2014).

${ }^{5}$ In future research, we aim to compare and contrast estimated connectedness measures—-for our selected sample of GSIBs and GSIIs - across the alternative aforementioned methodologies.

${ }^{6}$ Moreover, the estimated contribution of life insurers to the overall level of systemic risk in the global financial system has been increasing in recent years (GFSR, April 2016b).
} 
U.S. and Europe. Second, directional connectedness for global banks and insurers is from the United States and select European countries, to Asia. In other words, GSIBs from the United States, Germany, Spain, and France, and GSIIs from the United States, France, and Germany, are the sources of outward returns and volatility connectedness, while GSIBs from China and Japan tend to be on the receiving end, based on market data. Third, the degree of total system connectedness-i.e., among all GSIBs and GSIIs in our sample-tends to rise during financial stress, which coincides with predictions of what can broadly be described as a balance-sheet oriented systemic risk measure, the SRISK. ${ }^{7}$ The evolution of our market-based interconnectedness measure is also broadly in line with the SRISK measure-even though the latter does not explicitly seek to model interconnectedness. Fourth, we demonstrate that long term bond yields and global economic policy uncertainty play an important role in explaining system connectedness. The relevance of the former is based on the forward-looking information on economic growth it encompasses, which has been well documented in the literature. ${ }^{8}$ Together with policy uncertainty, yield curve information can be expected to inform pricing of securities in the market, and decision of market participants to trade in a particular direction, which in turn influences connectedness. ${ }^{9}$ Finally, on bank-specific return connectedness, we find that balance sheet variables such as asset quality and bank profitability play an important role in explaining market return connectedness for GSIBs. While these findings shed light on the connectedness and underlying drivers for GSIBs and GSIIs, they should not be interpreted as general conclusions for the overall financial systems of the countries in which these systemic institutions reside. ${ }^{10}$

The rest of the paper is structured as follows. We first outline the data, stylized facts and estimation methodology including measures of connectedness in Section II. We then present the findings on the connectedness of global banks and insurers based on the Diebold and Yilmaz methodology and compare the findings with a balance sheet-oriented systemic risk measure, the SRISK, in Section III. Section IV investigates factors that influencing connectedness, including common factors that drive global connectedness and the role of bank-specific factors. Finally, we offer some concluding remarks in Section V.

\footnotetext{
${ }^{7}$ SRISK attempts to quantify the expected shortfall in the system, if equity values of individual firms were to plunge to global financial crisis levels; see Acharya et al. (2012).

${ }^{8}$ See inter alia, Stock and Watson (1989), Estrella and Mishkin (1998) and Ang et al (2006).

${ }^{9}$ Concepts of risk aversion and economic uncertainty have been identified as important drivers of asset price dynamics within structural dynamic asset pricing models by inter alia, Campbell and Cochrane (1999) and Bansal and Yaron (2004).

${ }^{10}$ In some countries, the global systemically important institutions only represent a small subset of all institutions in a country's financial system, for example for Germany.
} 


\section{DAta AND Methodology}

\section{A. Data and Stylized Facts}

We considered a sample of global banks and insurers in our empirical analysis of connectedness. "Global banks and insurers" refers to banks and insurance companies that are classified by the Financial Stability Board (FSB) as GSIBs and GSIIs in 2016, 2015, and 2014. The list covers United States, European, and Asian financial institutions that are considered systemic due to their size, complexity, and interconnectedness, according to the Basel Committee on Banking Supervision (BCBS) methodology (Table 1). ${ }^{11}$

By assets, the largest GSIBs are located in Asia, followed by Europe and the United States. In Asia, the Industrial and Construction Bank of China (ICBC) and the China Construction Bank are at the top of the list with a combined asset value of US\$6.5 trillion. HSBC and BNP Paribas are the largest European banks. JP Morgan Chase and Bank of America are the top American banks by assets (Figure 1).

Table 1. Sample of Global Systemically Important Banks and Insurers

\begin{tabular}{|lclc|}
\hline GSIBs & Country & Europe & Country \\
US & US & BNP Paribas & France \\
JP Morgan Chase & US & Groupe Crédit Agricole & France \\
Bank of America & US & Société Générale & France \\
Wells Fargo & US & Deutsche Bank & Germany \\
Citigroup & US & HSBC & UK \\
Goldman Sachs & US & Barclays & UK \\
Morgan Stanley & US & Royal Bank of Scotland & UK \\
Bank of New York Mellon & US & Standard Chartered & UK \\
State Street & Country & Santander & Spain \\
Asia & China & BBVA & Spain \\
Industrial and Commercial Bank of China & Italy \\
China Construction Bank & China & Unicredit Group & Switzerland \\
Bank of China & China & UBS & Switzerland \\
Mitsubishi UFJ FG & Japan & Credit Suisse & Netherlands \\
Mizuho FG & Japan & ING Bank & Sweden \\
Sumitomo Mitsui FG & Japan & Nordea & \\
\hline GSIls & & & Country \\
US & Country & Europe & Netherlands \\
AIG & US & Aegon N.V. & Germany \\
Metlife & US & Allianz SE & UK \\
Prudential Financial & US & Aviva plc & UK \\
& & Prudential plc & France \\
Asia & Country & Axa S.A. & Italy \\
Ping An Insurance & China & Assicurazioni Generali & \\
\hline & & & \\
\end{tabular}

Note: The list of GSIBs and GSIls refer to those classified by the FSB in 2016, 2015 and 2014. The GSIB lists in these three years are broadly similar, the difference being that BBVA was dropped from the 2016 and 2015 lists and that the China Construction Bank was added. For insurers, Aegon was added while Assicurazioni was dropped from the 2015 list. Note that Groupe BPCE and the Agricultural Bank of China are not included in the empirical sample due to a lack of publicly traded data and short sample size, respectively.

${ }^{11}$ G-SIIs are designated by the FSB based on a recommendation by the IAIS and their methodology. 
Figure 1. Assets of Global Systemically Important Banks

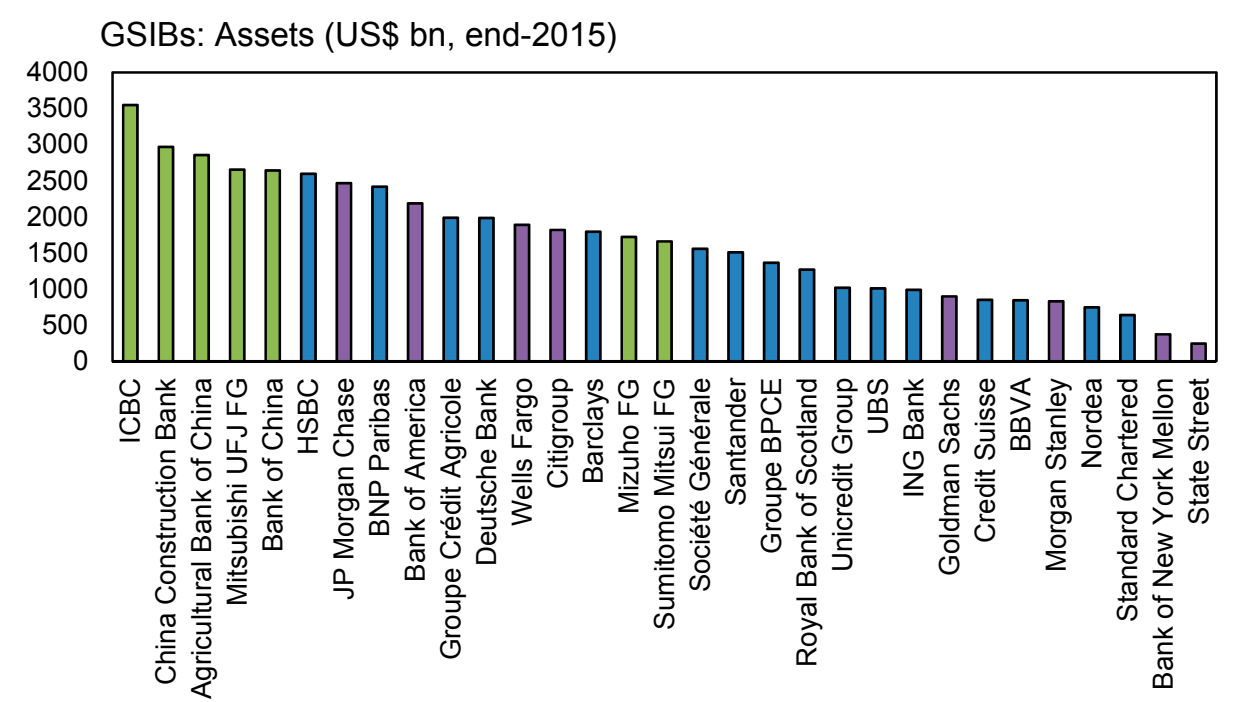

Note: The blue, purple and green bars denote European, US and Asian banks, respectively. Source: SNL.

While the asset size of insurers is lower than banks on average, the size of some GSIIs rivals that of GSIBs (Figure 2). For example, AXA, Allianz and Metlife, the largest three insurance companies, are comparable in size to Goldman Sachs, Morgan Stanley, and Credit Suisse. While the asset size of insurance companies would need to be sufficiently large to effectively pool and diversify risks for certain types of business (such as catastrophes insurance), some argue that large insurers may create too-big-to-fail type of risks (see GFSR, April 2016b).

Figure 2. Assets of Global Systemically Important Insurers

GSIls: Assets (US\$ bn, end-2015)

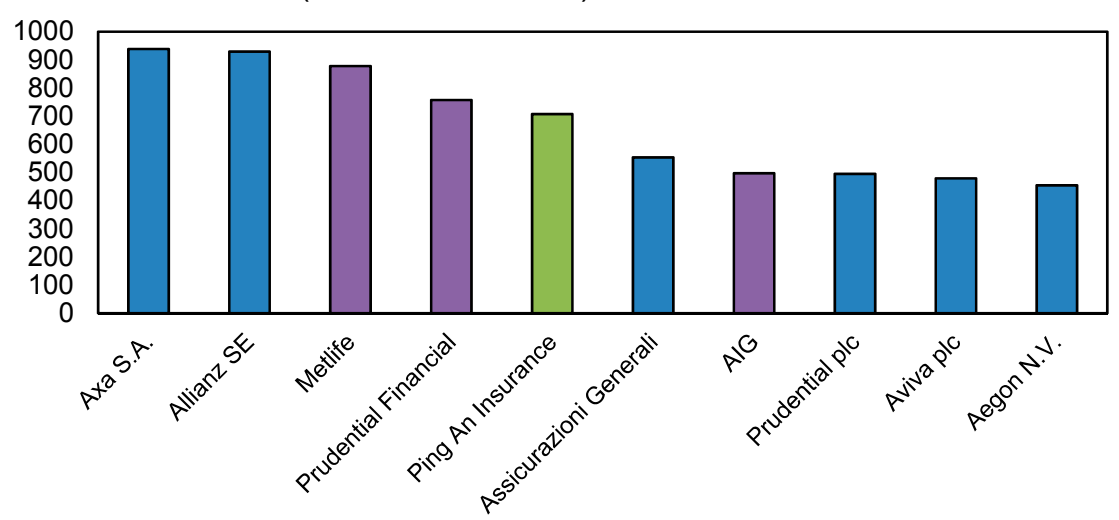

Note: The blue, purple and green bars denote European, US and Asian insurers, respectively.

Source: Moody's.

To examine the connectedness between GSIBs and GSIIs, we consider both daily equity returns and daily volatilities in equity prices from October 2007 to August 2016, derived 
from publicly-available equity price series from Datastream. ${ }^{12}$ To control for the differences in trading hours due to time zones, we compute average two-day log returns for equity prices in local currency (see, for example, Forbes and Rigobon, 2002, and GFSR, April 2016b). ${ }^{13}$ On average, European banks, Asian and U.S. insurers have the lowest (most negative) daily returns over the sample period (Figure 3 ). ${ }^{14}$

\section{Figure 3. Average Daily Returns of Equity Prices for GSIBs and GSIls}

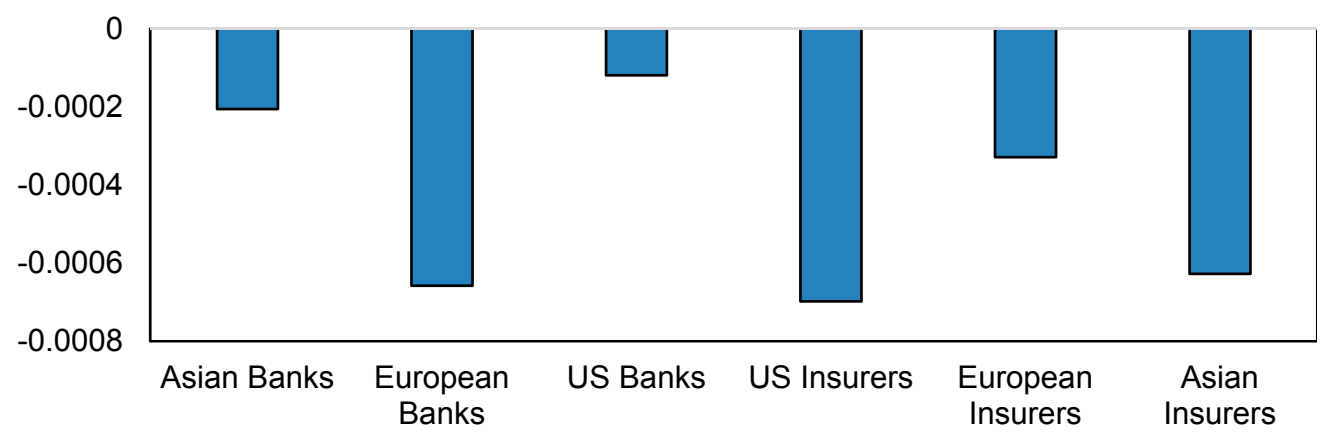

Note: Returns are calculated as the average two-day log differnce of equity prices.

On intra-day equity volatility, we follow the Parkinson (1980) and Diebold and Yilmaz $(2009,2012)$ methods and construct the daily variance for financial institution $i$ on day $t$ as

$$
\tilde{\sigma}_{i t}^{2}=0.361\left[\ln \left(P_{i t}^{\max }\right)-\ln \left(P_{i t}^{\min }\right)\right]^{2}
$$

where $P_{i t}^{\max }$ is the maximum price for financial institution $i$ on day $t$, and $P_{i t}^{\min }$ is the daily minimum price. Given that $\tilde{\sigma}_{i t}^{2}$ is an estimator of the daily variance, the annualized daily percent standard deviation (volatility) is then computed as $\hat{\sigma}_{i t}=100 \sqrt{365 \cdot \tilde{\sigma}_{i t}^{2}}$. European banks and U.S. insurers have the highest intra-day volatility on average, followed by U.S. banks, whereas the intra-day volatility for Asian banks tends to be lower (Figure 4). As highlighted by Diebold and Yilmaz (2014), volatilities tend to be distributed asymmetrically with a right skew. Therefore, we take natural logarithms to approximate normality and work with $\log$ volatilities in our analysis. ${ }^{15}$

\footnotetext{
${ }^{12}$ We treat holidays and missing observations as follows: we remove a day if more than half of the entities have missing data. We then interpolate the remaining missing observations.

${ }^{13}$ Alternatively, Friday-to Friday weekly returns also can be used to account for the time-zone effect. See for examples Diebold and Yilmaz (2009) and Guimaraes-Filho and Hong (2016).

${ }^{14}$ In general, the daily equity returns for the global banks and insurers have been negative for the sample period from October 2007 to August 2016 despite episodes of recovery.

${ }^{15}$ As noted in Diebold and Yilmaz (2014), normality-inducing transformations are important given that the generalized variance decomposition invokes normality.
} 
Figure 4. Intra-Day Volatility of Equity Prices for GSIBs and GSIIs

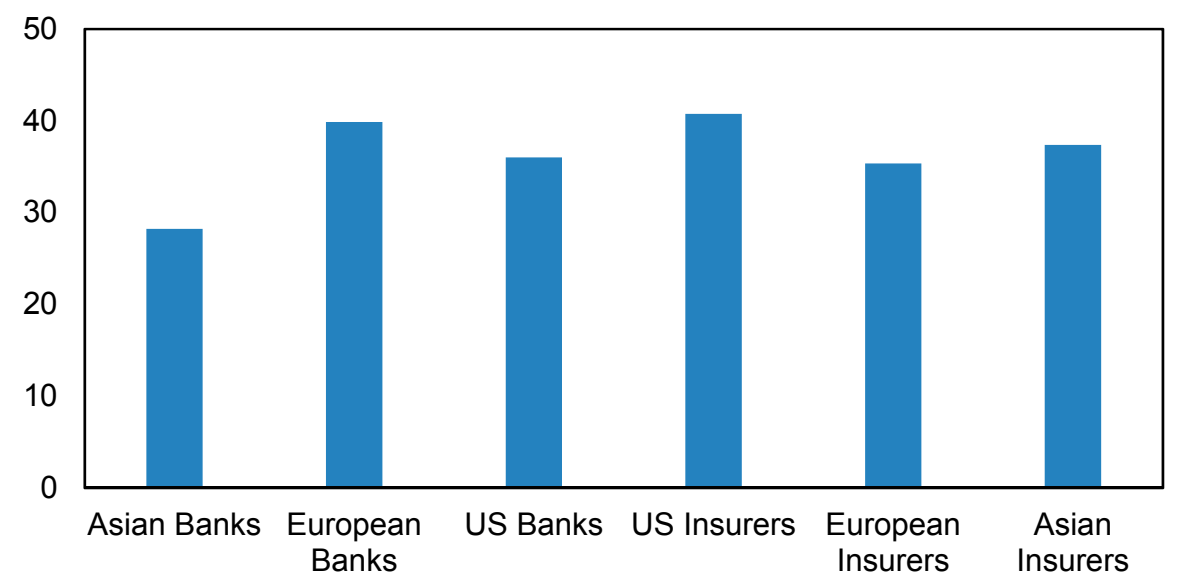

\section{B. Methodology and Measure of Connectedness}

The spillover analysis based on the Diebold and Yilmaz $(2014,2015)$ methodology first estimates a Vector Autoregression (VAR) approximating model with equity market data of global banks and insurers. ${ }^{16}$ The connectedness measure is then derived from the forecast error variance decomposition of the underlying VAR for equity returns and volatilities.

The Diebold and Yilmaz $(2014,2015)$ methodology has a number of advantages. This methodology is a unified and flexible framework for conceptualizing and empirically measuring connectedness at a variety of levels, from pairwise through systemic wide. Furthermore, these measures of connectedness can be static (i.e., for the full sample period) or dynamic (i.e., the nature of the relationship can evolve through time). Two particularly important features of the Diebold and Yilmaz model are, first, its ability to quantify the contribution of each financial institution to overall network connectedness and systemic risk, and second, the estimation of connections between financial institutions operating in different jurisdictions - as cross-border exposure data at entity level is typically confidential and not accessible. Additionally, as explained in Diebold and Yilmaz (2015), the methodology brings together desirable properties of alternative approaches of systemic risks, such as the Marginal Expected Shortfalls (see, for example, Acharya, Pedersen, Phillipon, and Richardson, 2010) and Delta CoVAR (Adrian and Brunnermeier, 2016).

Consider a covariance stationary $\mathrm{N}$ variable $\operatorname{VAR}(\mathrm{p}), x_{t}=\sum_{i=1}^{p} \Phi_{i} x_{t-i}+\varepsilon_{t}$, where $\varepsilon_{t} \sim(0, \Sigma)$. The moving average representation is $x_{t}=\sum_{i=0}^{\infty} A_{i} \varepsilon_{t-i}$, where the coefficients matrices $\mathrm{A}_{i}$ follows $\mathrm{A}_{i}=\sum_{i=1}^{p} \Phi_{i} A_{t-i}$, with $\mathrm{A}_{0}$ an $\mathrm{N} \times \mathrm{N}$ identity matrix and $\mathrm{A}_{i}=0$ for $i<0$.

\footnotetext{
${ }^{16}$ The approach was applied to U.S. financial firms in Diebold and Yilmaz (2004) and to the global bank network, including the world's top 150 banks in Demirer, Diebold, Liu, and Yilmaz (2015). It has also been used to examine cross-border spillovers based on equity indices, see for example, GFSR (April 2016a) and Guimaraes-Filho and Hong (2016).
} 
Forecast error variance decompositions are transformations of the moving-average coefficients, which attributes the H-step ahead forecast error variances of each variable $i$, to other variables in the system.

Following Diebold and Yilmaz (2014, 2015), we consider the generalized variance decomposition (Koop, Pesaran and Potter, 1996 and Pesaran and Shin, 1998) of the underlying VAR. In contrast to the Cholesky decomposition proposed by Sims (1980) and related identification strategies, the generalized variance decomposition (GVD) is invariant to the ordering of variables, which offers more flexibility in the modeling strategy without making any a priori assumption on the sequence of responses. GVD is particularly applicable to our global framework with a large number of entities (29 GSIBs and 10 GSIIs) because of the infeasibility of imposing a sensible ordering among the 39 financial institutions based on existing economic theory, especially given that the mechanism through which shocks are transmitted is likely to have evolved during the sample period. GVD, on the other hand, relies on a largely data-based identification scheme while allowing for correlated shocks and accounting for the correlation among them observed historically ("let the data speak"). ${ }^{17}$

Variable $j$ 's contribution to variable $i$ 's H-step-ahead generalized forecast error variance is given by:

$$
\theta_{i j}^{g}(H)=\frac{\sigma_{j j}^{-1} \sum_{h=0}^{H-1}\left(e_{i}^{\prime} A_{h} \sum e_{j}\right)^{2}}{\sum_{h=0}^{H-1}\left(e_{i}^{\prime} A_{h} \sum A_{h}^{\prime} e_{i}\right)}
$$

where $\sigma_{j j}$ is the standard deviation of $\varepsilon_{j}$, and $e_{i}$ is the selection vector with the $i$-th element unity and zeros elsewhere. The row sums of the variance decomposition matrix $\theta_{i j}^{g}(H)$ are not necessarily unity, due to non-zero correlations across the shocks (Garratt, Lee, Pesaran and Shin, 2006). Therefore, each forecast error variance composition is normalized by the row sum:

$$
\tilde{\theta}_{i j}^{g}(H)=\frac{\theta_{i j}^{g}(H)}{\sum_{j=1}^{N} \theta_{i j}^{g}(H)}
$$

where the row sums of $\tilde{\theta}_{i j}^{g}(H)$ equal to unity, $\sum_{j=1}^{N} \tilde{\theta}_{i j}^{g}(H)=1$ and $\sum_{i, j=1}^{N} \tilde{\theta}_{i j}^{g}(H)=N$, by construction. $\tilde{\theta}_{i j}^{g}(H)$ measures the pairwise directional connectedness from financial institution (FI) $j$ to $i$ at horizon $H$. In other words, $\tilde{\theta}_{i j}^{g}(H)$ captures the extent to which the variations in FI $i$ 's equity returns or volatility can be explained by FI $j$, based on the generalized forecast error variance decomposition. Following the notation in Diebold and

\footnotetext{
${ }^{17}$ Diebold and Yilmaz (2014) find that total connectedness, an important system-wide summary measure, is robust to Cholesky ordering. GVD does not imply a causal relationship between different financial institutions. Instead, GVD identifies the associations between financial entities based on historical relations and correlations.
} 
Yilmaz (2015), we denote the pairwise directional connectedness from FI $j$ to $i$ at horizon $\mathrm{H}$ as $C_{i \leftarrow j}^{H}=\tilde{\theta}_{i j}^{g}(H)$. The net pairwise directional connectedness measure is then defined as $C_{i j}^{H}=C_{j \leftarrow i}^{H}-C_{i \leftarrow j}^{H}$.

In aggregate, the total directional connectedness of the system to FI $i$ (the from-degree) is measured as:

$$
C_{i \leftarrow .}^{H}=\frac{\sum_{j=1, j \neq i}^{N} \tilde{\theta}_{i j}^{g}(H)}{\sum_{i, j=1}^{N} \tilde{\theta}_{i j}^{g}(H)} \times 100
$$

The total direction connectedness of FI $i$ to the system of all other financial institutions (the to-degree) is given by:

$$
C_{. \leftarrow i}^{H}=\frac{\sum_{j=1, j \neq i}^{N} \tilde{\theta}_{j i}^{g}(H)}{\sum_{i, j=1}^{N} \tilde{\theta}_{j i}^{g}(H)} \times 100
$$

The net total directional connectedness (net-degree) is then measured by $C_{i}^{H}=C_{. \leftarrow i}^{H}-C_{i \leftarrow \text {. }}^{H}$, which captures the net contribution of connectedness or systemic risks to the system. Finally, the system-wide connectedness, or total connectedness, is given by

$$
C^{H}=\frac{\sum_{i, j=1, i \neq j}^{N} \tilde{\theta}_{i j}^{g}(H)}{\sum_{i, j=1}^{N} \tilde{\theta}_{i j}^{g}(H)}
$$

which is the ratio of the sum of the off-diagonal elements of the variance decomposition matrix to the sum of all its elements.

As discussed in Diebold and Yilmaz (2014), the network-based connectedness measures above are related to modern measures of systemic risk. Specifically, the from-degree measure, $C_{i \leftarrow}^{H}$. , captures exposures of individual firms to systemic shocks from the network (inward spillover) in a fashion analogous to Marginal Expected Shortfalls. The to-degree measure, $C_{. \leftarrow i}^{H}$, captures contributions of individual firms to systemic network events (outward spillover) in a fashion analogous to Delta CoVaR. In addition, the net-degree measure (the difference between to-degree and from-degree measures, $C_{i}^{H}$ ) describes the relative contribution to systemic risks from each financial firm.

Following Demirer, Diebold, Liu and Yilmaz (2015), the elastic net estimator (Zou and Hastie, 2005) is used to estimate the high-dimensional VAR of global banks and insurers by blending shrinkage and selection to recover degrees of freedom and to deal with the "curse of dimensionality." Essentially, the elastic net estimator blends the lasso (Tibshirani, 1996) and ridge regression and solves: ${ }^{18}$

\footnotetext{
${ }^{18}$ The elastic net estimator is lasso when $\alpha=1$ and ridge when $\alpha=0$.
} 


$$
\hat{\beta}_{\text {Enet }}=\arg \min _{\beta}\left(\sum_{t=1}^{T}\left(y_{t}-\sum_{i} \beta_{i} x_{i t}\right)^{2}+\lambda \sum_{i=1}^{K}\left(\alpha\left|\beta_{i}\right|+(1-\alpha) \beta_{i}^{2}\right)\right)
$$

where $\beta_{i}$ is the coefficient of the linear regression and the elastic net estimator is lasso when $\alpha=1$ and ridge when $\alpha=0$.

\section{CONNECTEDNess OF GLOBAL BANKS AND INSURERS}

So far, we have discussed some stylized facts of the underlying data, the connectedness measure and the empirical framework to examine spillovers. We now apply the approach to study and to characterize the evolution of connectedness among GSIBs and GSIIs and to examine their pair-wise connectedness.

Three different samples are considered in the following empirical exercises. First, we study the global connectedness among GSIBs and GSIIs by grouping these financial institutions to regional levels, namely the United States, Europe and Asia, respectively. Second, we analyze a sub-sample of GSIBs at country level and study the evolution of their connectedness over time. Third, we examine the connectedness of a sub-sample of GSIIs. In addition, we consider several robustness checks of the main results and compare the global connectedness measure with a balance sheet-oriented systemic risk measure-SRISK.

\section{A. Global Connectedness Among GSIBs and GSIIs}

The total return and volatility connectedness of the system of GSIBs and GSIIs reveals that connectedness tends to rise during financial crises and economic recessions (Figure 5). Two financial crises are included in our sample from 2007 to 2016. The first one, the 2007-2009 global financial crisis, saw a sharp rise in total connectedness that peaked at 92.5 percent for returns and 87.5 percent for volatility in October 2008. This peak occurred shortly after Lehman Brothers filed for Chapter 11 bankruptcy protection (September 15, 2008) and as markets began to absorb the impact of the fallout, including losses through counter-party exposures and further selloffs in certain market segments, such as commercial mortgagebacked securities. 
Figure 5. Global Dynamic Connectedness among GSIBs and GSIls

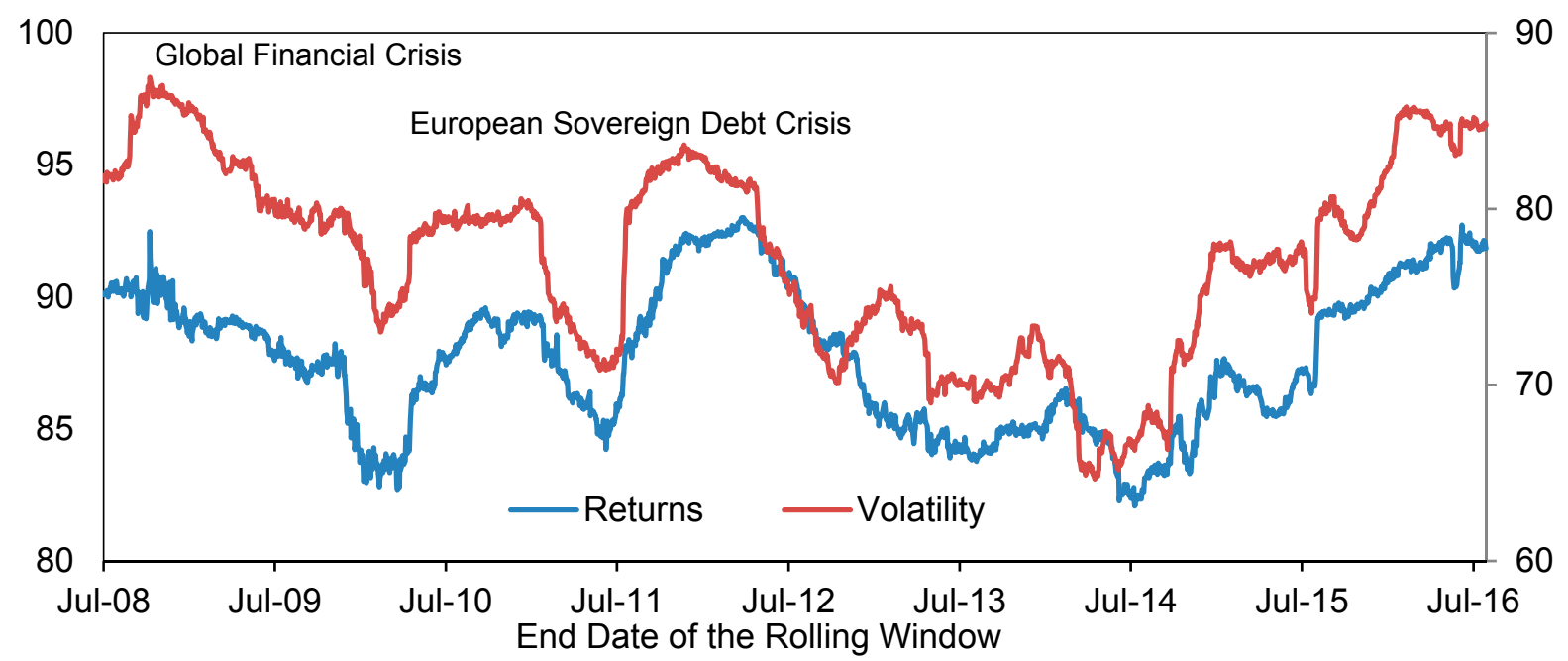

Note: Rolling Total Connectedness. The rolling estimation window width is 200 days, and the predictive horizon for the underlying variance decomposition is 12 days.

While the connectedness measure declined following the global financial crisis, this index again began to rise following the Greek sovereign debt crisis. The Greek debt crisis was triggered, in part, by the aftermath of the global financial crisis in addition to structural weakness in the Greek economy and the revelations about the true size of the Greek fiscal deficit and debt stock. Credit agencies such as Standard \& Poor's downgraded Greek bonds to below investment grade in April 2010. The connectedness index rose to 89 percent for returns and 79 percent for volatility in September 2010 and stayed high till February 2011.

As the bailout program for Greece started to restore market confidence, the connectedness measure declined to 84.4 percent for returns and to 70.8 percent for volatility in summer 2011. However, sovereign debt and banking sector issues started to emerge subsequently for Italy, Spain and Portugal, leading to renewed tensions in European sovereign bond markets and to a surge in system-wide connectedness among financial institutions. The connectedness measure rose to 93.2 percent for returns and to 83.2 percent for volatility at the beginning of 2012. European institutions undertook a number of policy measures to support and to clean up the balance sheets of banks. The long-term refinancing operation (LTRO) and LTRO2 provided European banks with long-term (three-year) funding at a low interest rate. The European Stability Mechanism (ESM) granted Spain a financial support package of $€ 100$ billion (10 percent of GDP) in June 2012. The return and volatility connectedness across the 39 financial institutions in Europe, the United States, and Asia declined to 88.4 percent and 70 percent, respectively, in October 2012.

In addition to these two major financial crises, the volatility connectedness measure became more elevated at the time of the "fiscal cliff" (January 2013) and at the time of the debt ceiling debate (October 2013), reflecting uncertainties in financial markets regarding the 
outlook of U.S. fiscal policy. However, the level of volatility connectedness was more moderate compared with the two aforementioned crisis episodes, and was at a level of around 75 percent at its peak at the beginning of 2013.

From July 2014, the level of connectedness for both equity returns and volatilities began to increase gradually. As noted in GFSR (April 2015), financial sector risks gradually shifted from advanced economies to emerging markets and from solvency to market liquidity risks at the beginning of 2015, when return and volatility connectedness rose to 87.6 percent and 77 percent, respectively. In summer 2015, the Chinese stock market experienced significant disturbances, with a sharp decline in stock prices across the majority of listed companies coupled with a rise in market volatility. Renewed tension also emerged in European banks at the beginning of 2016, when bank stocks experienced in a steep selloff amid investor concerns on their business models and low profitability in the negative interest rate environment. Notably, the degree of connectedness for both equity returns and volatilities among global banks and insurers has risen sharply since January 2016 and now has reached levels observed during the European Sovereign Debt Crisis.

We next focus on the pairwise return connectedness among GSIBs and GSIIs, which reveals clear regional clusters (Figure 6). We denote the financial institutions in our sample using the following naming convention: USA_B1 would represent US Bank 1 and USA_I1 would represent US Insurer 1. The strongest pairwise connectedness (based on the top 15 percent) could be found within the Asian, European, and U.S. clusters. Chinese GSIBs have the highest return connectedness with each institution explaining around 19 percent of equity returns of the other institutions. Furthermore, the Chinese GSIIs' equity returns could explain about 10 percent of equity returns of the Chinese GSIBs and vice versa. ${ }^{19}$

\footnotetext{
${ }^{19}$ We consider several robustness checks. First, we condition individual institution-specific returns on global returns and country-specific returns. Second, we condition individual institution-specific returns on countryspecific short-term and long-term interest rates. The regional cluster observation is found to be robust. Finally, the regional cluster could also be observed in volatility connectedness.
} 
Figure 6. Equity Return Connectedness among GSIBs and GSIIs

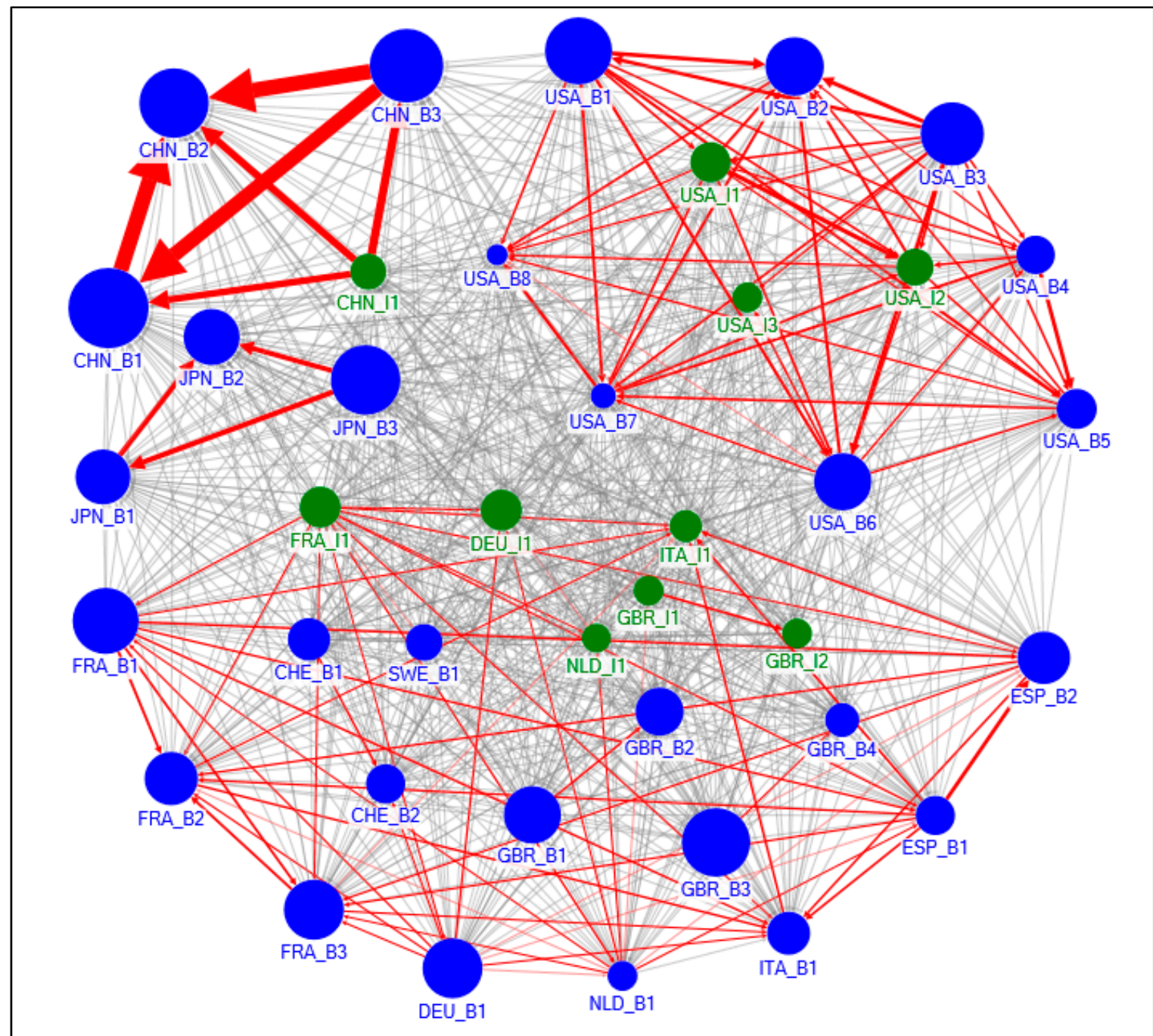

Note: Full sample return connectedness (October 2007 to August 2016). The blue and green nodes denote GSIBs and GSIls, respectively. Groupe BPCE and the Agricultural Bank of China (ABC) are not included due to the lack of public traded data and short sample size. The thickness of the edges reflects total connectedness (both inward and outward) with the strongest linkages (top 15 percent) highlighted in red and the remaining linkages shown in gray. The top 15 percent of the linkages are identified by ranking all bilateral pairs of connectedness among GSIBs and GSIls. The direction of the arrow captures the direction of net spillover. The size of the nodes reflects asset size. Chart constructed with NodeXL.

A similar pattern could be found among U.S. GSIBs and GSIIs. Two large U.S. GSIIs have the highest degree of connectedness, with each explaining about 7 percent of equity returns of the other. Among U.S. GSIBs, the strongest connectedness could be found among the four largest commercial banks (on average at 6.2 percent), and between the two large investment banks ( 6.4 percent). In addition, strong connections could be found between some U.S. GSIBs and GSIIs, with the highest bank-insurer connectedness at 5.3 percent.

Among European GSIBs and GSIIs, the two Spanish banks have the highest degree of connectedness, explaining about 6.4 percent of each other's equity returns. The next highest 
degree of connectedness could be seen among the by the large French GSIBs (4.9 percent). Among European GSIIs, the two British insurers are highly connected at 4.9 percent based on equity returns.

Interestingly, the connectedness among GSIBs across different regions (for example, the United States and Europe) does not appear to be as intense compared with the connectedness among GSIBs and GSIIs within the same region. The strong regional linkages between global systemically important banks and insurers could be attributed to cross exposures such as inter-sectoral loans, common investment exposure, client base, macroeconomic conditions and financial regulations. In general, insurers are connected to banks and the broader financial markets through their investments, capital raising and debt issuance activities (International Association of Insurance Supervisors, 2011). For example, European insurance groups hold a sizable portion of their investments in securities issued by other financial institutions, predominantly debt instruments, and to a smaller degree, equity securities. The regional clusters of banks and insurers could also be observed for equity volatility connectedness.

Figure 7. Net Directional Connectedness in the System of GSIBs and GSIIs

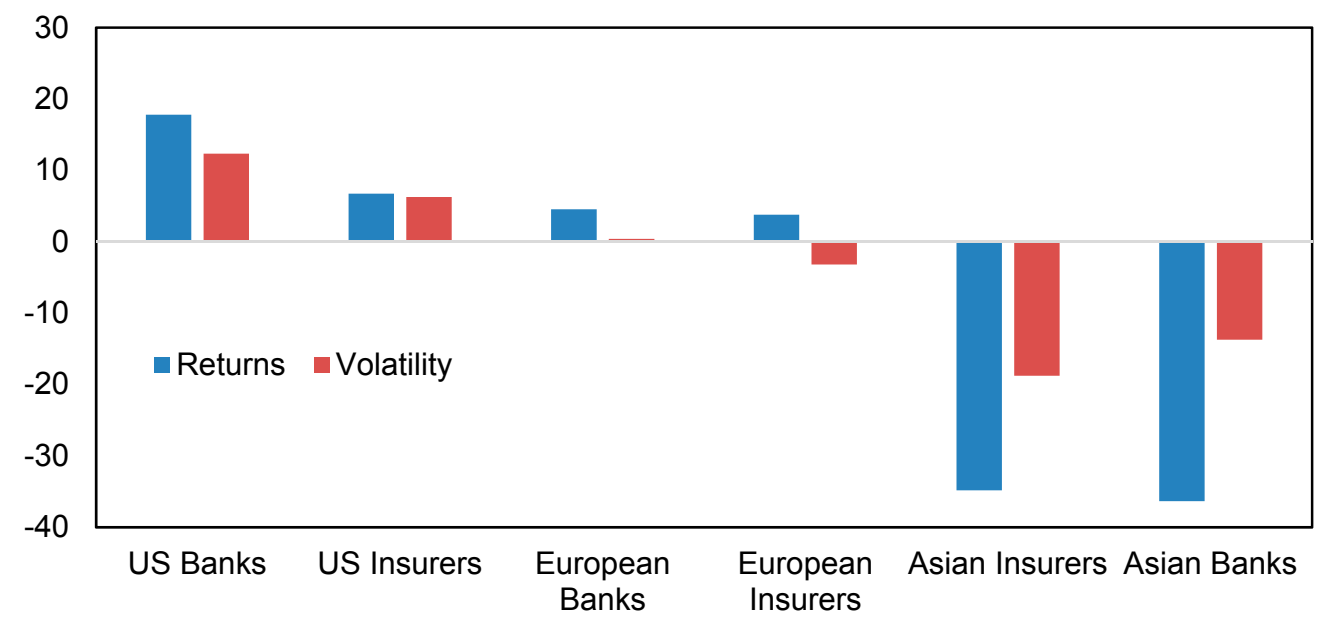

Note: Full sample net connectedness (October 2007 to August 2016). Net directional connectedness is constructed as the difference between the total directional connectedness of financial institution $i$ to the system (the to-degree) and the total directional connectedness of the system to financial institution i (the from-degree).

Having identified the regional clusters, we next examine the net directional connectedness in the system of GSIBs and GSIIs. Collectively, U.S. banks and insurers appear to be the most important source of net directional connectedness to the system of GSIBs and GSIIs based on both equity returns and volatilities (Figure 7). In contrast, Asian GSIBs and GSIIs tend to be 
the recipients. While the net directional connectedness from European GSIBs and GSIIs are more moderate on average, there appears to be significant variations across countries. ${ }^{20}$

Next, we analyze the dynamic return connectedness of United States, European, and Asian GSIBs and GSIIs based on rolling sample estimation with a 200 day window and a forecast horizon of 12 days (Figure 8). Similar to the full sample estimation, U.S. banks and insurers are the most important sources of return connectedness in the system of GSIBs and GSIIs for the majority of the estimation period, with particularly elevated level of contribution to return connectedness during the 2007-2009 global financial crisis. This observation is consistent with the evidence that U.S. financial institutions experienced sharp losses and severe market disruptions during the subprime mortgage crisis, especially leading to and after the demise of Lehman Brothers, and the subsequent $\$ 180$ billion bailout of AIG by the Federal government. In general, Asian GSIBs and GSIIs appear to be the recipient of equity returns connectedness through the estimation sample from October 2007 to August 2016.

Figure 8. Net Dynamic Return Connectedness in the System of GSIBs and GSIls
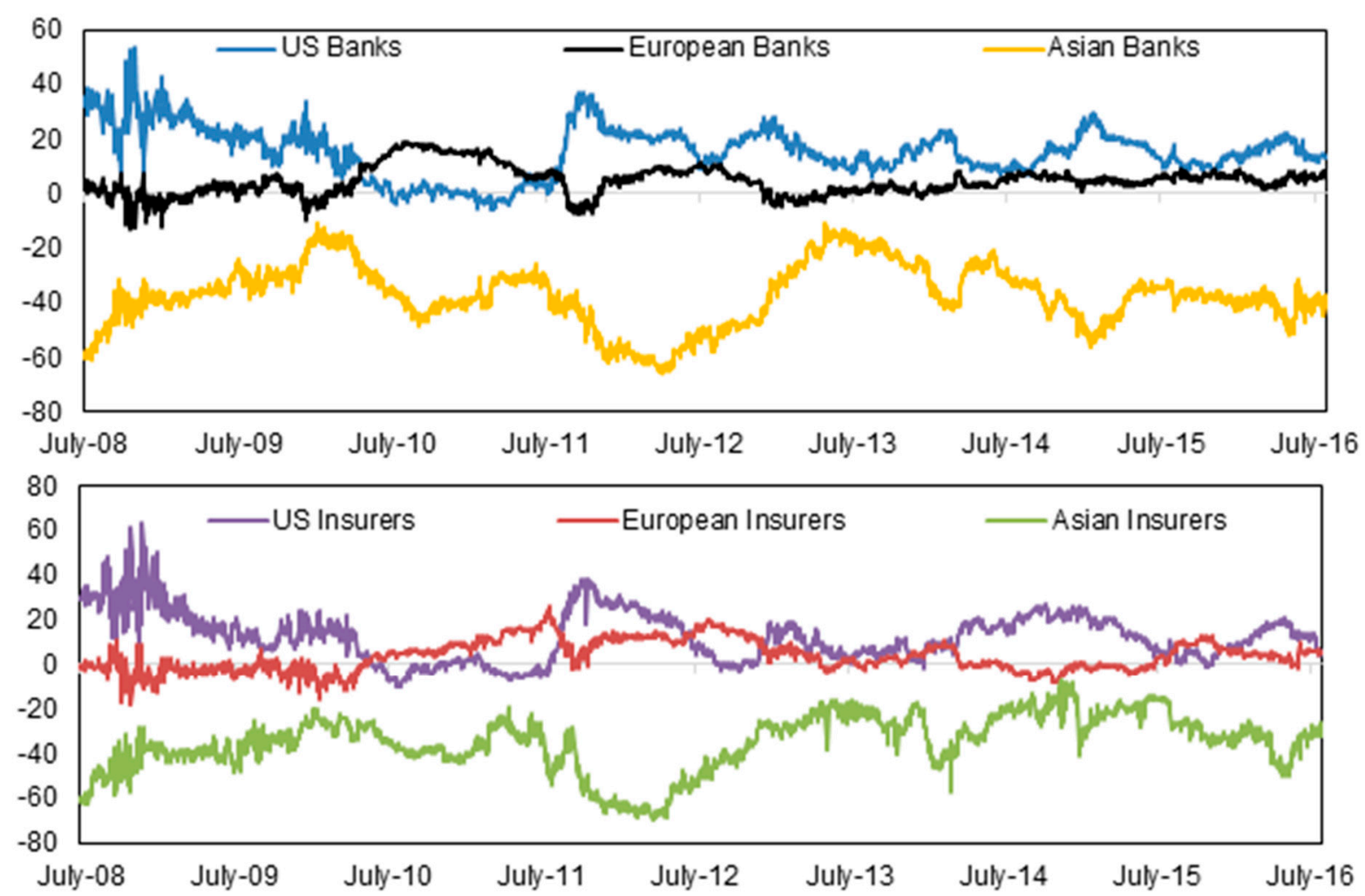

Note: Rolling net directional connectedness. The rolling estimation window width is 200 days, and the predictive horizon for the underlying variance decomposition is 12 days.

\footnotetext{
${ }^{20}$ We will examine specific country cases in more detail when analyzing the sub-samples of GSIBs and GSIIs in Section III.B and C.
} 
Figure 9. Net Dynamic Volatility Connectedness in the System of GSIBs and GSIIs
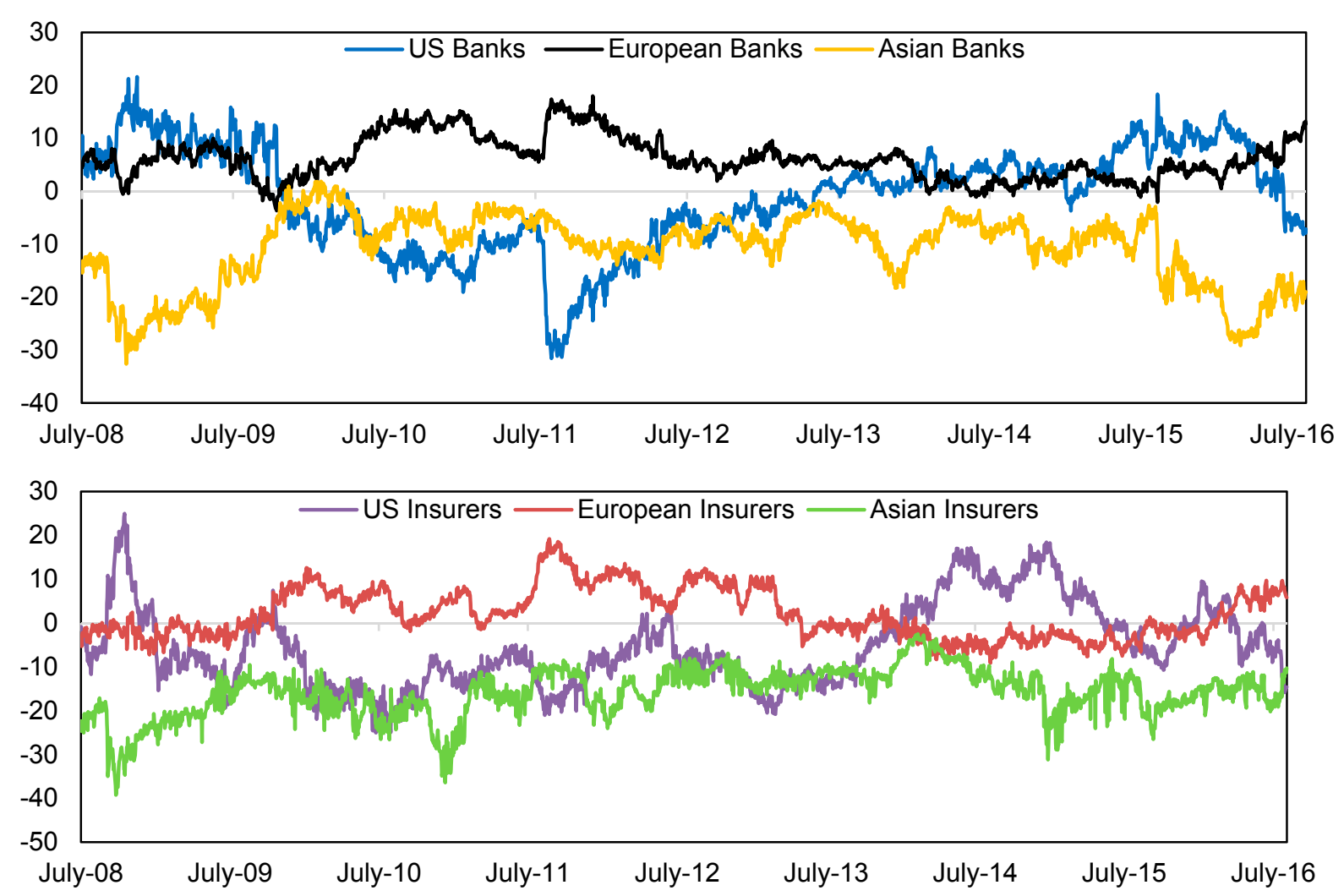

Note: Rolling net directional connectedness. The rolling estimation window width is 200 days, and the predictive horizon for the underlying variance decomposition is 12 days.

Dynamic volatility connectedness points to a more prominent role of European systemically important financial institutions compared with returns connectedness (Figure 9). European GSIBs and GSIIs overtook their U.S. counterparts in driving volatility connectedness in two main episodes. The first episode encompasses the period from mid-2009 to end-2013, which coincides with the beginning and the peak, respectively, of the European sovereign debt crisis, when investors were concerned about the solvency and liquidity of European banks and potential vicious feedback loop between banks and sovereigns. The second episode starts at the beginning of 2016, when European banking stocks experienced sharp losses due to investor concerns on business models and the profitability and viability of these institutions. European banks and insurers remained the key drivers of volatility connectedness in the system of GSIBs and GSIIs with U.S. and Asian financial institutions being net receivers at the end of the sample in August 2016.

\section{B. Global Connectedness Among GSIBs}

We then analyze a sub-sample of 29 GSIBs at country level and study the evolution of their interconnectedness over time. We also examine pair-wise relations within this sub-sample, and compare the contributions of GSIBs in select countries to return and volatility connectedness. 
The pairwise connectedness among GSIBs confirms that clear regional clusters are apparent from equity returns (Figure 10). The highest 15 percent of the pair-wise linkages are among banks from the same region or country. By country groups, the strongest linkages could again be found in China, Japan, and the United States. In Europe, we observe strong return connectedness in Spain, France, the United Kingdom, and Switzerland. In addition, Spanish, Italian, and French GSIBs are highly connected among themselves, explaining more than 5 percent of each other's equity returns on average.

Figure 10. Equity Return Connectedness among GSIBs

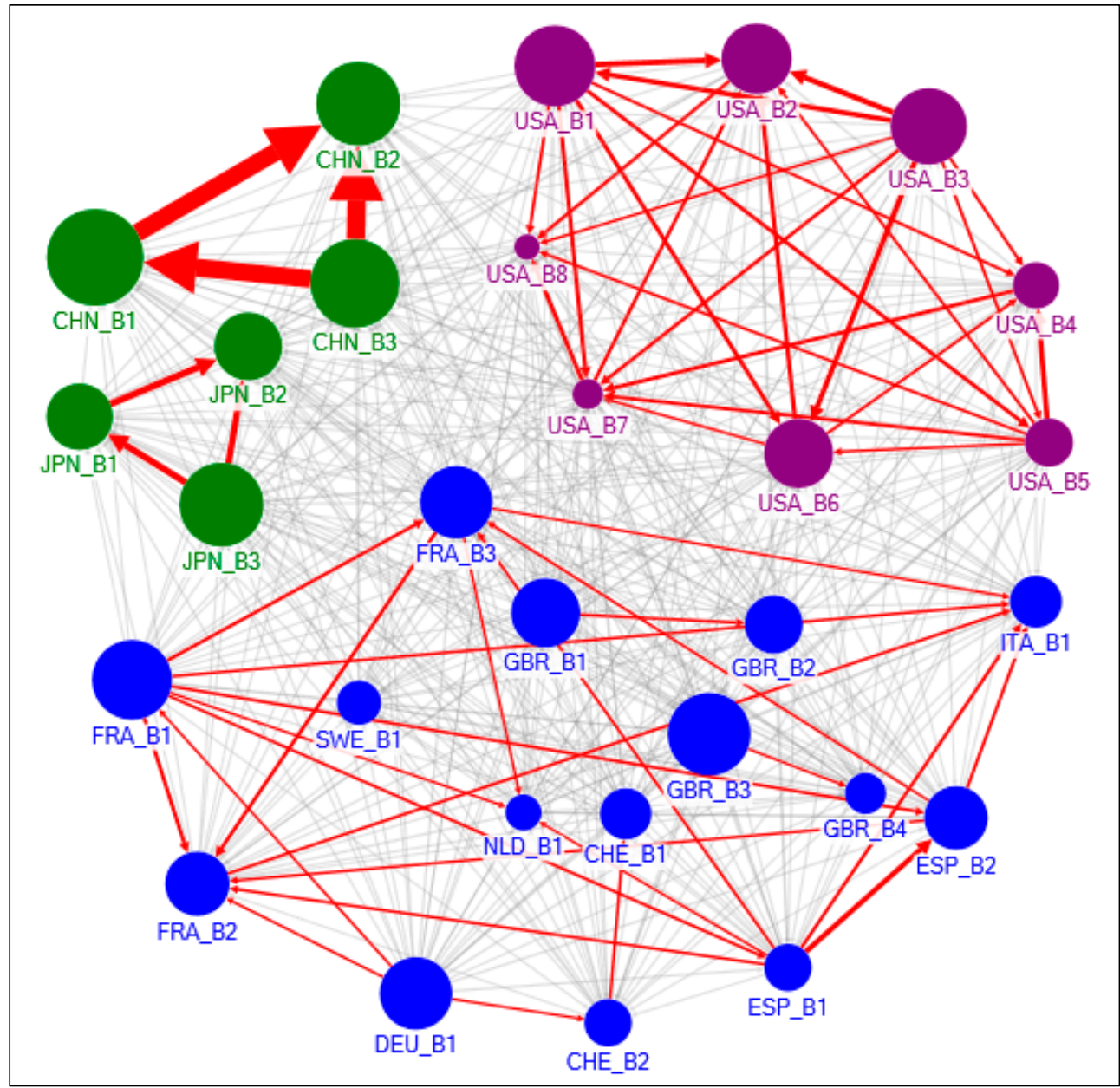

Note: Full sample return connectedness (October 2007 to August 2016). The blue, green and purple nodes denote European, Asian, and U.S. GSIBs, respectively. Groupe BPCE and the Agricultural Bank of China $(A B C)$ are not included due to the lack of public traded equity data and short sample size. The thickness of the edges capture total connectedness (both inward and outward), with the strongest (top 15 percent) linkages highlighted in red. The top 15 percent of the linkages are identified by ranking all bilateral pairs of connectedness among GSIBs. The direction of the arrows captures the direction of net spillover. The size of the nodes reflects asset size. Chart constructed with NodeXL.

Global banks from the United States and several European countries appear to be the main sources of return and volatility connectedness among GSIBs (Figure 11). On the other hand, 
GSIBs in Asia appear to be on the receiving end, despite their relatively large size by assets. Notably, there are also sizable variations among U.S. financial institutions, with the largest institutions driving returns and volatility connectedness.

Figure 11. Net Directional Connectedness in the System of GSIBs (By Country Average)

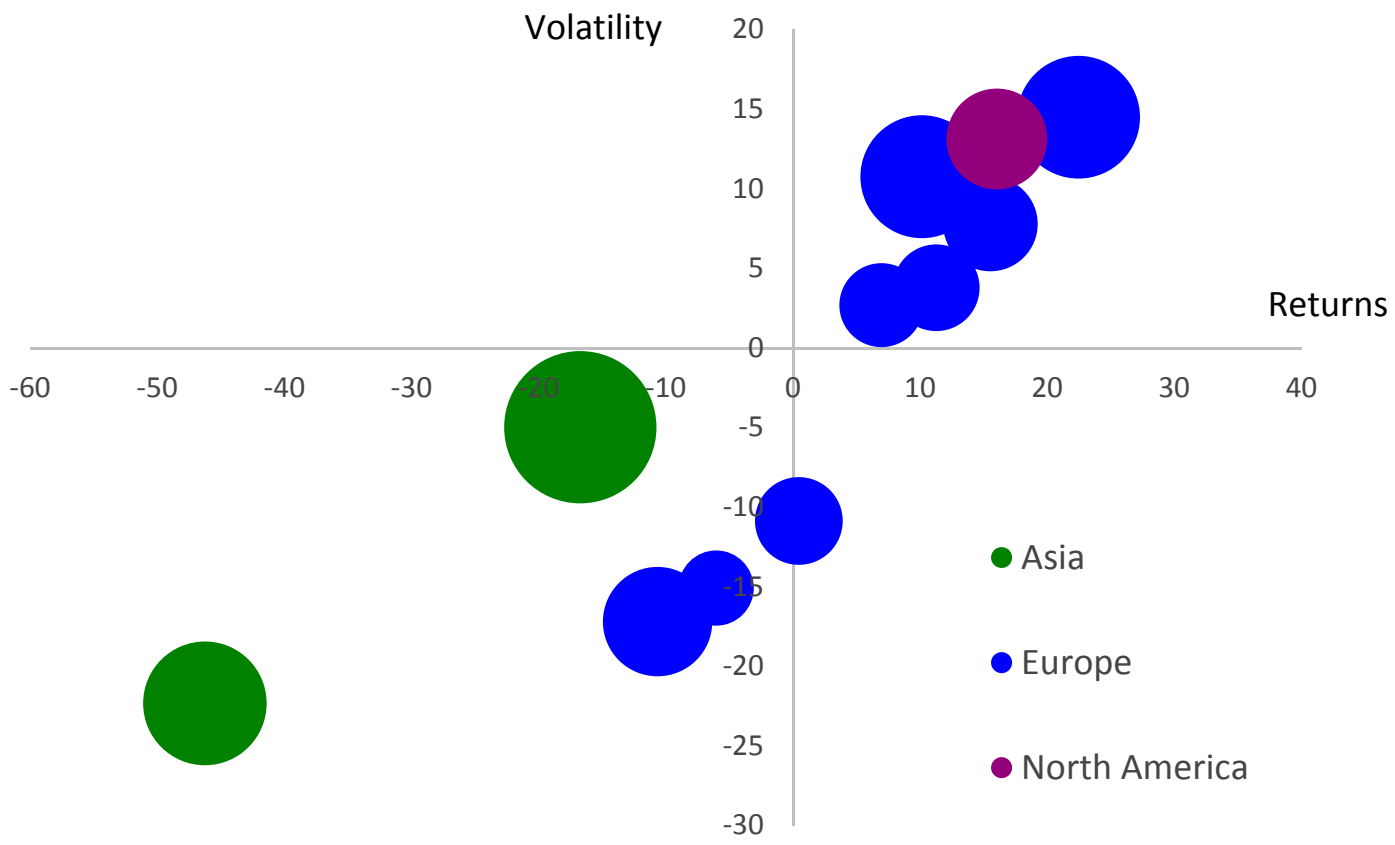

Note: Full sample net connectedness (October 2007 to August 2016). Net directional connectedness is constructed as the difference between the total directional connectedness of financial institution $\mathrm{i}$ to the system (the to-degree) and the total directional connectedness of the system to financial institution $i$ (the from-degree). The $x$-axis denotes net return connectedness and the $y$-axis denotes net volatility connectedness. The size of the nodes denotes average asset size by country.

For dynamic returns connectedness, we consider several country groups in North America, Europe and Asia. ${ }^{21}$ Historically, the net return connectedness was elevated for GSIBs in Germany and the United States during the global financial crisis and the European sovereign debt crisis (Figure 12). Spanish and U.K. GSIBs also appear to be net contributors of return connectedness during the two crises, albeit, to a lesser extent. As in the full sample, Chinese and Japanese GSIBs are net recipients of system returns connectedness throughout the sample period based on rolling sample estimation.

${ }^{21}$ Additional results for other country groups can be found in Appendix Figures 1 and 2. 
Figure 12. Net Dynamic Return Connectedness in the System of GSIBs
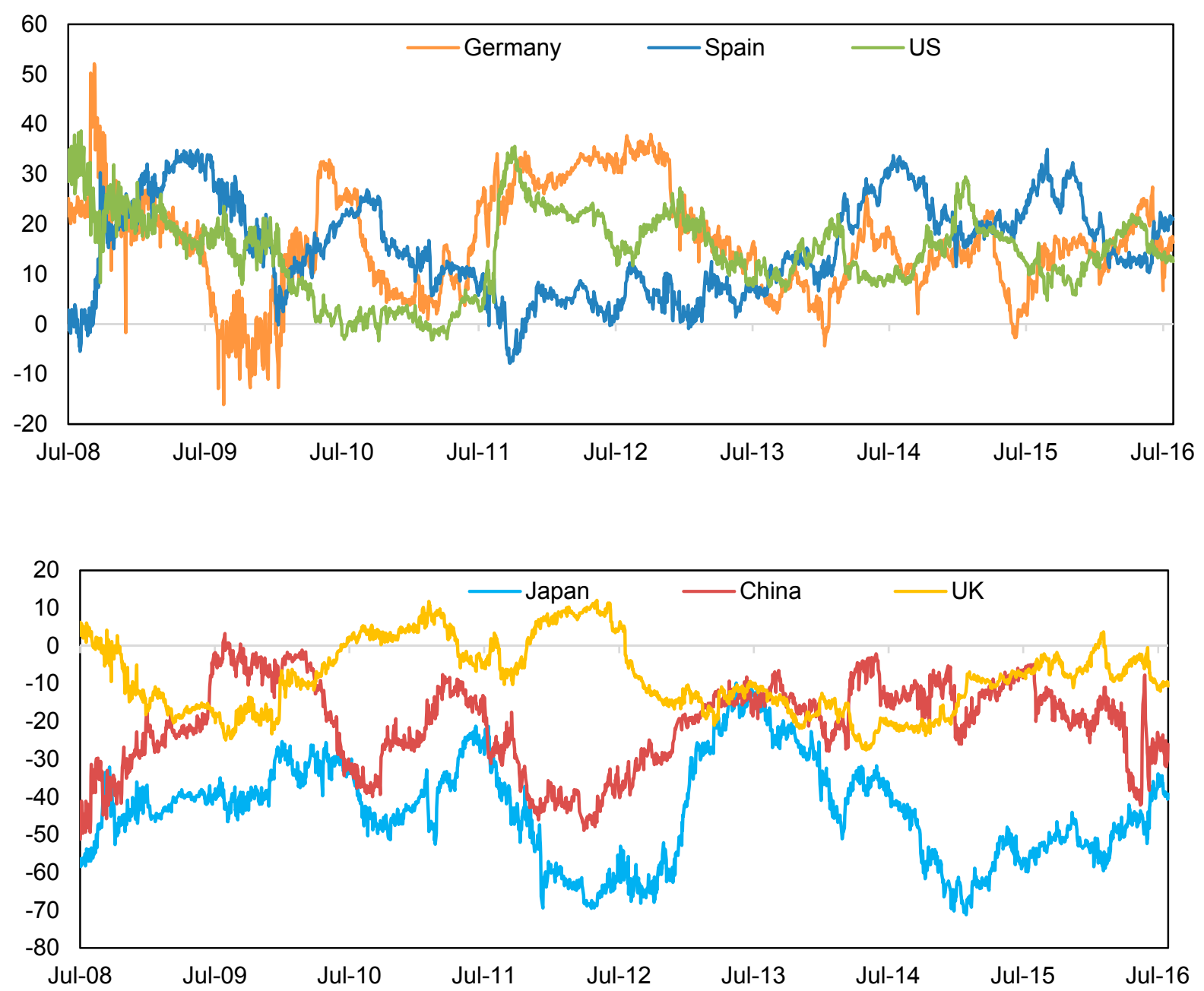

Note: Rolling net directional connectedness. The rolling estimation window width is 200 days, and the predictive horizon for the underlying variance decomposition is 12 days.

We focus on the same groups of GSIBs to examine dynamic volatility connectedness. While the directional connectedness from German and Spanish GSIBs were relatively elevated during the two crises, U.S. GSIBs appear to be the net recipient of volatility connectedness during the European sovereign debt crisis (Figure 13). Similar to equity returns connectedness, GSIBs in Japan and China are on the receiving end of volatility connectedness in the system of GSIBs. 
Figure 13. Net Dynamic Volatility Connectedness in the System of GSIBs
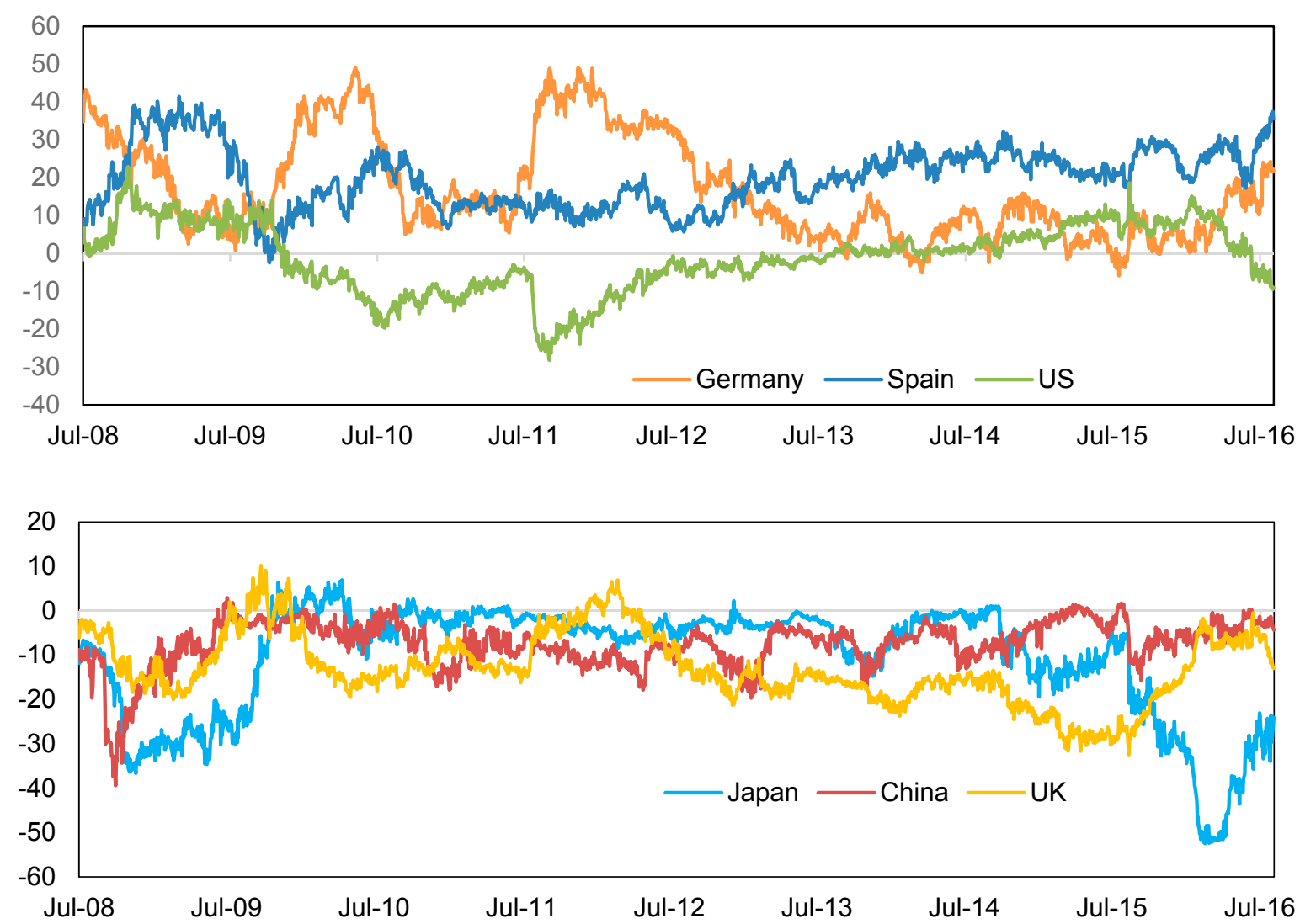

Note: Rolling net directional connectedness. The rolling estimation window width is 200 days, and the predictive horizon for the underlying variance decomposition is 12 days.

\section{Global Connectedness Among GSIIs}

We also consider a sub-sample of GSIIs and examine their equity return and volatility connectedness. As noted earlier, European GSIIs are highly interconnected among themselves, and there is a similar degree of close linkages between U.S. and European GSIIs (Figure 14). The strongest pairwise connectedness could be found between two U.S. GSIIs, and in Europe, between French and Italian GSIIs and between German and U.K. GSIIs. 
Figure 14. Equity Return Connectedness Among GSIls

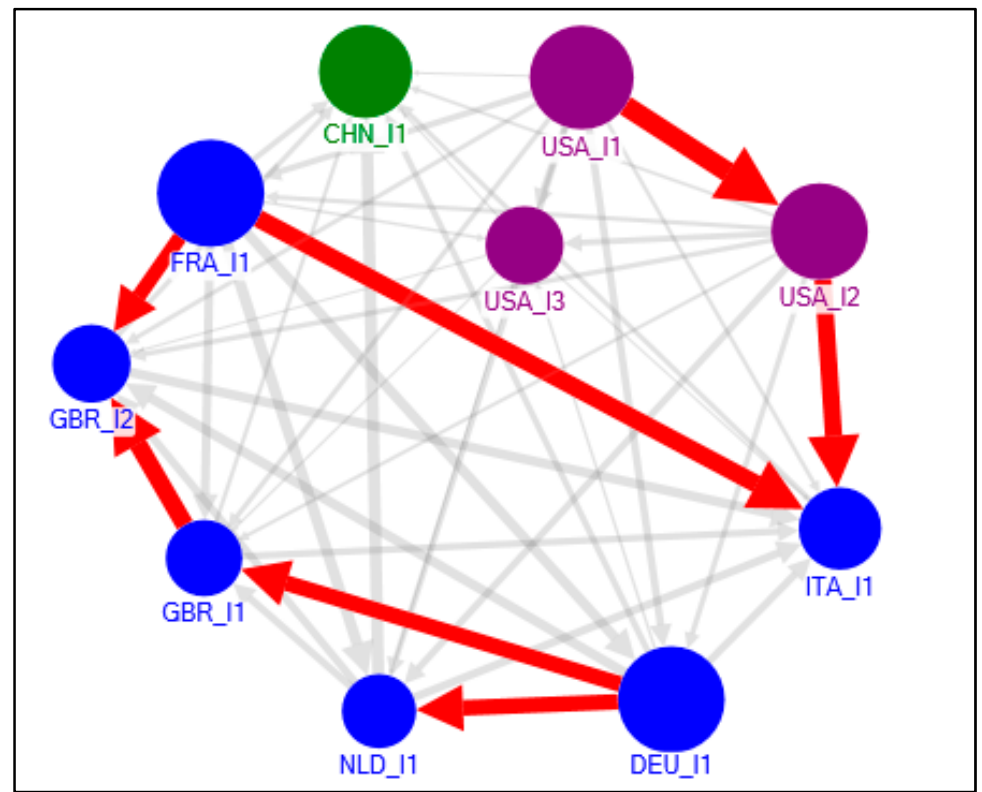

Note: Full sample return connectedness (October 2007 to August 2016). The blue, green and purple nodes denote European, Asian and U.S. GSIls, respectively. The thickness of the edges reflects total connectedness (both inward and outward), with the strongest (top 15 percent) linkages highlighted in red and the remaining linkages shown in gray. The top 15 percent of the linkages are identified by ranking all bilateral pairs of connectedness among GSIls. The direction of each arrow captures the direction of net spillover. The size of the nodes reflects asset size. Chart constructed with NodeXL.

Global systemically-important insurers from North America appear to be major contributors to both return and volatility connectedness among GSIIs, while GSIIs from two European countries are also important contributors to system return connectedness (Figure 15). On the other hand, the rest of the GSIIs from Europe and Asia tend to be key recipients of both equity returns and volatility connectedness. This finding suggests that some of the largest GSIIs by assets also appear to be the most important sources of net directional connectedness. 
Figure 15. Net Directional Connectedness in the System of GSIls (By Country Average)

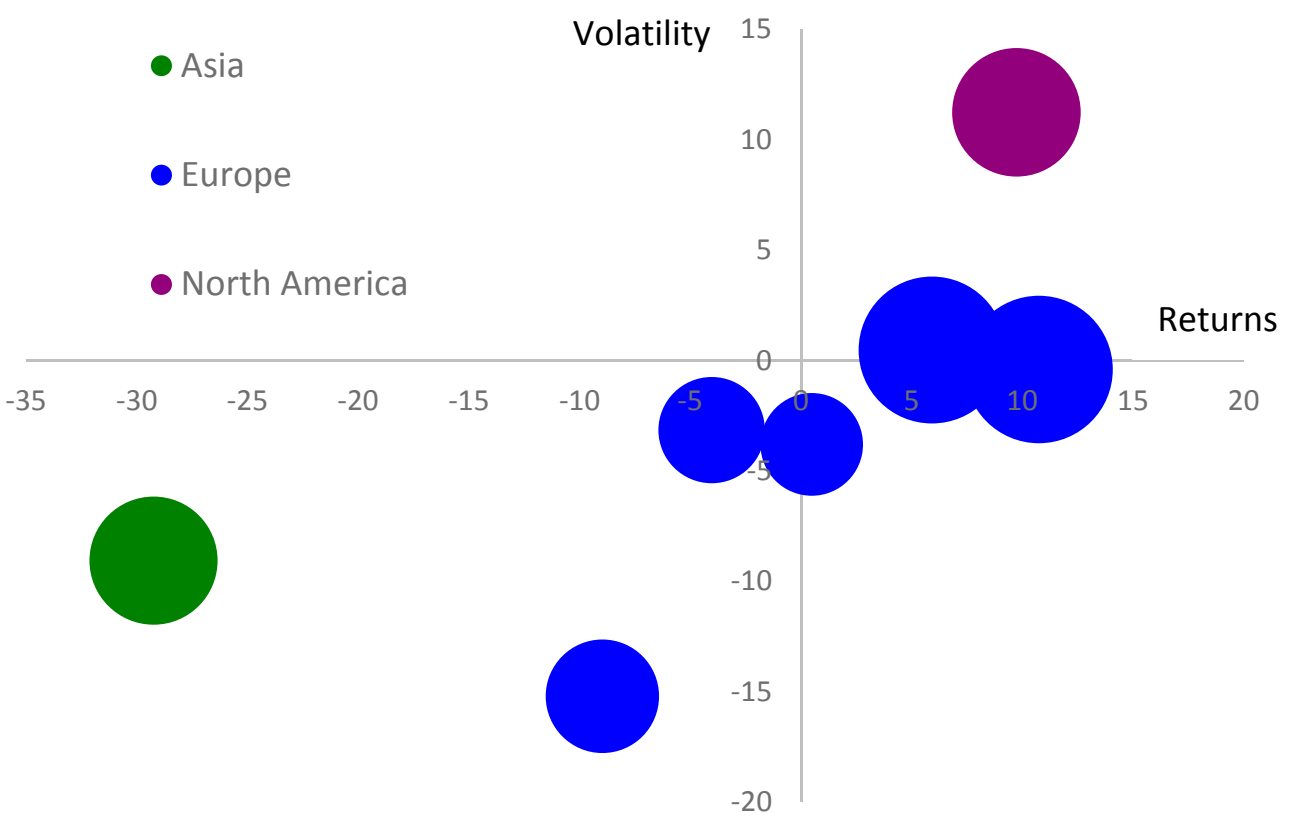

Note: Full sample net connectedness (October 2007 to August 2016). Net directional connectedness is constructed as the difference between the total directional connectedness of financial institution $i$ to the system (the to-degree) and the total directional connectedness of the system to financial institution $i$ (the from-degree). The $x$-axis denotes net return connectedness and the y-axis denotes net volatility connectedness. The size of the nodes denotes average asset size by country.

We then examine the evolution of returns and volatility connectedness for three groups of insurers based on rolling sample estimation (Figure 16). ${ }^{22}$ Historically, U.S. GSIIs appear to have been the most important net contributor of equity returns and volatility connectedness during the global financial crisis. The spike in directional return connectedness corresponds to the first day of trading after the failure of Lehman Brothers (September 15, 2008), when markets were concerned with the health of other financial intermediaries in the United States, including the insurer AIG. While traditional insurance business models that rely on the pooling of idiosyncratic risks should help insurers diversify risks, insurance groups and conglomerates that engage in non-traditional or non-insurance activities are more vulnerable and are more likely to amplify or contribute to systemic risks (International Association of Insurance Supervisors, 2011). AIG, whose bank subsidiary was involved in the underwriting of credit default swaps (CDS) leading to the global financial crisis, is a clear example of such a case. Similarly, during the European Sovereign Debt Crisis, German and French GSIIs were the main sources of equity return and volatility connectedness. ${ }^{23}$

\footnotetext{
${ }^{22}$ Additional results for other country groups can be found in Appendix Figure 3 and Appendix Figure 4.

${ }^{23}$ Some analysis finds that the designation of GSIIs is good news for equity investors of these firms (see, for example, Dewenter and Riddick, 2015). On the other hand, our analysis based on rolling window estimation does not indicate sizeable shifts in level or cyclical dynamics of connectedness as a result of the FSB designation.
} 
Figure 16. Net Dynamic Return and Volatility Connectedness in the System of GSIIs
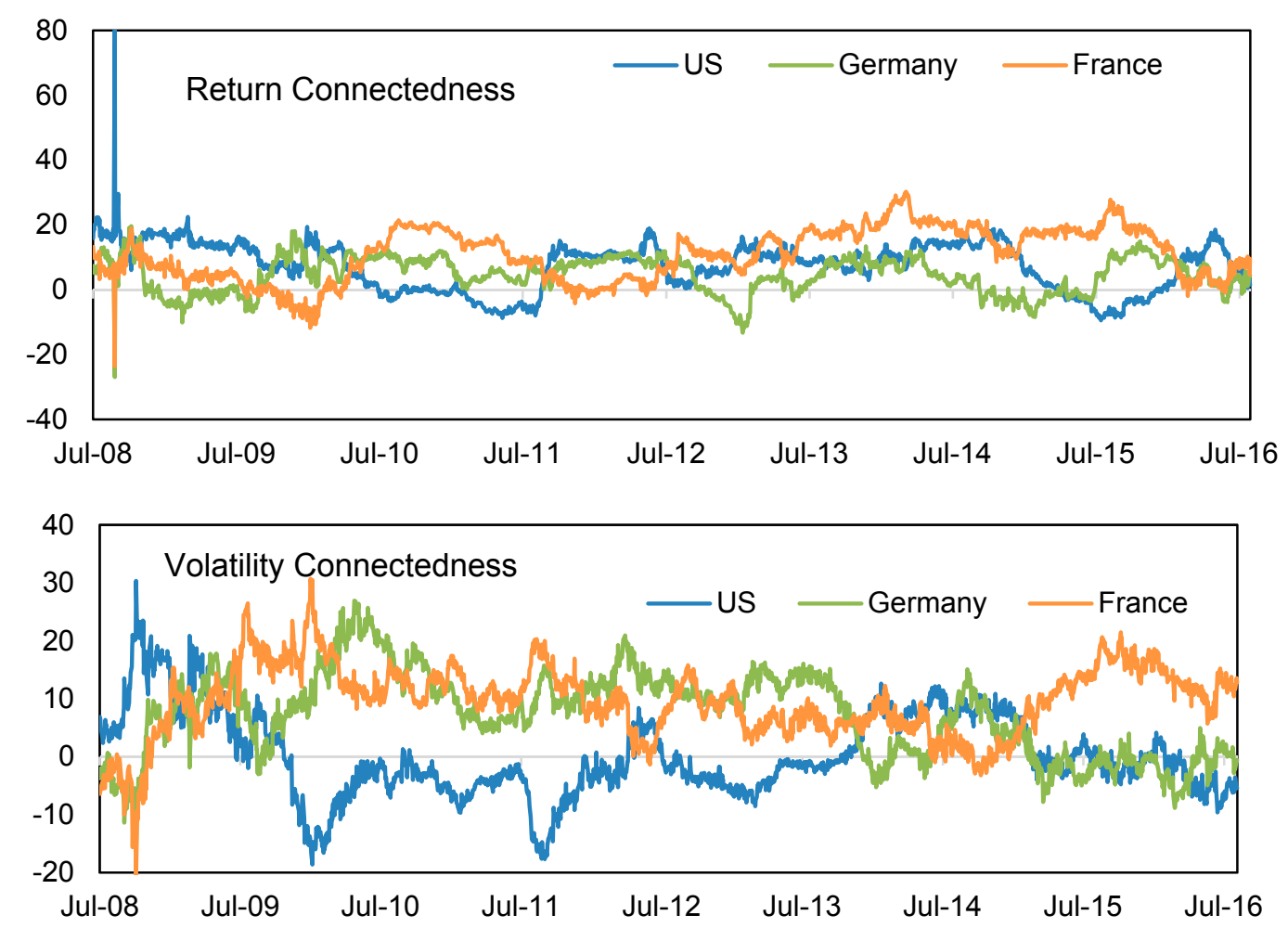

Note: Rolling net directional connectedness. The rolling estimation window width is 200 days, and the predictive horizon for the underlying variance decomposition is 12 days.

\section{Robustness}

We examine the robustness of the results by conducting several additional estimations. In the first group of robustness checks, we condition the institution-specific returns on global and country-specific returns and bond yields, and re-run the entire analysis using the residuals of the filtered series.

In the second group of robustness checks, we consider the robustness of results to alternative market prices such as Credit Default Swaps (CDS) spreads. The purpose of this exercise is to examine interconnectedness while accounting for the probability of the default of financial intermediaries under "extreme" market conditions. The CDS series refer to senior five-year spreads from Datastream. We consider CDS spreads in log-difference as commonly used in the literature. ${ }^{24}$

\footnotetext{
${ }^{24}$ The coverage of the CDS series for banks and insurers is lower than equity prices, both in terms of the crosssectional and time-series dimensions. The estimation sample spans from December 2007 to August 2016. The following institutions were not included in the estimation due to a lack of CDS data or short coverage of the time series data: Mitsubishi, ICBC, China Construction Bank, Bank of New York Mellon, State Street, UniCredit, Nordea, Credit Suisse and Ping An Insurance.
} 
In the third group of robustness checks, we focus on the assumptions on the empirical estimation strategy for equity returns and volatilities. First, we consider an estimation window of 150 days in addition to the 200-day window presented in the main results. Second, we vary the lag order of the estimation from two lags to three lags to capture a potentially higher degree of persistence in the data. Third, we consider alternative forecast horizons for the forecast error variance decomposition, from which connectedness measures are computed.

The robustness checks suggest that our results are robust to conditioning on country-specific returns and bond yields, alternative market prices, the width of estimation window, lag order, and the forecast horizon for variance decomposition. Specifically, the total connectedness index in the robustness checks remains largely unchanged, with elevated levels of system interconnectedness still apparent in the global financial crisis, in the European sovereign debt crisis, and in the past year. Detailed results on robustness checks can be found in the appendix (Appendix Figure 5 to Appendix Figure 8).

\section{E. Connectedness Compared with a Balance Sheet-oriented Systemic Risk Measure- SRISK}

Here we gauge how broad trends in total dynamic connectedness - referred to as global connectedness henceforth - among GSIBs and GSIIs (see Figure 5) compare with the SRISK measure, put forth by Acharya et al. (2012). The latter is a well-established systemic risk measure based, in part, on information contained within firms' balance sheet structures, as well as market capitalization values, and regulatory constraints. Specifically, the measure tracks (in monetary terms) the expected capital shortfall if firms' equity values were to decline to GFC levels. ${ }^{25}$ The overall SRISK measure for an assumed system is an aggregate of expected shortfall measures across the largest (in terms of asset size) financial firms - both banks and nonbanks - in that system. For the majority of countries in our sample, nonbanks covered within SRISK computations are generally insurers.

SRISK computation - very broadly — entails the following steps. It begins by establishing a long run marginal expected shortfall, LRMES. For an individual firm in a system, LRMES is determined by: $1-\exp (\log (1-d) \cdot \beta)$. Here, $d$ denotes the six-month crisis threshold for the broad market index decline (taken to be the MSCI World Index), which is assumed to be 40 percent in our analysis. $\beta$ is the firm's CAPM-based beta coefficient, which measures the volatility, or risks of the firm's security in comparison to the broader equity market. Equity losses expected in a crisis (LRMES) are then combined with the current equity market value, and the outstanding measure of debt, in order to determine (approximately) the amount of capital that would be needed in a crisis. By default, the prudential capital requirement used in

\footnotetext{
${ }^{25}$ See: https://vlab.stern.nyu.edu/
} 
SRISK calculation (given below) is set at 8 percent for firms in Africa, Asia, and Americas, and 5.5 percent for firms in Europe, based on differences in accounting standards.

$$
S R I S K=k \cdot D E B T-(1-k) \cdot E Q U I T Y \cdot(1-L R M E S)
$$

Here, $k$ denotes the capital requirement, EQUITY is the current market capitalization of a firm, and $D E B T$ is the book value of debt, computed as book value of assets minus book value of equity.

Figure 17. Global Connectedness vs. SRISK

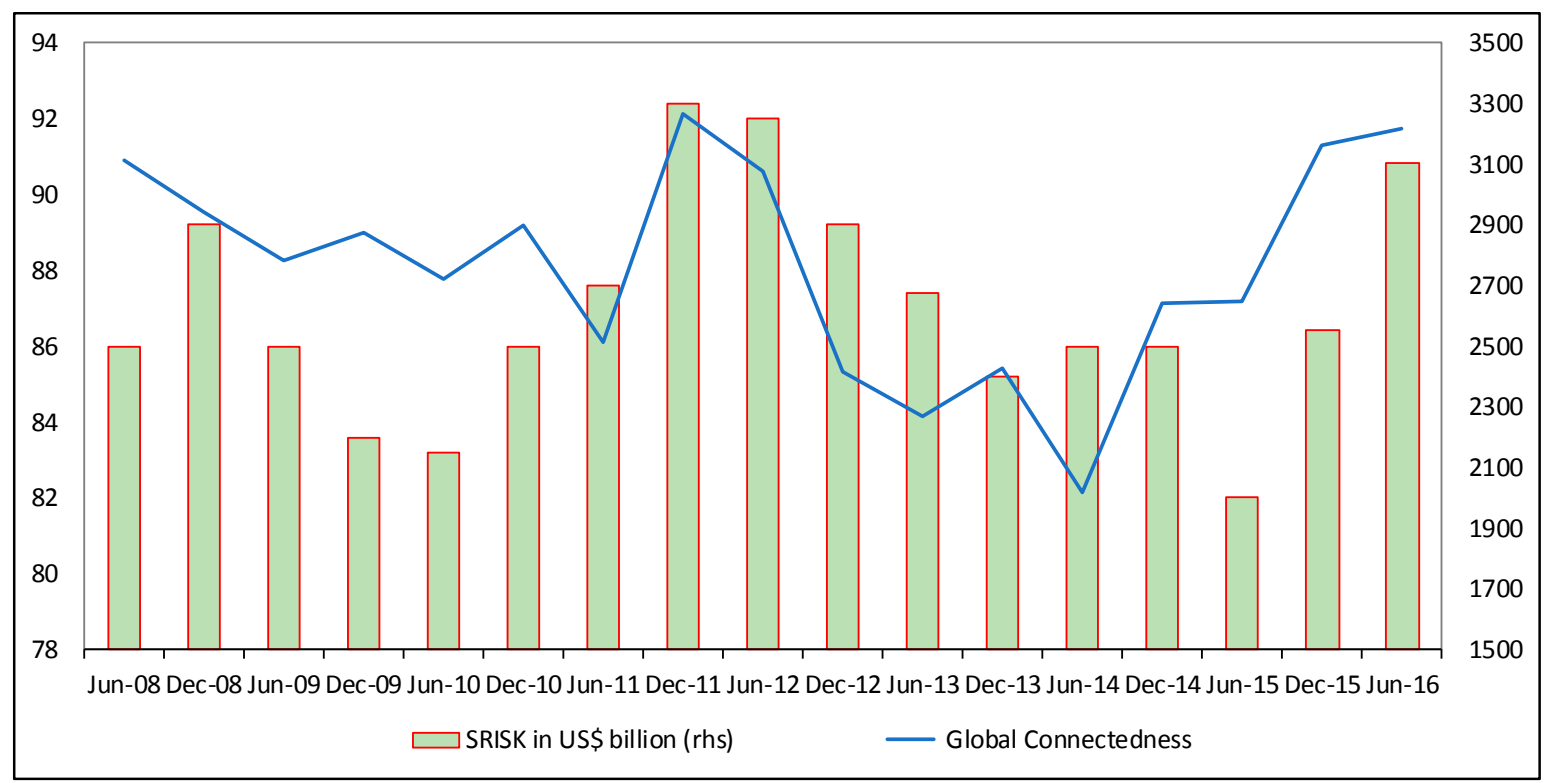

Source: Bloomberg, Bankscope, V-Lab [http://vlab.stern.nyu.edu/en/], IMF Staff estimates Note: SRISK and connectedness measures are reported on a semi-annual frequency.

In addition to the global connectedness measure derived in Section III, Figure 17 plots the SRISK measure corresponding to a global system including 11 domiciliary countries for GSIBs and GSIIs under investigation (see Table 1) on a bi-annual frequency. The main result from our comparison is that broad trends in our exclusively market information-based connectedness measure, accord closely with SRISK. The latter incorporating firm-specific balance sheet information, risk pricing (captured in individual firm $\beta$ ), and asset size. For illustrative purposes, we confined attention to the returns-based connectedness measure; however, connectedness based on volatility generates qualitatively very similar results. We note that SRISK in an increasing function of the correlation between individual firms' equity returns, and returns on the broad market index, reflected in the (CAPM) $\beta$ parameter. Hence, 
while $\beta$ can be seen to govern cyclical dynamics of SRISK, $k$, the capital requirement, would impact the overall level of SRISK, and therefore, the level of systemic risks. ${ }^{26}$

\section{InVESTIGATION INTO FACTORS INFLUENCING CONNECTEDNESS}

\section{A. Common Factors and Global Connectedness}

We investigate potential drivers underlying the evolution of the global connectedness measure. We begin by comparing the measure to selected market risk indicators, and then with short and long-maturity bond yields for countries in our sample. Information contained within these indicators is expected to inform pricing of securities in the market, and decision of market participants to trade in a particular direction, therefore, influencing market connectedness. ${ }^{27}$

\section{Selected Market Risk Indicators}

The VIX and MOVE indices are considered leading proxies for market risk, and routinely monitored by market participants and policymakers. Based on implied volatility of S\&P 500 index options, VIX is a popular metric used to track equity market (and broader market) volatility, and also global risk aversion (see Bekaert and Hoerova, 2016). The MOVE index-Merrill Lynch Option Volatility Estimate - is a yield curve weighted index of normalized implied volatility on Treasury options. MOVE is a popular indicator of volatility in fixed-income markets. In addition, a third metric we consider is the U.S. Dollar Index, the DXY, which measures the value of the U.S. dollar relative to a basket of foreign currencies. An increase in DXY indicates an appreciation (strengthening) of the U.S. dollar compared to the other currencies. ${ }^{28}$ Lastly, we employ a measure for global economic policy uncertainty, computed based on the methodology put forth in Baker, Bloom and Davis (2016). The authors construct indices of economic policy uncertainty utilizing information on the frequency with which certain terms appear in national newspapers. ${ }^{29}$ The global index we

\footnotetext{
${ }^{26}$ While $k=8$ percent $/ 5.5$ percent imposed in SRISK computations is tailored more for banks as compared to non-banks, the overall measure still appropriately reflects relative period-to-period movements in book-value of equity across all firm-types. Hence, even though the assumption on regulatory constraint could have implications for the level of SRISK, at any point in time, we are confident that broad dynamics of SRISK would not be materially impacted as a result.

${ }^{27}$ Concepts of risk aversion and economic uncertainty have been identified as important drivers of asset price dynamics within structural dynamic asset pricing models by inter alia, Campbell and Cochrane (1999) and Bansal and Yaron (2004).

${ }^{28}$ DXY is a weighted geometric mean of the U.S. Dollar's value relative to select currencies with weights: Euro (57.6 percent); Yen (13.6 percent); Sterling (11.9 percent); Canadian Dollar (9.1 percent); Swedish Krona (4.2 percent) and Swiss Franc (3.6 percent).

${ }^{29}$ For instance, the relevant index for the U.S. reflects the frequency of articles in 10 leading U.S. newspapers that contain the following triple: "economic" or "economy;" "uncertain" or "uncertainty;" and one or more of "congress," "deficit," "Federal Reserve," "legislation," "regulation," or "White House."
} 
employ here is essentially a (purchasing power parity-adjusted) GDP-weighted average of national economic policy indices for 16 countries: Australia, Brazil, Canada, China, France, Germany, India, Ireland, Italy, Japan, Russia, South Korea, Spain, the United Kingdom, and the United States. Each national index reflects the relative frequency of own-country newspaper articles that contain a trio of terms pertaining to the economy, policy and uncertainty.

Figure 18. Global Connectedness vs. Selected Risk Indicators July 2008-August 2016
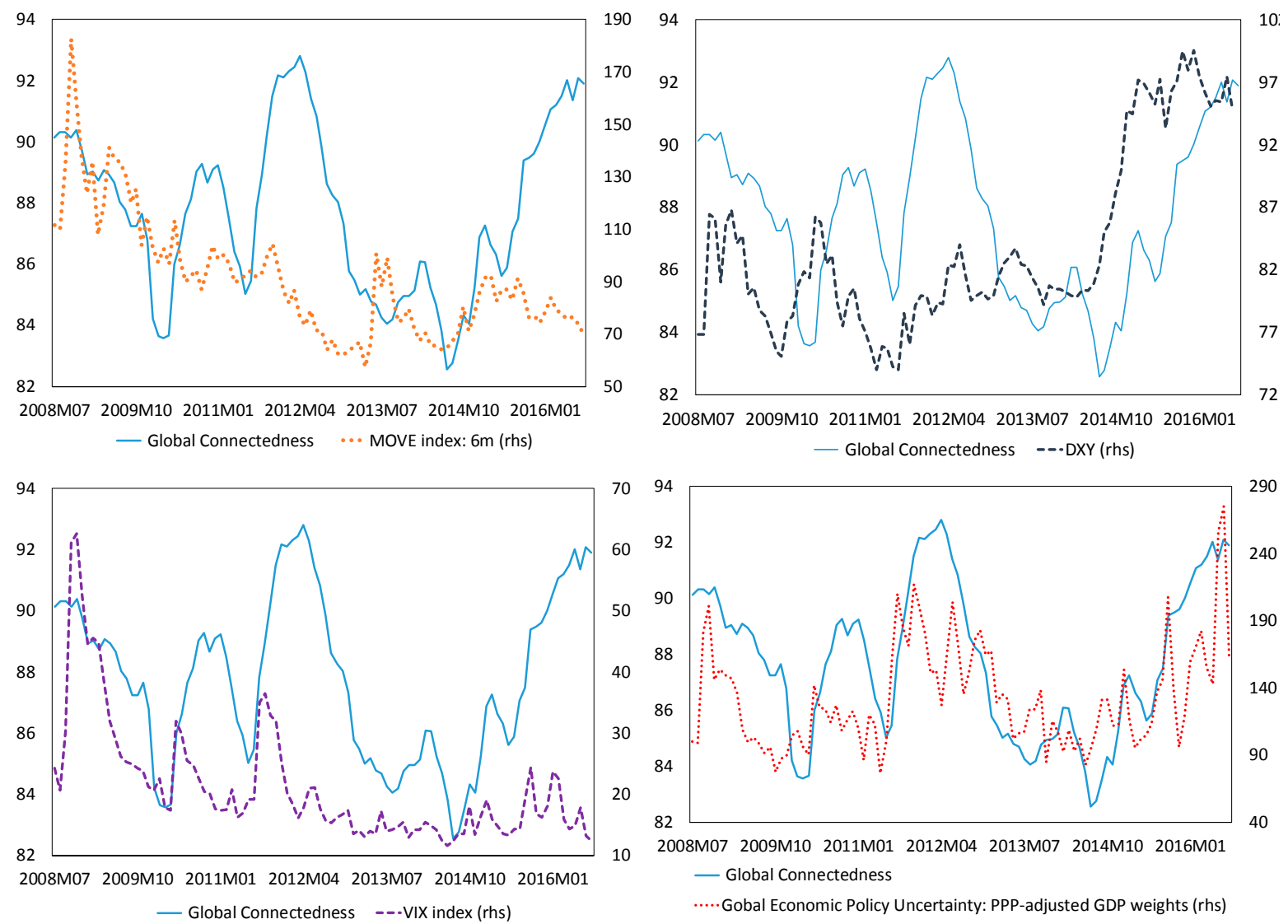

Source: Bloomberg, Bankscope, FRED, http://www.policyuncertainty.com/, IMF Staff estimates Note: U.S. Dollar Index = DXY. The index of global economic policy uncertainty is derived using the methodology put forth in Baker, Bloom and Davis (2016). Purchasing power parity-adjusted GDP weights are used for cross-country aggregation to compute the global measure. The DXY is an index of the value of the US dollar relative to a basket of foreign currencies, computed as a weighted geometric mean of the US dollar's value relative to other select currencies. The Merrill lynch Option Volatility Estimate (MOVE) Index is a yield curve weighted index of the normalized implied volatility on 1-month Treasury options, weighted on the 2, 5,10, and 30 year contracts. The Chicago Board Options Exchange Volatility Index (VIX), measures implied volatility of S\&P 500 index options. 
Figure 18 compares the evolution over time of global connectedness and the four measures described above. To recall, the global connectedness measure we focus on is based on market prices, specifically equity returns of GSIBs and GSIIs. We may thus a priori expect that movements in equity returns for these entities to be influenced by risks in the broader markets for these instruments. However, for the sample considered here, co-movement between global connectedness, and the two market risk/volatility proxies, MOVE and VIX, is not very compelling. Especially focusing on the more recent period since mid-2014, both MOVE and VIX appear to be diverging somewhat over time vis-a-vis connectedness. In comparison, connectedness seems to have consistently moved in line with trends in global economic policy uncertainty (referred to as GPU, henceforth) which has, on average, displayed pro-cyclicality vis-à-vis global connectedness over the sample. Considering trends in DXY, it seems like the upswing in connectedness witnessed since late 2014 has been accompanied by a period of steady appreciation of the U.S. dollar.

\section{Short and Long-Maturity Bond Yields}

The stance of monetary policy, and the forward-looking information pertaining to macroeconomic outlook contained within bond markets, is relevant for the expectation formation mechanism of market participants. These in turn have implication for pricing of securities and broader market dynamics. Therefore, we now compare global connectedness with 3-month and 10-year bond yields. Whereas the former largely reflects expectations of monetary policy, longer-maturity, 10-year yields, have typically been considered a barometer for economic growth outlook. A flattening of the yield curve - or fall in long yields - is indicative of expectations of recessionary pressures. ${ }^{30}$

Visual inspection of data for China, Germany and the United States, plotted in Figure 19, suggests the following broad trends: a countercyclical relationship between 10-year yields vis-a-vis connectedness (over the sample), with Germany displaying a comparatively more persistent downward trend. The focus here on these three countries is illustrative, to provide summary evidence pertaining to what could be considered representative yields, corresponding to broad geographical regions (United States, Europe, and Asia). Comparisons between connectedness dynamics and 3-month and 10-year yields for the full set of 11 countries covered in our analysis are provided in Appendix Figures 9 and 10. Evidence of counter-cyclicality is found across all 10-year yields, albeit with differing degrees of downward-trajectory persistence. In contrast, the relationship between shorter-maturity yields and connectedness, appears to display systematic variability, and is more heterogeneous across countries, in terms of direction and strength of correlation.

\footnotetext{
${ }^{30}$ For more discussion on the predictive power of the yield curve slope, see inter alia Stock and Watson (1989), Estrella and Mishkin (1998) and Ang et al (2006).
} 
Figure 19. Global Connectedness vs. Selected Bond Yields

3-month yields
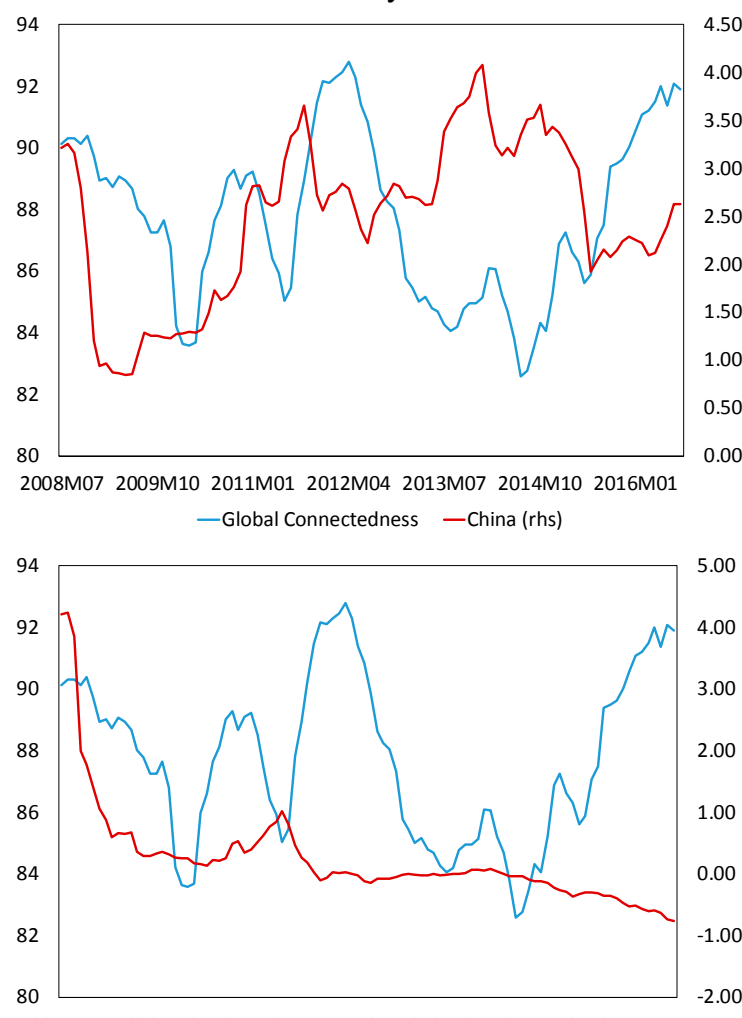

2008M07 2009M10 2011M01 2012M04 2013M07 2014M10 2016M01

-Global Connectedness -Germany (rhs)

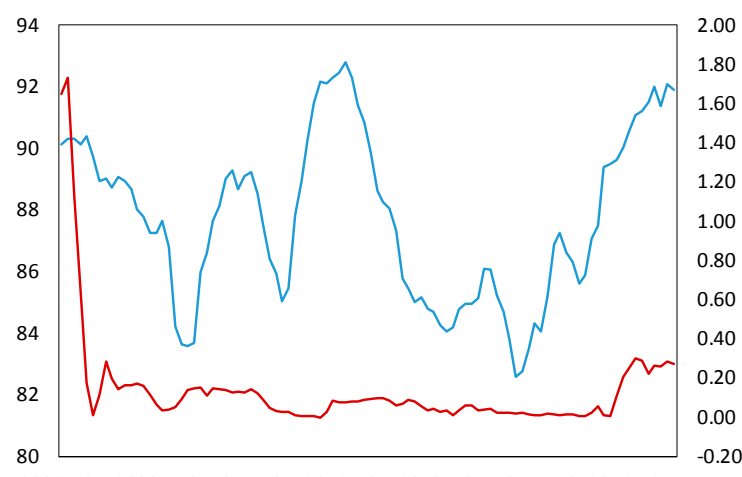

2008M07 2009M10 2011M01 2012M04 2013M07 2014M10 2016M01

-Global Connectedness -U.S. (rhs) 10-year yields
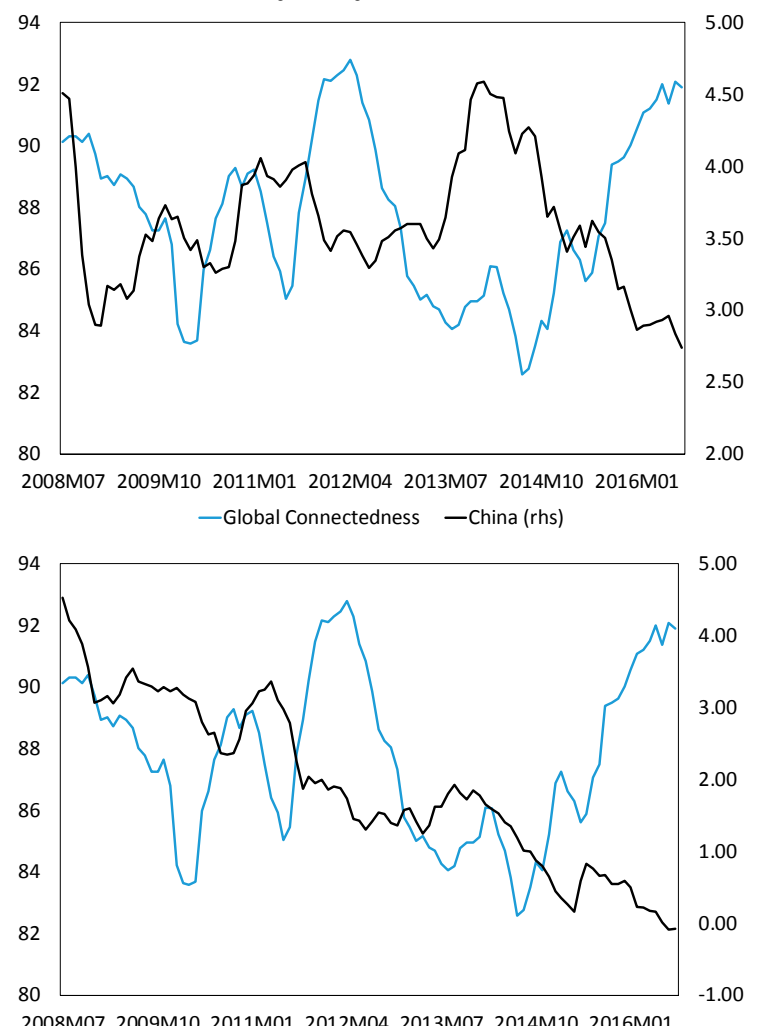

-Global Connectedness -Germany (rhs)

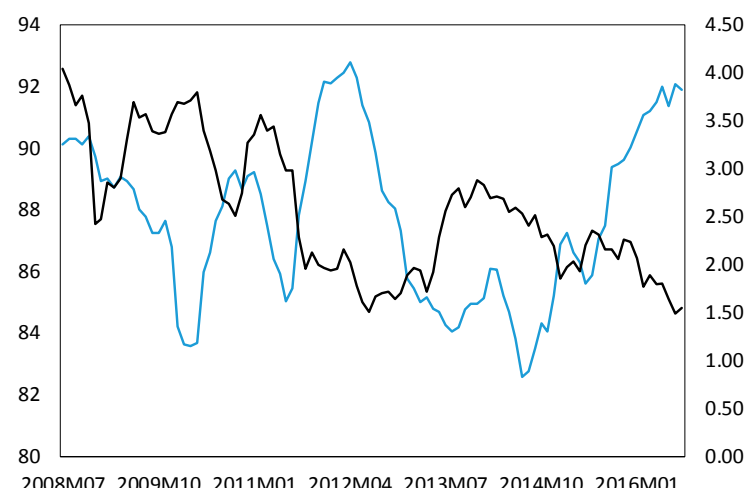

-Global Connectedness -U.S. (rhs)

Source: Bloomberg, Bankscope, FRED, IMF Staff estimates

Note: Interest rates correspond to spot rates, and are measured on the right hand side (rhs) axis, in percent.

To extract summary information contained within10-year yield series for all 11 countries covered in our analysis, we proceeded to extract principal components from the underlying series. The first principal component (PC) was found to move in line with the U.S. 10-year yield (US10, henceforth), albeit with more pronounced cyclical amplitude; see Figure 20. In what follows, attention will be restricted to US10. We do not, however, rule out predictive 
capacity of yields of other countries; comparative analysis of which we intend to undertake in future research.

Beyond visual inspection, in order to assess more formally the relative degrees of comovement between global connectedness and the key indicators under consideration, we compute pair-wise correlations for these indicators (see Appendix Table 1). It was found that in absolute terms, GPU is most strongly correlated with the GC measure, whereas DXY is the weakest. The counter-cyclicality of US10 is borne out in a non-trivial negative correlation. For an examination into subsample stability of the correlation relationship between GC, US10, and GPU—within a more general dynamic setting — we also conduct dynamic impulse response analysis. The results suggest that $\mathrm{GC}$ responds significantly to shocks to GPU and US10 across the entire sample and two subsamples under consideration. Specifically, GC responds positively to a shock to GPU and negatively to a shock to US10, as expected (see Box 1).

Figure 20. U.S.10-year Yield vs. Common Factor

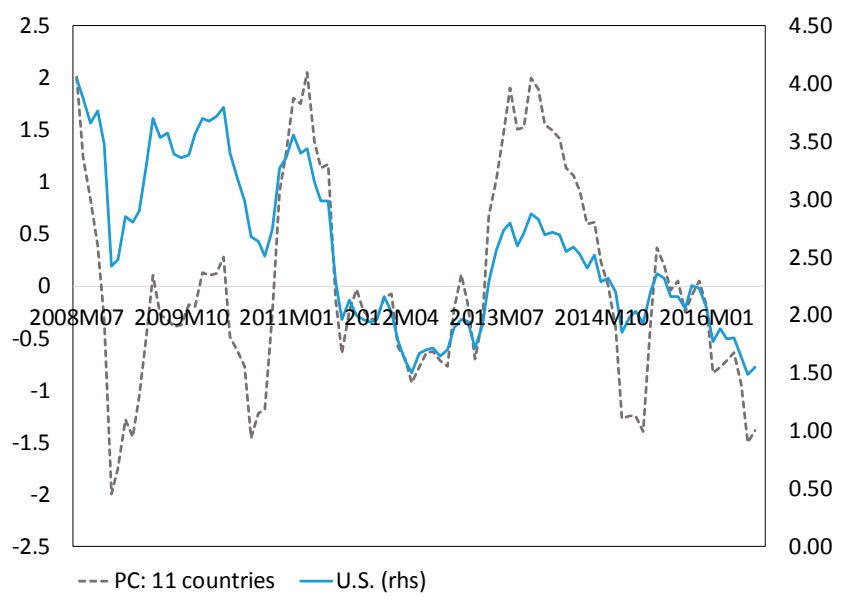

Source: Bloomberg, Bankscope, FRED, IMF Staff estimates

Note: $\mathrm{PC}$ denotes the first principal component of 10 -year yields extracted from the cross-section of all 11 countries covered in our analysis. 


\section{Box 1. Dynamic Responses of Global Connectedness to Selected Shocks}

In order to assess whether the global connectedness responds significantly - in a dynamic sense - to shocks in GPU and US10, we examine three simple bivariate vector autoregressive (VAR) systems. The first relates GPU and GC, and the second, US10 and GC. We assume the direction of (contemporaneous) causality runs from GPU and US10 towards connectedness. The VARs are accordingly identified via a Cholesky scheme. In order to control for broad based market risk, VIX is also included as an exogenous variable. Three estimation samples are considered: (i) the full sample span, July 2008-August 2016; (ii) subsample A., July 2008-August 2012; and (iii) subsample B., August 2012-August 2016.

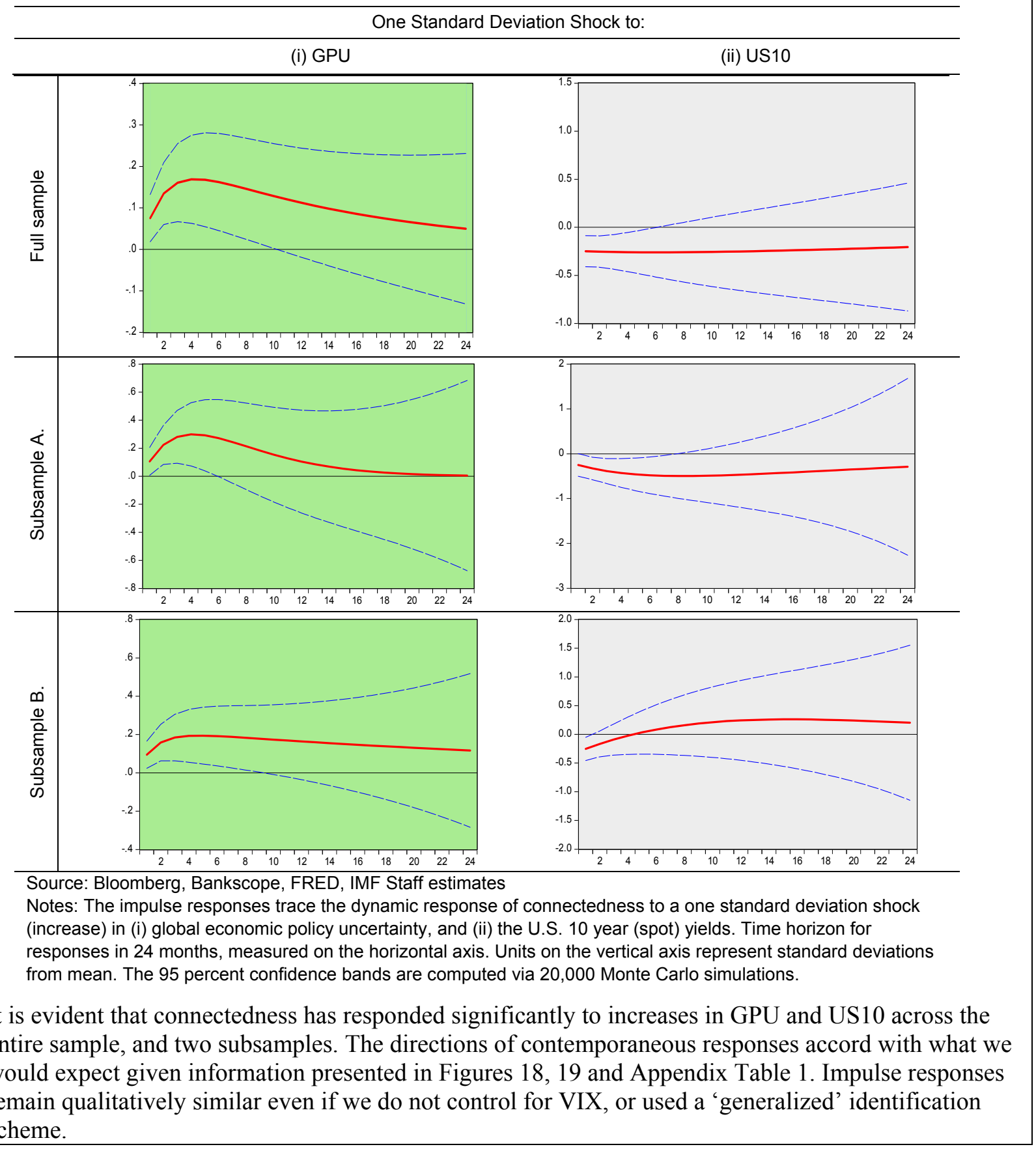




\section{B. Predicting Connectedness via Common Factors}

We now attempt to utilize information contained within common factors explored in Section IV.A to predict global connectedness. Our predictive model is postulated below.

$$
G C_{t}=\alpha+\beta G P U_{t}+\gamma U S 10_{t}+\delta V I X_{t}+\theta G C_{t-1}+\varepsilon_{t}
$$

The conditioning variables were chosen based on the strength of co-movement with respect to global connectedness (GC henceforth) uncovered earlier. GPU, US10, and VIX are assumed to affect GC contemporaneously. One-period lagged GC is included to account for the persistence in the process. However, in preliminary testing, lags for the other variables were found to be insignificant, and hence were dropped from the regression. Global economic policy uncertainty and U.S.10-year rates are assumed to influence developments in connectedness - but not vice versa. The inclusion of VIX is warranted in order to control for volatility in equity market and as a proxy for risk aversion (Bekeart and Hoerova, 2016).

For the sake of generality, we allow for a GARCH $(1,1)$ process in the disturbance term such that, $\varepsilon_{t} \sim \mathrm{N}\left(0, h_{t}\right)$, and $h_{t}=\omega_{0}+\omega_{1} G C_{t-1}^{2}+\omega_{2} h_{t-1}$; following Bollerslev (1986). The use of the GARCH process is to accommodate any latent factors potentially giving rise to timevarying variability in GC, which may not be captured by information within our observed conditioning variables.

Table 2 reports the estimation results for the regression C1, over the span July 2008 to August 2016. All our conditioning variables are found to be significant at the 5 percent level, with an overall R-squared of 89 percent. Pro-cyclicality of GPU and counter-cyclicality of US10 with respect to GC is evident. However, no evidence of time-varying heteroscedasticity governing the evolution of GC is found. ${ }^{31}$

Results from a quantile regression - based on specification C1 - suggests that US10, although countercyclical with respect to GC in conditional mean terms, has a more significant impact on higher percentiles of the conditional distribution of GC; i.e., $\tau \geq 0.60$. GPU, on the other hand, has a more uniform impact - in terms of magnitude and statistical significance - across the range of percentiles.

\footnotetext{
${ }^{31}$ Variance inflation factors for each of the included variables in specification $\mathrm{C} 1$ were found to be subdued, and less than 2 in all cases. We take this to be evidence against serious collinearity.
} 
Table 2. Predictive Regression: Global Connectedness

\begin{tabular}{|c|c|c|c|c|c|c|c|c|c|c|c|}
\hline \multicolumn{12}{|c|}{$\begin{array}{c}G C_{t}=\alpha+\beta G P U_{t}+\gamma U S 10_{t}+\delta V I X_{t}+\theta G C_{t-1}+\varepsilon_{t} ; \varepsilon_{t} \sim \mathrm{N}\left(0, h_{t}\right) \\
h_{t}=\omega_{0}+\omega_{1} G C_{t-1}^{2}+\omega_{2} h_{t-1}\end{array}$} \\
\hline & \multirow{2}{*}{$\begin{array}{c}\text { Linear } \\
\text { Regression }\end{array}$} & \multicolumn{10}{|c|}{ Quantile regression } \\
\hline & & $\tau$ & 0.1 & 0.2 & 0.3 & 0.4 & 0.5 & 0.6 & 0.7 & 0.8 & 0.9 \\
\hline \multirow[t]{2}{*}{$\alpha$} & $21.65^{\star \star}$ & & $28.83^{* \star}$ & $20.38^{\star \star}$ & $20.39 * *$ & $18.30^{\star \star}$ & $17.78^{\star \star}$ & $16.88^{\star \star}$ & $24.21^{\star \star}$ & $24.41^{\star *}$ & $22.61^{* *}$ \\
\hline & $(4.50)$ & & $(7.35)$ & $(5.03)$ & $(5.70)$ & (5.94) & (6.68) & $(5.21)$ & (4.49) & (3.51) & (2.95) \\
\hline \multirow[t]{2}{*}{$\beta$} & $0.01^{* *}$ & & 0.01 & 0.01 & $0.01^{* *}$ & $0.01^{* *}$ & $0.01^{\star *}$ & $0.01^{\star \star}$ & $0.01^{* *}$ & $0.01^{* *}$ & $0.01^{* *}$ \\
\hline & $(0.00)$ & & $(0.00)$ & $(0.00)$ & $(0.00)$ & $(0.00)$ & $(0.00)$ & $(0.00)$ & $(0.00)$ & $(0.00)$ & $(0.00)$ \\
\hline \multirow[t]{2}{*}{$\gamma$} & $-0.52^{* *}$ & & -0.42 & -0.29 & -0.15 & -0.04 & -0.40 & $-0.69^{* *}$ & $-0.94^{\star *}$ & $-0.75^{* *}$ & $-1.08^{* *}$ \\
\hline & $(0.26)$ & & $(0.41)$ & $(0.29)$ & $(0.33)$ & $(0.34)$ & $(0.38)$ & $(0.30)$ & $(0.26)$ & $(0.21)$ & $(0.18)$ \\
\hline \multirow[t]{2}{*}{$\delta$} & $0.04^{* *}$ & & $0.05^{* *}$ & $0.03^{*}$ & $0.04^{*}$ & 0.02 & $0.04^{*}$ & $0.05^{* *}$ & $0.06^{\star *}$ & $0.06^{* *}$ & $0.09 * *$ \\
\hline & $(0.02)$ & & $(0.03)$ & $(0.02)$ & $(0.02)$ & $(0.02)$ & $(0.02)$ & $(0.02)$ & $(0.01)$ & 0.01 & 0.01 \\
\hline \multirow[t]{2}{*}{$\theta$} & $0.74^{* *}$ & & $0.64^{\star *}$ & $0.74^{\star *}$ & $0.73^{* *}$ & $0.76^{\star \star}$ & $0.78^{\star \star}$ & $0.80 \star \star$ & $0.73^{* *}$ & $0.73^{* *}$ & $0.76^{* *}$ \\
\hline & $(0.05)$ & & $(0.08)$ & $(0.06)$ & $(0.07)$ & $(0.07)$ & $(0.08)$ & $(0.06)$ & $(0.05)$ & $(0.04)$ & $(0.03)$ \\
\hline \multirow[t]{2}{*}{$\omega_{0}$} & 1.01 & & & & & & & & & & \\
\hline & $(0.80)$ & & & & & & & & & & \\
\hline \multirow[t]{2}{*}{$\omega_{1}$} & 0.58 & & & & & & & & & & \\
\hline & $(0.39)$ & & & & & & & & & & \\
\hline \multirow[t]{2}{*}{$\omega_{2}$} & 0.33 & & & & & & & & & & \\
\hline & $(0.61)$ & & & & & & & & & & \\
\hline \multicolumn{2}{|c|}{ R-squared $=0.89$} & & & & & & & & & & \\
\hline
\end{tabular}

Source: Bloomberg, Bankscope, FRED, IMF Staff estimates

Note: Sample span for estimation: July 2008 - August 2016. The linear regression estimated via maximum likelihood. $\tau$ denotes the quantiles (or percentiles) investigated via the quantile regression. The quantile regression is estimated via sparsity method based on Epanechnikov kernel. Standard errors are computed via bootstrap, based on 20,000 residual resamples. $\left({ }^{* *}\right)$ denotes significance at the 5 percent level.

We verify high degree of within-sample predictive accuracy by comparing one-step ahead predictions from the model with actual global connectedness; see Figure 21. Having established accuracy of the model within-sample, we now proceed to investigate how conditional predictions of the model behave out-of-sample. We re-estimate the model over a shorter span of July 2008 to April 2016. Using the latter date as the prediction origin, and conditioning on the observed exogenous variables over the prediction horizon April 2016 to August 2016, we generate (dynamic) out-of-sample predictions for GC, and compare with actuals; see Figure 22. It is evident that the model behaves reasonably well out of sample, in that it appears to track closely broad trends in GC. We next examine out-of-sample predictions based on counterfactual paths for our conditioning variables. 
Figure 21. Within-Sample Predictive Accuracy

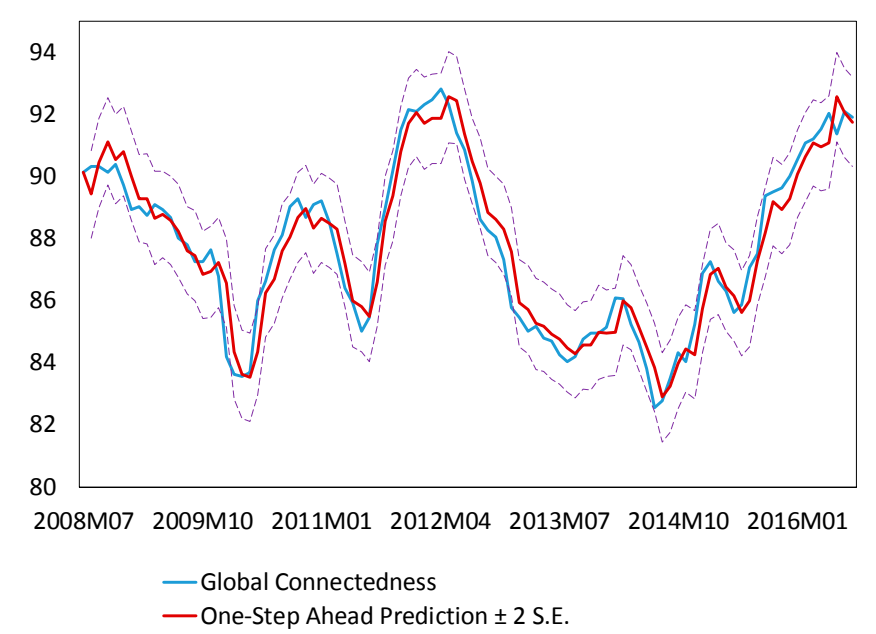

Source: Bloomberg, Bankscope, FRED, IMF Staff estimates

Notes: Estimation sample is July 2008 to August 2016. Standard error bands (S.E.) are computed using bootstrap resampling of the error term, and paths for the GC generated for each resample. 5,000 bootstrap resamples are used at each time-step, with one-step ahead predictions corresponding to the conditional mean.

To begin, we condition on values of GPU, US10, and VIX, observed between August 2016 and January 2017; Figure 23 (left panel). This period witnessed an upward trend in both US10 and GPU. US10 increased from 1.55 percent in August 2016 to 2.43 percent by January 2017, while GPU increased from an index level of 175.73 to 270.15 over the same period. VIX displayed fairly low variability, hovering close to its average value recorded over the preceding six-month period. The predicted path for GC appears to oscillated slightly, albeit around the level witnessed at the prediction origin (i.e., August 2016).

Figure 22. Out-of-Sample Predictive Accuracy

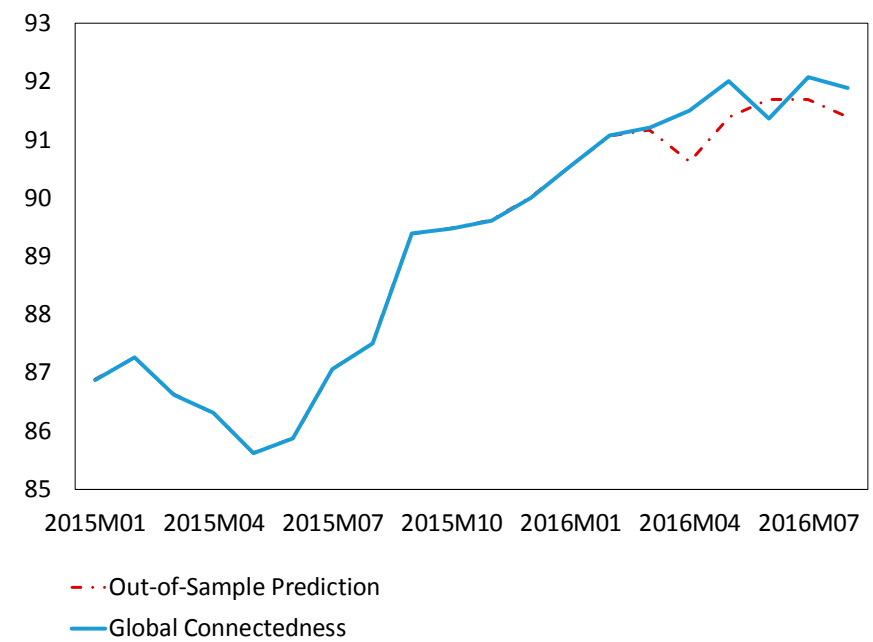

Source: Bloomberg, Bankscope, FRED, IMF Staff estimates Note: Estimation sample is July 2008 to April 2016.

Prediction horizon is April 2016 to August 2016. 
Counterfactual 1 assumes that the rise in US10 was accompanied by a flat-lining of GPU at its average value over 12 months prior to our prediction origin - a value approximately equal to 166 . Conditioning on this path, and inserting observed values for the remaining variables, would set GC on a downward trajectory Figure 23 (right panel). Alternatively, in Counterfactual 2, we ask what magnitude of increase for US10 would be needed to counteract the effect of the observed 70 percent increase in GPU (from 175.73 to 270.15); such that predictions of GC can be aligned (more or less) with the downward trajectory generated under Counterfactual 1. We find that in order to generate the same downward trajectory for GC, US10 would need to have risen extremely (and implausibly) steeply, from 1.55 percent to near 4 percent. ${ }^{32}$

\section{Figure 23. Out-of-Sample Predictions and Counterfactuals}
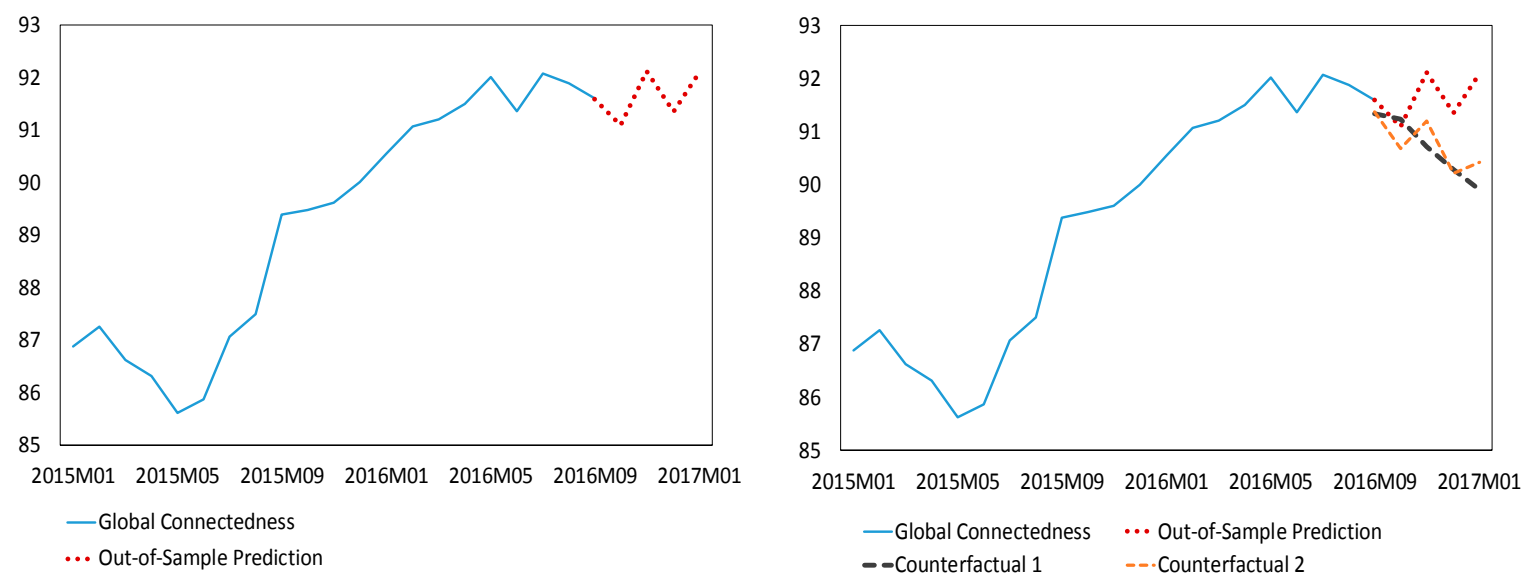

Source: Bloomberg, Bankscope, FRED, IMF Staff estimates

Note: Estimation sample is July 2008 to August 2016, with the latter date the (out-of-sample) prediction origin.

Having examined factors influencing developments in global connectedness, we now inquire how relevant they are at forecasting at a more disaggregated level. Recall that global connectedness is the aggregate of to- and from-degrees (see Section II). The to-degree, for instance, denotes the total directional connectedness of GSIBs (GSIIs) in a particular region 'to' the system of GSIBs (GSIIs). If we denote this as $T_{-} G C_{j, t}$, where $j=$ GSIBs, GSIIs, the predictive regression $\mathrm{C} 1$ can be simply recast as:

$$
T_{-} G C_{j, t}=\alpha+\beta G P U_{t}+\gamma U S 10_{t}+\delta V I X_{t}+\theta T_{-} G C_{j, t-1}+\varepsilon_{t} ; \varepsilon_{t} \sim \mathrm{N}\left(0, h_{t}\right)
$$

and $h_{t}=\omega_{0}+\omega_{1} T_{-} G C_{j, t-1}^{2}+\omega_{2} h_{t-1}$, defines the GARCH $(1,1)$ process. Total directional connectedness to GSIBs (GSIIs) in a particular region 'from' the system of GSIBs (GSIIs) is denoted by $F_{-} G C_{j, t}$. The corresponding predictive regression remaining the same, barring replacement of $T_{-} G C_{j, t}$ with $F_{-} G C_{j, t}$.

\footnotetext{
${ }^{32}$ In Box B, we consider a longer-term projection of GC, which conditions on a scenario for US10, based on a historical reading of U.S. growth.
} 
Table 3. Predictive Regression: Total Directional Connectedness-To- and From-Degrees

\begin{tabular}{|c|c|c|c|c|c|c|}
\hline \multicolumn{7}{|c|}{$\begin{array}{c}T_{-} G C_{j, t}=\alpha+\beta G P U_{t}+\gamma U S 10_{t}+\delta V I X_{t}+\theta T_{-} G C_{j, t-1}+\varepsilon_{t} ; \varepsilon_{t} \sim \mathrm{N}\left(0, h_{t}\right) \\
h_{t}=\omega_{0}+\omega_{1} T_{-} G C_{j, t-1}^{2}+\omega_{2} h_{t-1} .\end{array}$} \\
\hline & \multicolumn{3}{|c|}{$j=\mathrm{GSIBS}$} & \multicolumn{3}{|c|}{$j=$ GSIIs } \\
\hline & U.S. & Europe & Asia & U.S. & Europe & Asia \\
\hline \multirow[t]{2}{*}{$\alpha$} & $46.90^{* *}$ & $18.81^{\star *}$ & 3.46 & $47.87^{\star \star}$ & $9.72^{\star *}$ & 1.92 \\
\hline & $(6.57)$ & $(5.06)$ & (3.30) & (5.94) & $(4.70)$ & $(4.41)$ \\
\hline \multirow[t]{2}{*}{$\beta$} & -0.01 & 0.01 & 0.02 & -0.01 & $0.04^{\star *}$ & 0.01 \\
\hline & $(0.00)$ & $(0.01)$ & $(0.00)$ & $(0.02)$ & $(0.00)$ & $(0.02)$ \\
\hline \multirow[t]{2}{*}{$\gamma$} & $-3.95^{\star *}$ & -0.56 & $1.78^{* *}$ & $-4.37^{\star *}$ & $1.63^{* *}$ & 0.33 \\
\hline & $(0.93)$ & $(0.60)$ & $(0.71)$ & $(0.75)$ & (1.28) & (1.08) \\
\hline \multirow[t]{2}{*}{$\delta$} & $0.29 * \star$ & $-0.04^{* *}$ & 0.04 & $0.24^{* *}$ & $0.09 * *$ & 0.06 \\
\hline & $(0.05)$ & $(0.02)$ & $(0.20)$ & $(0.08)$ & $(0.04)$ & $(0.01)$ \\
\hline \multirow[t]{2}{*}{$\theta$} & $0.58^{* *}$ & 0.82 ** & $0.73^{* *}$ & $0.61^{\text {** }}$ & $0.82^{* *}$ & 0.80 ** \\
\hline & $(0.04)$ & $(0.05)$ & $(0.06)$ & $(0.06)$ & $(0.06)$ & $(0.02)$ \\
\hline \multirow[t]{2}{*}{$\omega_{0}$} & $10.68^{* *}$ & $1.55^{\text {** }}$ & $4.60^{* \star}$ & $30.07^{* *}$ & $0.74^{\star *}$ & 4.79 \\
\hline & (3.37) & $(0.12)$ & (1.99) & $(8.57)$ & $(0.56)$ & $(5.41)$ \\
\hline \multirow[t]{2}{*}{$\omega_{1}$} & 0.69 ** & $0.78^{* *}$ & $0.71^{* *}$ & $0.73^{\star *}$ & $0.10^{*}$ & $0.42^{*}$ \\
\hline & $(0.25)$ & $(0.33)$ & $(0.28)$ & $(0.28)$ & $(0.04)$ & $(0.21)$ \\
\hline \multirow[t]{2}{*}{$\omega_{2}$} & 0.10 & 0.19 & 0.15 & $0.35^{\star *}$ & $0.61^{* *}$ & $0.46^{*}$ \\
\hline & $(0.11)$ & $(0.15)$ & $(0.17)$ & $(0.15)$ & $(0.12)$ & $(0.23)$ \\
\hline \multicolumn{7}{|c|}{$\begin{array}{c}F_{-} G C_{j, t}=\alpha+\beta G P U_{t}+\gamma U S 10_{t}+\delta V I X_{t}+\theta F_{-} G C_{j, t-1}+\varepsilon_{t} ; \varepsilon_{t} \sim \mathrm{N}\left(0, h_{t}\right) \\
h_{t}=\omega_{0}+\omega_{1} F_{-} G C_{j, t-1}^{2}+\omega_{2} h_{t-1} .\end{array}$} \\
\hline & \multicolumn{3}{|c|}{$j=\mathrm{GSIBS}$} & \multicolumn{3}{|c|}{$j=$ GSIIs } \\
\hline & U.S. & Europe & Asia & U.S. & Europe & Asia \\
\hline \multirow[t]{2}{*}{$\alpha$} & 27.60 ** & $21.77^{\star \star}$ & $28.19 * \star$ & $22.37^{\star *}$ & $15.56^{\text {** }}$ & $17.61^{* *}$ \\
\hline & $(4.30)$ & (3.29) & $(4.12)$ & $(7.20)$ & $(4.04)$ & $(6.07)$ \\
\hline \multirow[t]{2}{*}{$\beta$} & $0.01^{\star *}$ & $0.01^{* *}$ & 0.00 & 0.00 & $0.02^{\star \star}$ & 0.00 \\
\hline & $(0.00)$ & $(0.01)$ & $(0.00)$ & $(0.00)$ & $(0.00)$ & $(0.02)$ \\
\hline \multirow[t]{2}{*}{$\gamma$} & $-0.98^{\star *}$ & $-0.84^{* *}$ & $-1.54 * *$ & $-1.24^{\star *}$ & $0.17^{\star *}$ & 0.89 \\
\hline & $(0.17)$ & $(0.17)$ & $(0.48)$ & $(0.28)$ & $(0.19)$ & (1.19) \\
\hline \multirow[t]{2}{*}{$\delta$} & $0.03^{* *}$ & $0.07^{* *}$ & $0.09 * *$ & -0.01 & 0.01 & 0.09 \\
\hline & $(0.00)$ & $(0.01)$ & $(0.03)$ & $(0.02)$ & $(0.01)$ & $(0.06)$ \\
\hline \multirow[t]{2}{*}{$\theta$} & $0.71^{* *}$ & $0.76^{* *}$ & $0.66^{* *}$ & $0.78^{* *}$ & $078^{* *}$ & $0.71^{* *}$ \\
\hline & $(0.04)$ & $(0.04)$ & $(0.05)$ & $(0.08)$ & $(0.05)$ & $(0.07)$ \\
\hline \multirow[t]{2}{*}{$\omega_{0}$} & $0.29 * *$ & $0.47^{* *}$ & $2.50^{\star *}$ & 0.13 & $0.16^{* *}$ & $1.54^{* *}$ \\
\hline & $(0.09)$ & $(0.17)$ & $(0.83)$ & $(0.16)$ & $(0.00)$ & $(0.21)$ \\
\hline \multirow[t]{2}{*}{$\omega_{1}$} & $0.83^{* *}$ & $0.81^{* *}$ & $0.91^{* *}$ & $0.78^{* *}$ & $0.12^{\star *}$ & $0.06^{\star *}$ \\
\hline & $(0.36)$ & $(0.23)$ & $(0.33)$ & $(0.22)$ & $(0.02)$ & $(0.03)$ \\
\hline \multirow[t]{2}{*}{$\omega_{2}$} & 0.06 & $0.15^{\text {** }}$ & 0.00 & $0.10^{\star \star}$ & $0.73^{* *}$ & $0.90^{* *}$ \\
\hline & $(0.03)$ & $(0.12)$ & (0.11) & $(0.01)$ & $(0.17)$ & $(0.07)$ \\
\hline
\end{tabular}

Source: Bloomberg, Bankscope, FRED, IMF Staff estimates

Note: Sample span for estimation: July 2008-August 2016. The linear regression estimated via maximum likelihood. Standard errors in parentheses. $\left({ }^{* *}\right)$ and $\left({ }^{*}\right)$ indicate significance at the 5 percent and 10 percent significance levels, respectively. 
Results from predictive regressions for the to- and from-degrees reveals evidence of heterogeneity across regions, and firm types, with regards to both direction and significance of influence of our selected factors (Table 3). But more importantly, we find that whereas for the aggregate (i.e., global connectedness measure), GARCH effects were found to be relatively unimportant (Table 2, Linear Regression column), these appear to be very relevant at a disaggregated level (Table 3 ). This is taken as evidence that idiosyncratic factors-firm or region-specific - may play a significant role in governing the dynamics of to- and fromdegrees, in addition to the influence of, for example, level of global economic policy uncertainty, and U.S. 10-year yield. But at an aggregate level, dynamics of global connectedness can be explained almost exclusively by development in systemic factors U.S. long-term bond yield, and global economic policy uncertainty.

\section{The Role of Bank-Specific Factors}

To examine the role of bank-specific factors in driving connectedness, we consider a panel regression for to- and from-degree connectedness for the sample of GSIBs. More specifically, the panel regression is estimated with the Arellano-Bover/Blundell-Bond linear dynamic panel- estimator, incorporating robust standard errors ${ }^{33}$, specified as follows:

$$
\begin{aligned}
& T_{-} G C_{j, t}=\delta T_{-} G C_{j, t-1}+\vartheta_{j}+\phi^{\prime} X_{j, t}+\Theta^{\prime} I_{t}+\varepsilon_{j, t} \\
& F_{-} G C_{j, t}=\delta F_{-} G C_{j, t-1}+\vartheta_{j}+\phi^{\prime} X_{j, t}+\Theta^{\prime} I_{t}+\varepsilon_{j, t}
\end{aligned}
$$

where $T_{-} G C_{j, t}$ and $F_{-} G C_{j, t}$ capture to-degree and from-degree connectedness, respectively for bank $j$ at time $t$. In order to take into account bank characteristics, we include a set of bank-fixed effects $\left(\vartheta_{j}\right)$ and a vector of (time-varying) bank-specific indicators $X_{j, t}$, capturing bank characteristics including bank profitability (ROAA), asset quality (NPL ratio) and asset size, all taken from FitchConnect. International or global indicators, $I_{t}$, capture global factors such as the level of global economy policy uncertainty and U.S. 10-year yield.

The panel regression reveals that bank profitability plays an important role in driving return connectedness, both inward and outward. Less profitable GSIBs tend to be a source of return connectedness, and are also more prone to contagion from the system. Furthermore, low asset quality as measured by the high NPL ratio is also associated with a high degree of inward connectedness. On average, elevated global uncertainty and high U.S. 10-year interest rate also imply that GSIBs become more prone to inward connectedness and contagion from the rest of the banking system (Table 4).

\footnotetext{
${ }^{33}$ A dynamic panel regression is specified due to the persistence in return connectedness. The ArellanoBover/Blundell-Bond system estimator is an extension of the Arellano-Bond estimator that accommodates large autoregressive parameters and a large ratio of the variance of the panel-level effect to the variance of idiosyncratic error. The Arellano-Bover/Blundell-Bond system estimator is designed for datasets with many panels and few periods, which is the case for our datasets at annual frequency.
} 
Table 4. Panel Regression Controlling for Bank-Specific and Global Factors

\begin{tabular}{|c|c|c|}
\hline VARIABLES & $\begin{array}{c}(1) \\
\text { To_Connectedness } \\
\end{array}$ & $\begin{array}{c}(2) \\
\text { From_Connectedness }\end{array}$ \\
\hline Lagged dependent variables & $\begin{array}{c}\mathbf{0 . 4 6 7 * * *} \\
(0.105)\end{array}$ & $\begin{array}{l}0.229 * * \\
(0.0928)\end{array}$ \\
\hline ROAA & $\begin{array}{c}-7.905 * * \\
(3.466)\end{array}$ & $\begin{array}{c}-4.807 * * * \\
(1.770)\end{array}$ \\
\hline NPL ratio & $\begin{array}{c}1.077 \\
(1.189)\end{array}$ & $\begin{array}{l}0.906 * \\
(0.485)\end{array}$ \\
\hline Total assets (In) & $\begin{array}{l}-3.148 \\
(5.392)\end{array}$ & $\begin{array}{l}-1.666 \\
(1.033)\end{array}$ \\
\hline Global uncertainty & $\begin{array}{c}0.0624 \\
(0.0761)\end{array}$ & $\begin{array}{c}0.130 * * * \\
(0.0267)\end{array}$ \\
\hline US 10 -year interest rate & $\begin{array}{l}0.0173 \\
(2.540)\end{array}$ & $\begin{array}{l}1.948^{*} \\
(1.084)\end{array}$ \\
\hline Constant & $\begin{array}{l}80.37 \\
(81.62)\end{array}$ & $\begin{array}{c}\text { 65.51*** } \\
(18.08)\end{array}$ \\
\hline $\begin{array}{l}\text { Observations } \\
\text { Number of Bank id }\end{array}$ & $\begin{array}{c}195 \\
29\end{array}$ & $\begin{array}{c}195 \\
29\end{array}$ \\
\hline \multicolumn{3}{|c|}{$\begin{array}{l}* * * p<0.01, * * p<0.05,{ }^{*} p<0.1 \\
\text { Source: FitchConnect, http://www.policyuncertainty.com/, IMF Staff estimates } \\
\text { Note: Sample span for estimation: } 2008 \text { to } 2015 . \text { Arellano-Bover/Blundell-Bond } \\
\text { linear dynamic panel-data estimator with robust standard errors (in parentheses). }\end{array}$} \\
\hline
\end{tabular}

\section{Conclusions}

This paper examines interconnectedness among global systemically-important banks and global insurers by using publicly available equity returns and intra-day volatility data from October 2007 to August 2016. The connectedness measure is derived from the forecast error variance decomposition of the underlying VAR model of GSIBs and GSIIs using the Diebold and Yilmaz approach.

The empirical results reveal the important role of GSIBs in the United States and several European countries as sources of directional equity return and volatility connectedness. Similarly, GSIIs from the United States and some European countries tend to influence the equity returns and volatilities of other GSIIs. Interestingly, while the largest GSIBs appear to be the recipients of connectedness, the largest GSIIs tend to be the sources of outward returns and volatility connectedness.

There is strong evidence of regional clusters of return and volatility connectedness among global systemically-important financial intermediaries. The strongest pair-wise 
connectedness is found among Asian, United States', and European GSIBs and GSIIs. In other words, the cross-sectoral connectedness between GSIBs and GSIIs within the same region appears to be more intense than the cross-regional linkage within sectors. Strong intraregional linkages could be attributed to factors including cross-sectoral loans and investment, common macroeconomic conditions, and financial regulations. Furthermore, the total system connectedness measure tends to rise during financial stress episodes, as observed in the Global Financial Crisis and the European Sovereign Debt Crisis.

Finally, the paper shows that the global economic policy uncertainty and the U.S. 10-year bond yield have significant impact on market connectedness, based on linear and quantile regressions. Specifically, higher global economic policy uncertainty and lower U.S. 10-year bond yields are associated with increased degree of market connectedness among GSIBs and GSIIs. Bank-specific factors such as profitability and asset quality also play an important role in driving return connectedness.

These findings are relevant for a number of significant financial stability issues. First, the relative importance of GSIBs from the United States, Germany, Spain, and France underscores the importance of risk management and intense supervision of global systemically-important institutions, as well as the close monitoring of their cross-border exposures. The same applies to GSIIs from France, the United States, and Germany. Supervision should account for the impact of both inward and outward spillovers. Second, the high degree of return and volatility connectedness between GSIBs and GSIIs, especially on a regional level, highlights the importance of monitoring cross-sectoral exposures between banks and insurance companies, and the need for intense supervision of financial conglomerates. Comprehensive group-wide supervision should account for all risk activities undertaken in a group and its constituent entities, including subsidiaries. Moreover, a rise in system connectedness should alert policymakers and regulators to be vigilant about potential build-up of risks in the global financial system. Finally, 'non-traditional' indicators, such as global economic policy uncertainty, may convey useful information on risks in the financial system.

Going forward, the current analysis can be extended and enhanced along several dimensions. First, it would be interesting to explore whether factors considered relevant for predicting global connectedness are priced within the cross-section of GSIBs and GSIIs. For example, what is the (time-varying) price of risk corresponding to each factor? Second, we intend to analyze dynamics of global connectedness under different scenarios for the pricing factors, using quantile regression frameworks. Finally, it would be interesting to contrast the connectedness measure with other types' of systemic risk measures including the CoVAR. 


\section{Box 2. Projecting Global Connectedness Conditional on a U.S. Growth Scenario}

Here we explore longer-term projections from our model. Extended paths for our conditioning variables are calibrated based on their historical behavior from September 2002 to December 2004. The motivation for focusing on this period is based on a historical reading of the U.S. growth data. Since 1990, this was the only period of time when U.S. growth increased over subsequent years to be close to 4 percent, after starting from a point very close to current 2016 level. Over the same period, specifically September 2002 to December 2004, the U.S. 10-year yield maintained a general upward trend from 3.87 percent to 4.23 percent. At our prediction origin, the level of yields is considerably lower than where is stood at September 2002. Our conditioning path for US10 is thus adapted to circumvent shift in level, by constructing a trend based on the average growth rate in yields over the historical period.

U.S. Real Growth and 10-year Yields-2002-2004
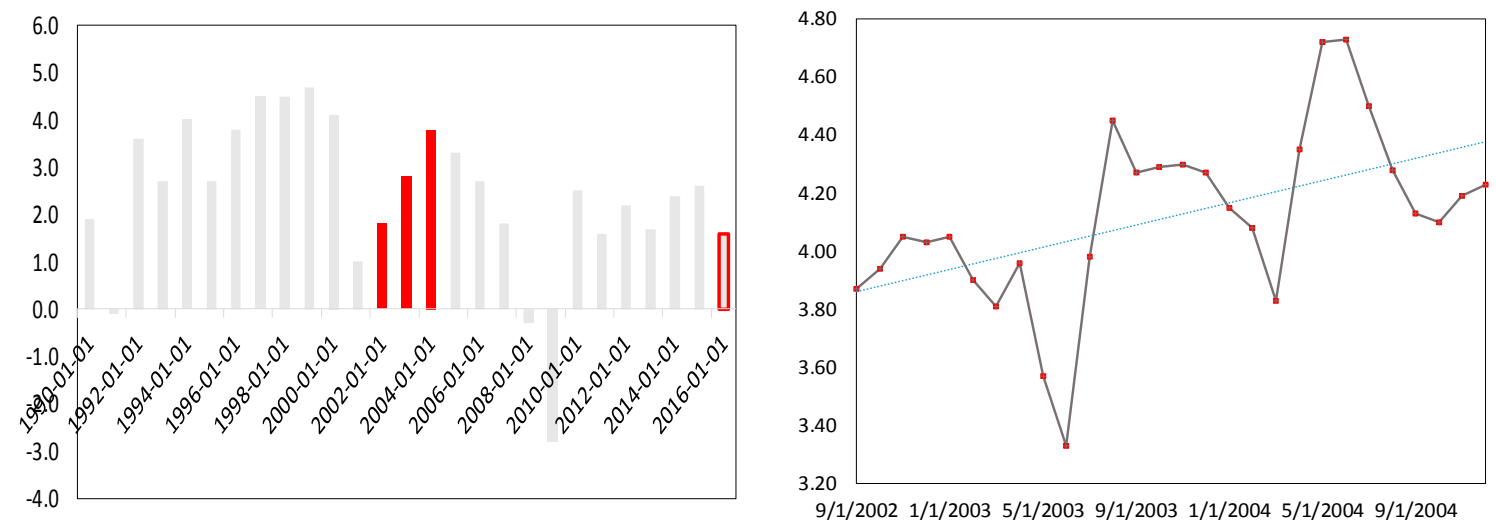

Source: Bloomberg, FRED, IMF Staff estimates

Notes: Left panel - Real GDP percentage change from previous period, not seasonally adjusted. Right panel - evolution of U.S. 10-year yield (in percent) from September 2002 to December 2004.

We consider three different conditioning paths for the global economic policy uncertainty (GPU), based on the maximum, minimum, and median levels of the index, observed over 12 months preceding January 2017. The level of VIX is taken to be the 2002-2004 average. In the figure, dashed lines traced the predictions for GC, conditional on the median GPU measure. The median path is located within upper and lower bounds, defined by conditioning paths based on the historical maximum and minimum for GPU.

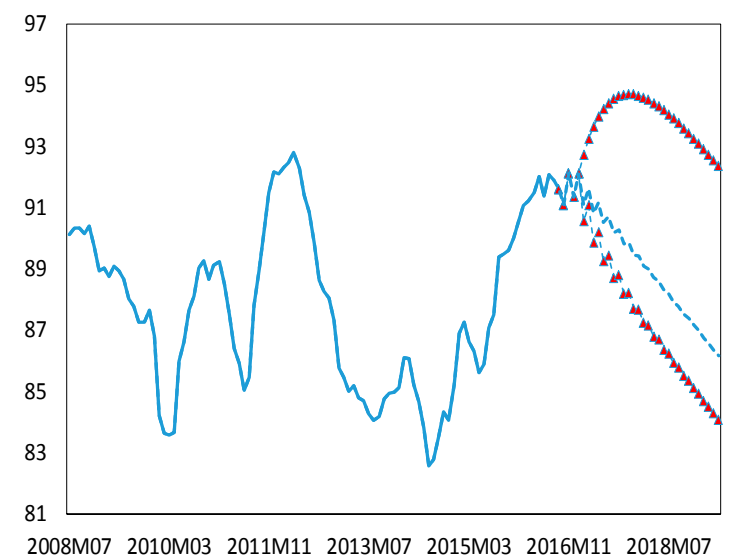

The main takeaway from our long-term projection - conditioning on a trajectory for US10 informed by U.S. growth scenario, described above, and the median level of economic policy uncertainty—is that a fall in global connectedness to its early 2015 level can be expected over a horizon of 2.5 years, approximately. 


\section{REFERENCES}

Acharya, Viral V. and Lasse H. Pedersen and Thomas Philippon and Matthew Richardson, (2010), "Measuring systemic risk," Federal Reserve Bank of Cleveland Working Paper 1002, Federal Reserve Bank of Cleveland.

Acharya, Viral V., Robert Engle and Matthew Richardson (2012), "Capital Shortfall: A New Approach to Ranking and Regulating Systemic Risks", American Economic Review, 102, 3, 59-64. See also V-Lab: http://vlab.stern.nyu.edu/en/welcome/risk/

Adrian, Tobias, and Markus K Brunnermeier (2016), "CoVAR”, American Economic Review $106,7,1705-1741$.

Ang, Andrew, Monika Piazzesi, and Min Wei (2006), "What Does the Yield Curve Tell Us About GDP Growth?” Journal of Econometrics, vol. 131, no. 1-2, pp. 359-403.

Baker, Scott R. Nicholas Bloom, and Steven J. Davis (2016), "Measuring Economic Policy Uncertainty." Quarterly Journal of Economics, vol. 131(4), pp. 1593-1636.

Bansal, R., and Yaron, A., (2004), "Risk for the Long-Run: A Potential Resolution of Asset Pricing Puzzles.” Journal of Finance 59, pp. 1418-1485.

Bekaert, G., and Hoerova, M., (2016), "What Do Asset Prices Have to Say About Risk Appetite and Uncertainty?” Journal of Banking and Finance, 67, pp 103-118.

Bollerslev T. (1986), "Generalized Autoregressive Conditional Heteroscedasticity." Journal of Econometrics 31:307-27. 1986.

Campbell, J. Y., and Cochrane, J. H., (1999), "By Force of Habit: A Consumption Based Explanation of Aggregate Stock Market Behavior.” Journal of Political Economy 107, pp. 205-251.

Dewenter, Kathryn L., and Leigh A. Riddick, (2015) "What's the Value of a TBTF Guaranty? Evidence from the G-SII Designation for Insurance Companies." Available at SSRN: https://ssrn.com/abstract=2547723 or http://dx.doi.org/10.2139/ssrn.2547723

Demirer, Mert and Diebold, Francis X. and Liu, Laura and Y1lmaz, Kamil (2015), "Estimating Global Bank Network Connectedness," Koç University-TUSIAD Economic Research Forum Working Papers 1512, Koc University-TUSIAD Economic Research Forum.

Diebold, Francis X. and Y1lmaz, Kamil (2009), "Measuring Financial Asset Return and Volatility Spillovers, with Application to Global Equity Markets," Economic Journal (119), $158-171$.

, (2012), "Better to Give than to Receive: Predictive Measurement of Volatility of Spillovers," International Journal of Forecasting, 28, 57-66. 
, (2014), "On the Network Topology of Variance Decompositions: Measuring the Connectedness of Financial Firms," Journal of Econometrics, Elsevier, vol. 182(1), pages 119-134.

, (2015), "Trans-Atlantic Equity Volatility Connectedness: U.S. and European Financial Institutions, 2004-2014," Journal of Financial Econometrics, Society for Financial Econometrics, vol. 14(1), pp 81-127.

Estrella, A. and Mishkin, F.S. (1996), "The Yield Curve as a Predictor of U.S. Recessions." Current Issues in Economics and Finance, Federal Reserve Bank of New York 2, 1-6.

Forbes, Kristin J. and Rigobon, Roberto (2002), "No Contagion, Only Interdependence: Measuring Stock Market Comovements," Journal of Finance, 57, 2223-2261.

GFSR (April 2015), “Enhancing Policy Traction and Reducing Risks,” GFSR Report, Chapter 1.

GFSR (April 2016a), “The Growing Importance of Financial Spillovers from Emerging Market Economies" GFSR Report, Chapter 2.

GFSR (April 2016b), “The Insurance Sector-Trends and Systemic Risk Implications” GFSR Report, Chapter 3.

Guimaraes-Filho, Roberto and Hong, Gee Hee (2016), "Dynamic Connectedness of Asian Equity Markets," IMF Working Paper 16/57.

International Association of Insurance Supervisors (2011), "Insurance and Financial Stability", November 2011.

Jackson, M.O. (2008), “Social and Economic Networks," Princeton University Press.

Newman, M.E.J. (2010), Networks: An Introduction, Oxford University Press.

Ohnsorge, F. L., M. Wolski, and Zhang, Y. S. (2014), "Safe Havens, Feedback Loops, and Shock Propagation in Global Asset Prices," IMF Working Papers 14/81, International Monetary Fund

Pearl, J. (2000), Causality: Models, Reasoning, and Inference, Cambridge University Press.

Segoviano, M., S. Malik, P. Lindner, and P. Cortes (2017), "A Comprehensive Multi-Sector Framework for Surveillance of Systemic Risk and Interconnectedness (SyRIN)", IMF Working Paper, forthcoming.

Sims, C. A. (2002), "Solving Linear Rational Expectations Models," Computational Economics, 20(1-2),1-20. 
Stock, J. H., and Watson, M.W. (1989), "New Indexes of Coincident and Leading Indicators.” In: Blanchard, O., Fischer, S. (Eds.), NBER Macroeconomics Annual. MIT Press, Cambridge, MA.

Pesaran, M. Hashem, and Shin, Yongcheol (1996), "Cointegration and Speed of Convergence to Equilibrium," Journal of Econometrics, 71(1-2), 117-143.

Porter, Nathan, and Xu, TengTeng (2006), "Money-Market Rates and Retail Interest Regulation in China: The Disconnect between Interbank and Retail Credit Conditions," International Journal of Central Banking, vol. 12(1), pages 143-198, March 2016.

White, H. and K. Chalak (2009), "Settable Systems: An Extension of Pearl's Causal Model with Optimization, Equilibrium, and Learning," Journal of Machine Learning Research, 10, 1759-1799. 


\section{APPENDIX}

Appendix Figure 1. Net Dynamic Return Spillover to the System of GSIBs
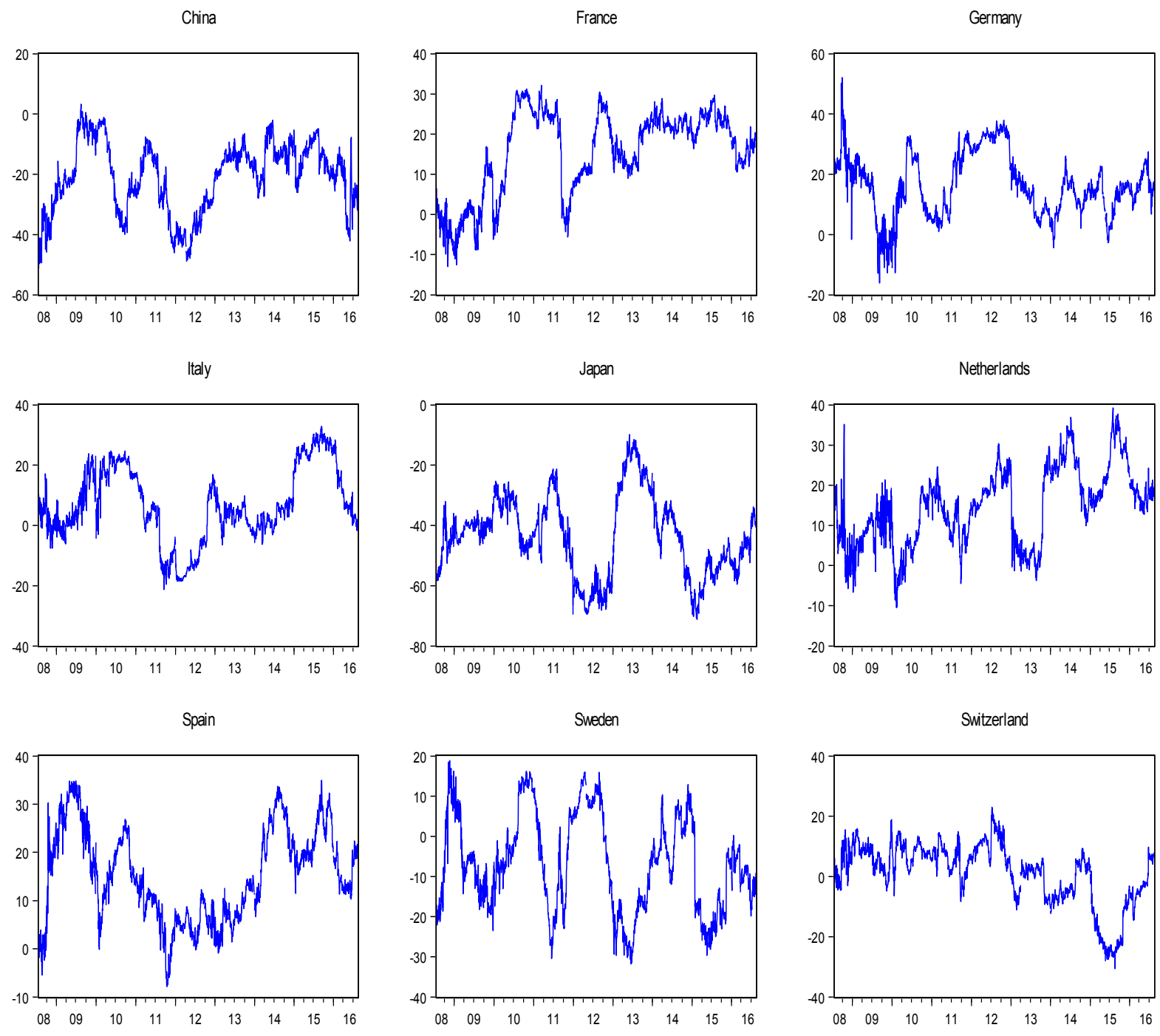

UK
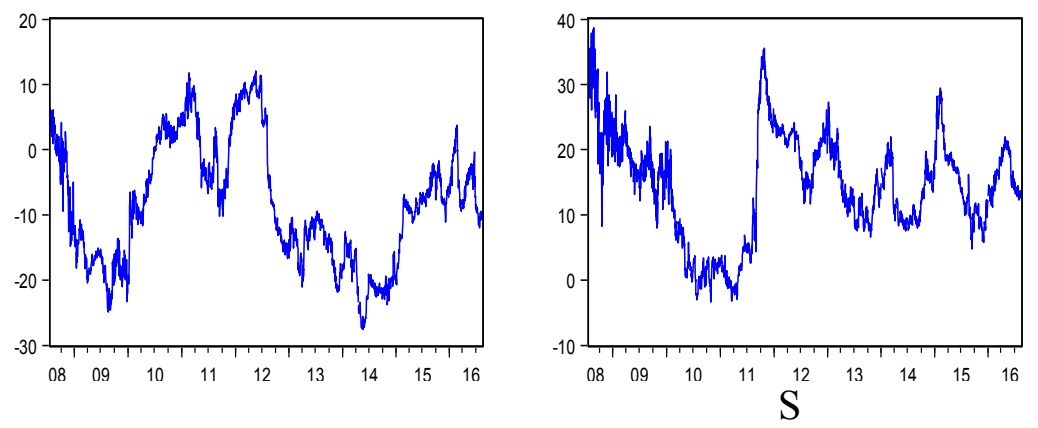
Appendix Figure 2. Net Dynamic Volatility Spillover to the System of GSIBs

China

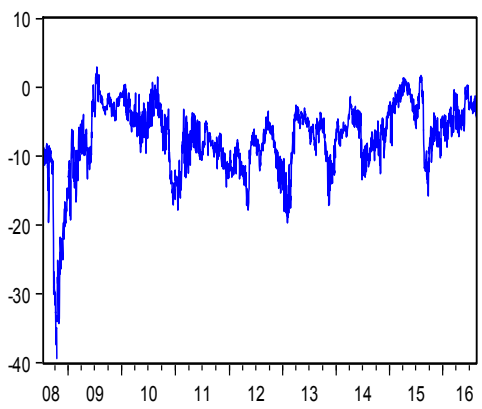

Italy

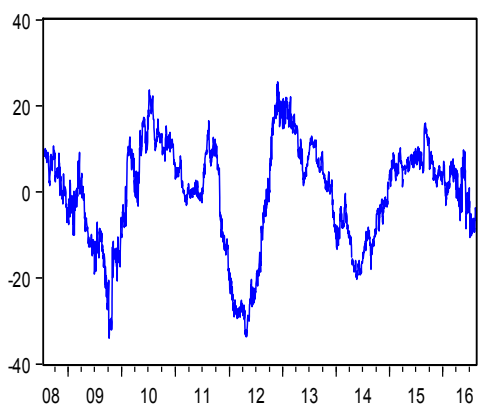

Spain

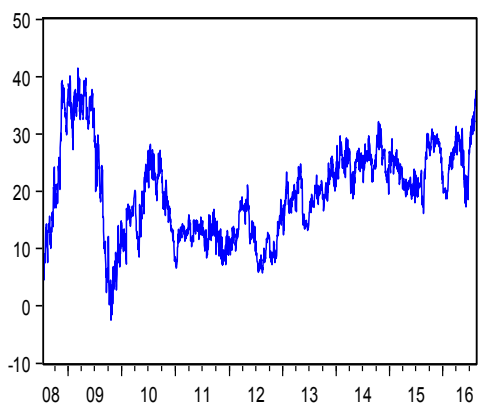

UK

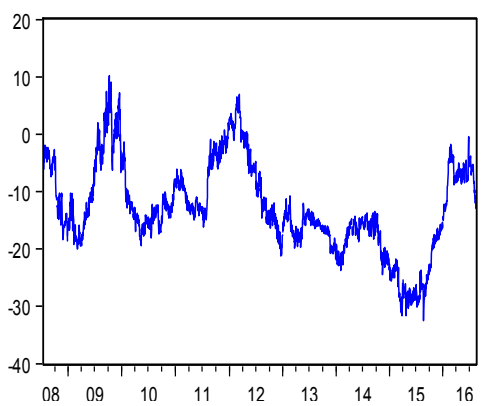

France

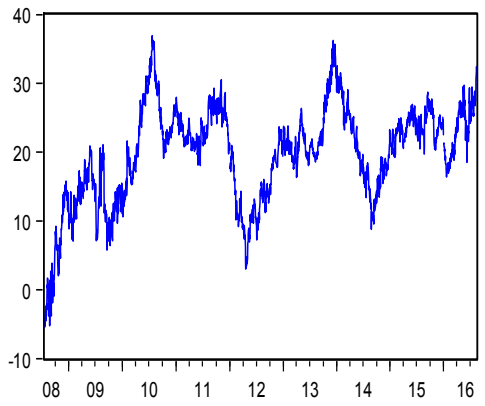

Japan

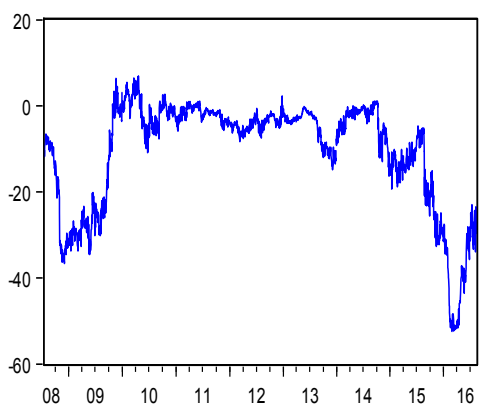

Sweden

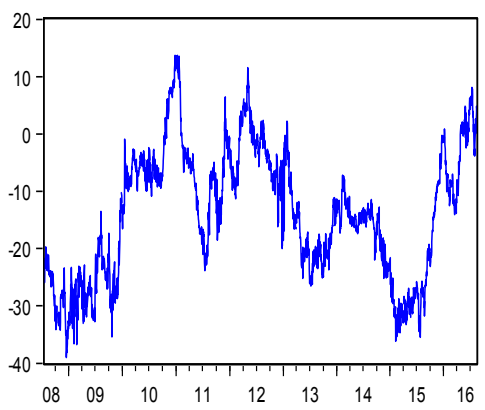

US

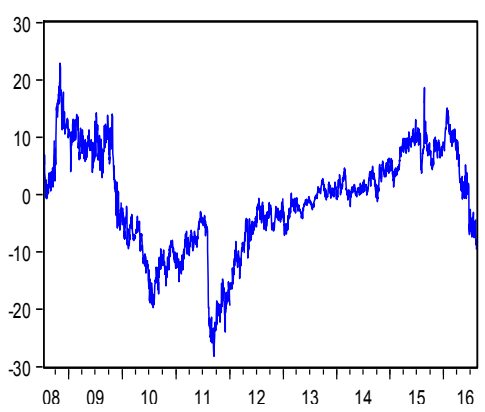

Germany

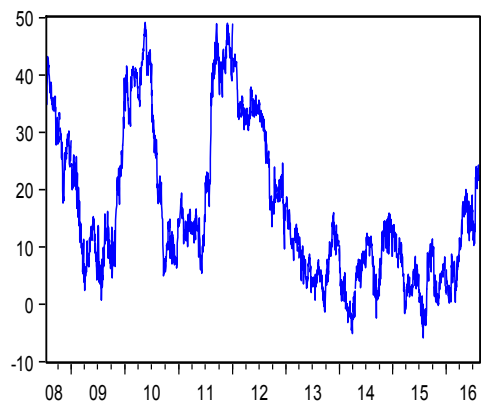

Netherlands

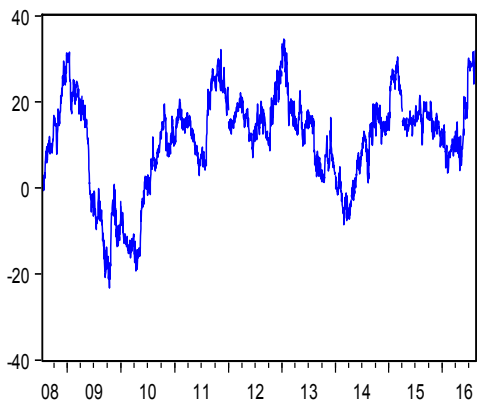

Switzerland

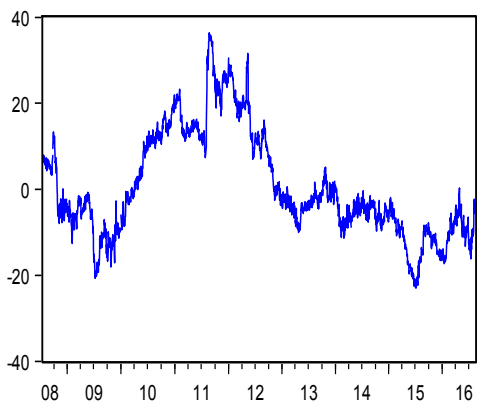


Appendix Figure 3. Net Dynamic Return Spillover to the System of GSIls
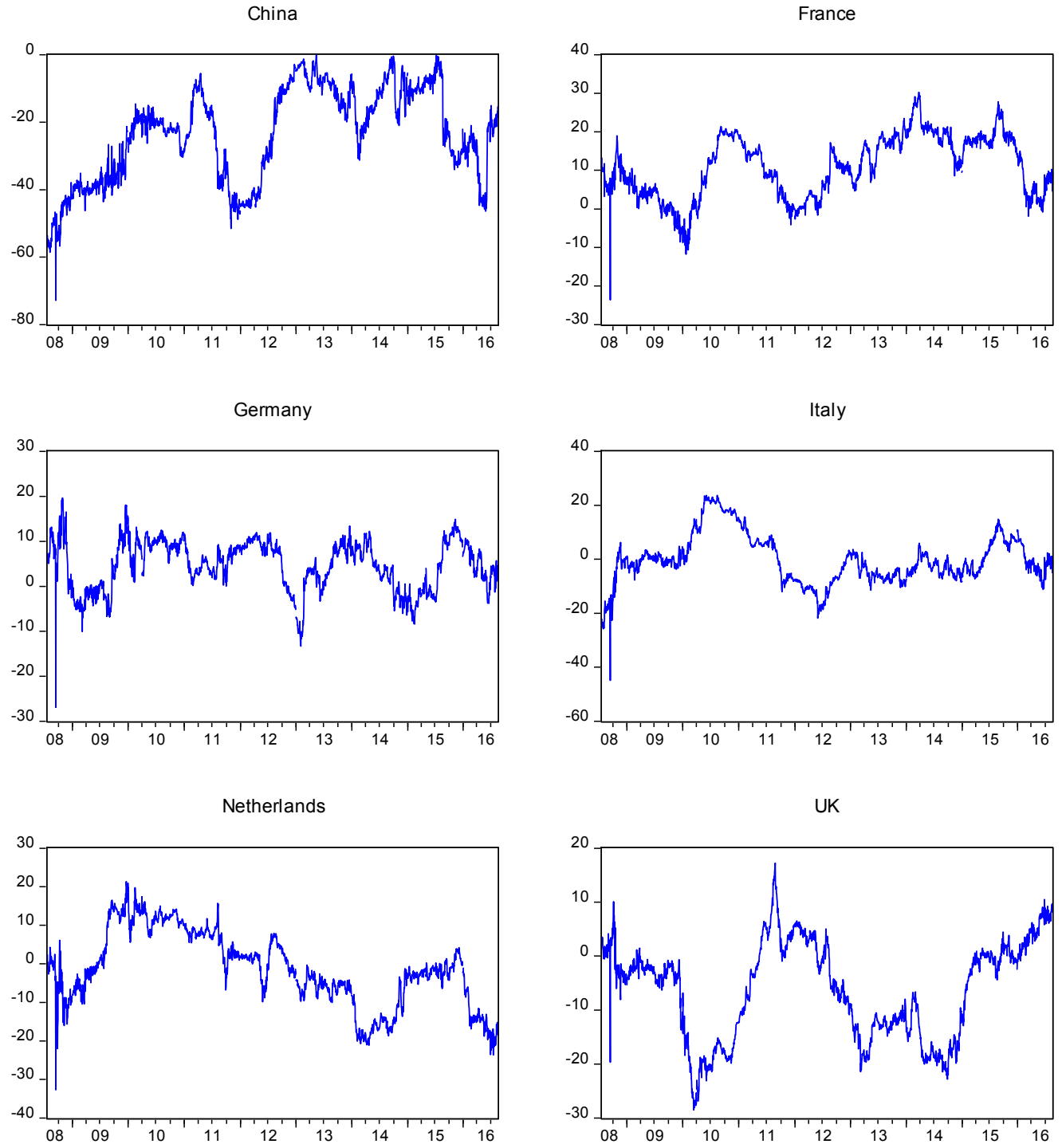

US

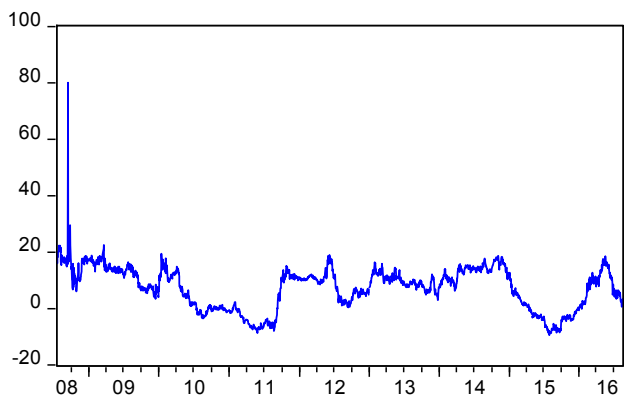


Appendix Figure 4. Net Dynamic Volatility Spillover to the System of GSIIs
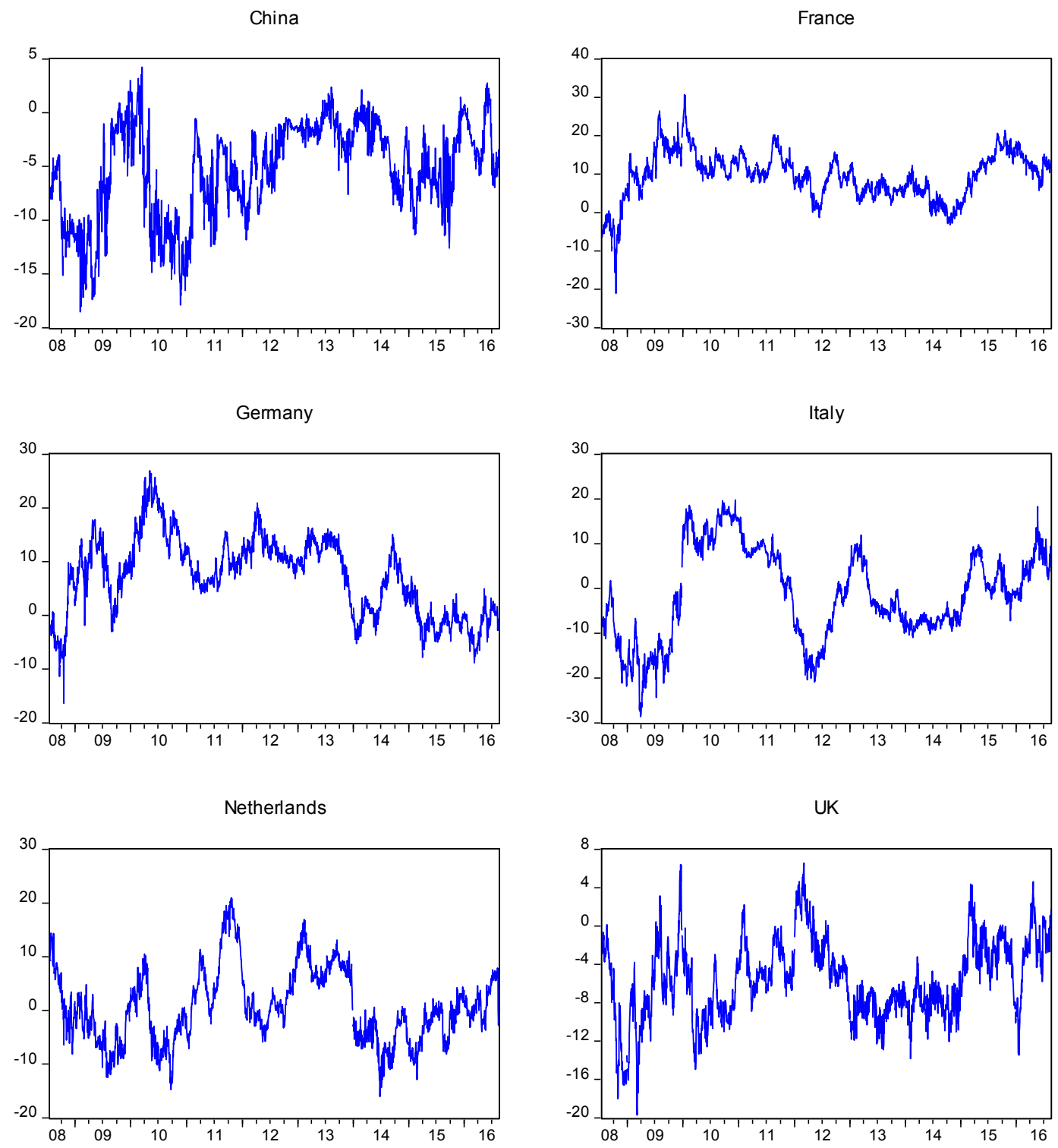

US

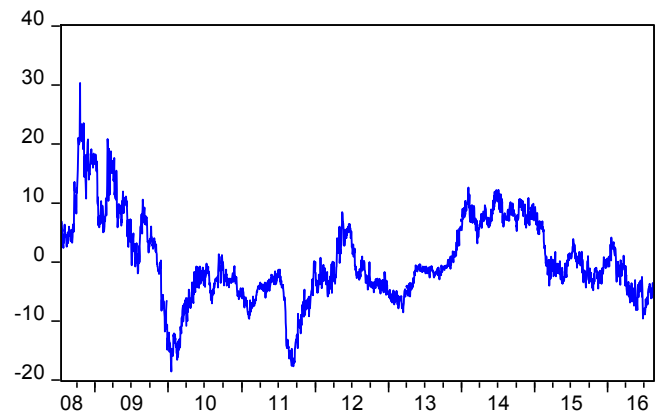


Appendix Figure 5. Robustness Check—Alternative Market Prices

Total Connectedness: CDS Spreads

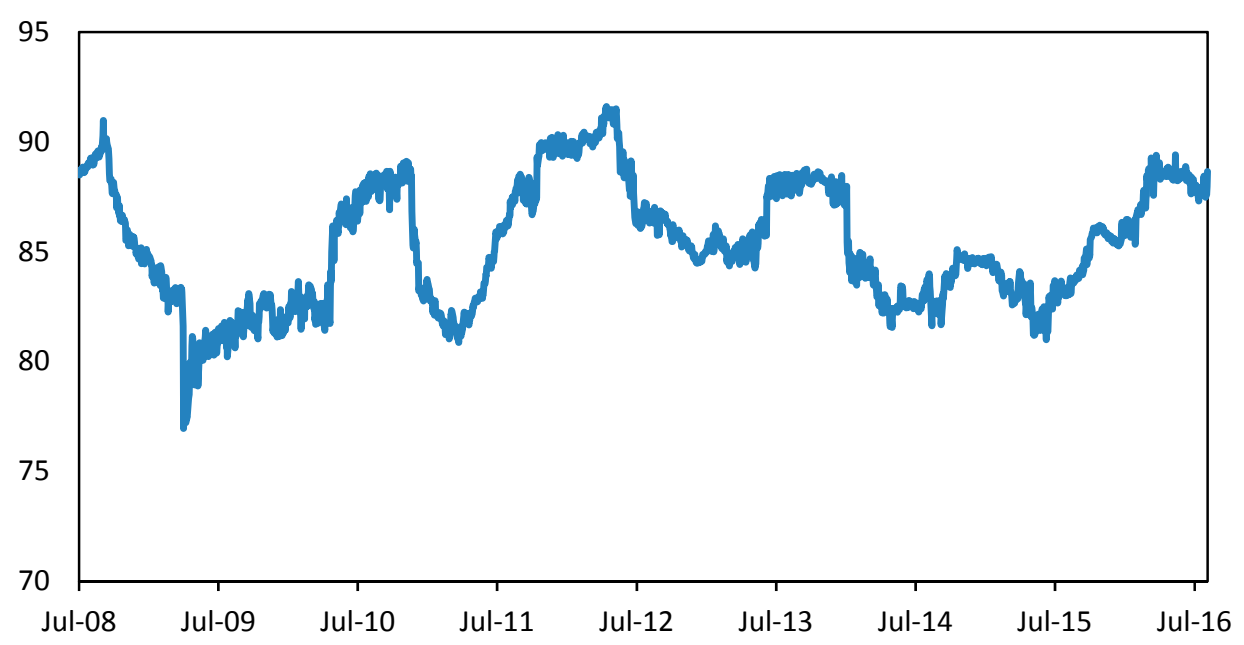

Total Connectedness: Equity Volatility

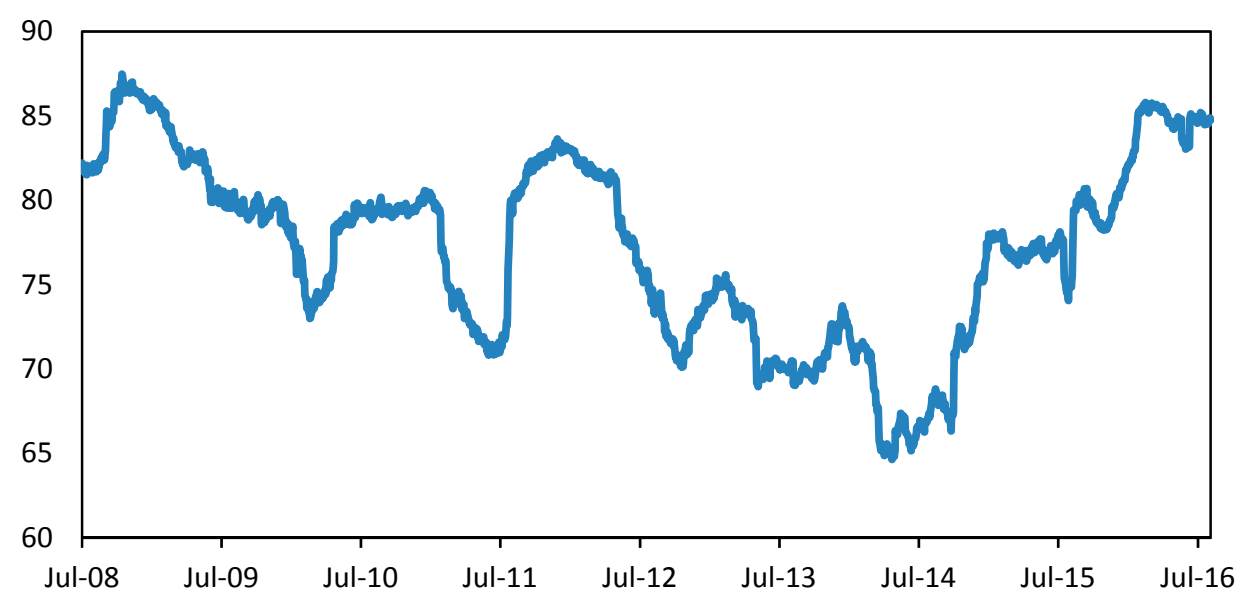

CInternational Monetary Fund. Not for Redistribution 


\section{Appendix Figure 6. Robustness Check-Estimation Window}

Total Return Connectedness: Estimation window $=150$ days

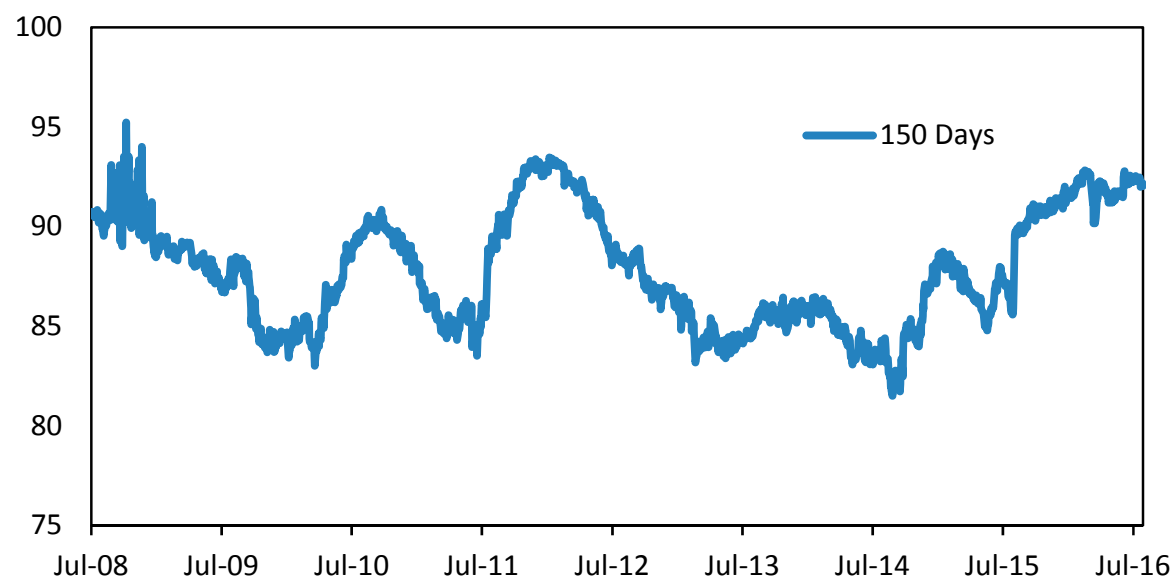

Total Return Connectedness: Estimation window $=200$ days

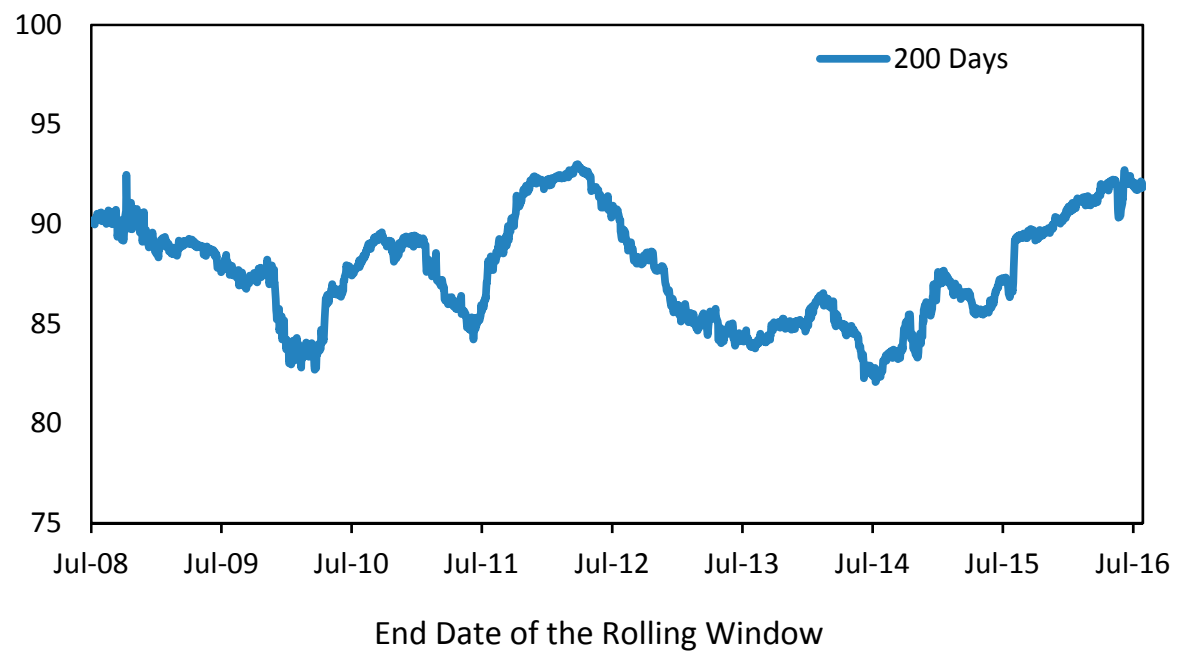

CInternational Monetary Fund. Not for Redistribution 


\section{Appendix Figure 7. Robustness Check-Lag Order}

Total Volatility Connectedness: Lag Order $=2$

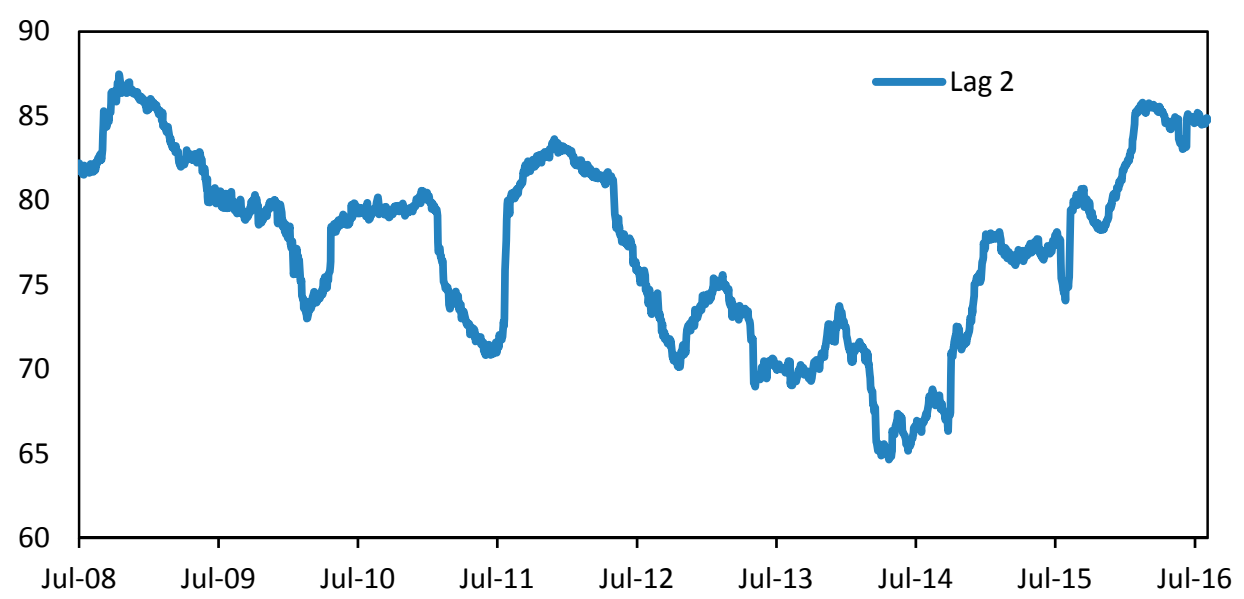

Total Volatility Connectedness: Lag Order $=3$

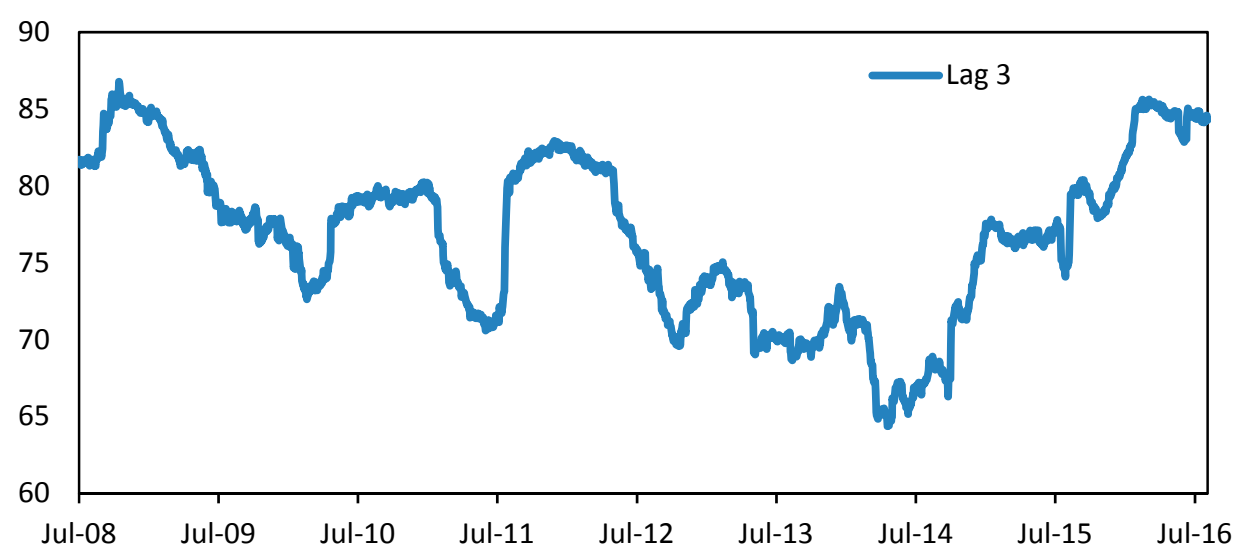


Appendix Figure 8. Robustness Check-Forecast Horizon

Total Return Connectedness: Forecast Horizon $=12$ Days

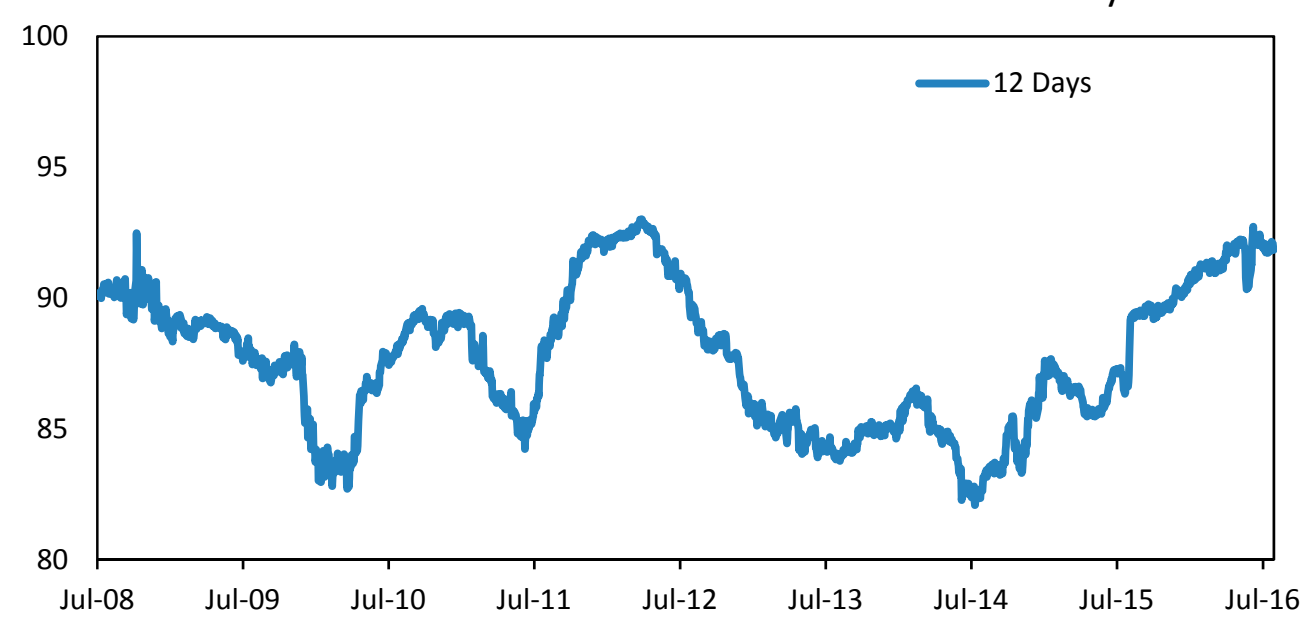

Total Return Connectedness: Forecast Horizon $=24$ Days

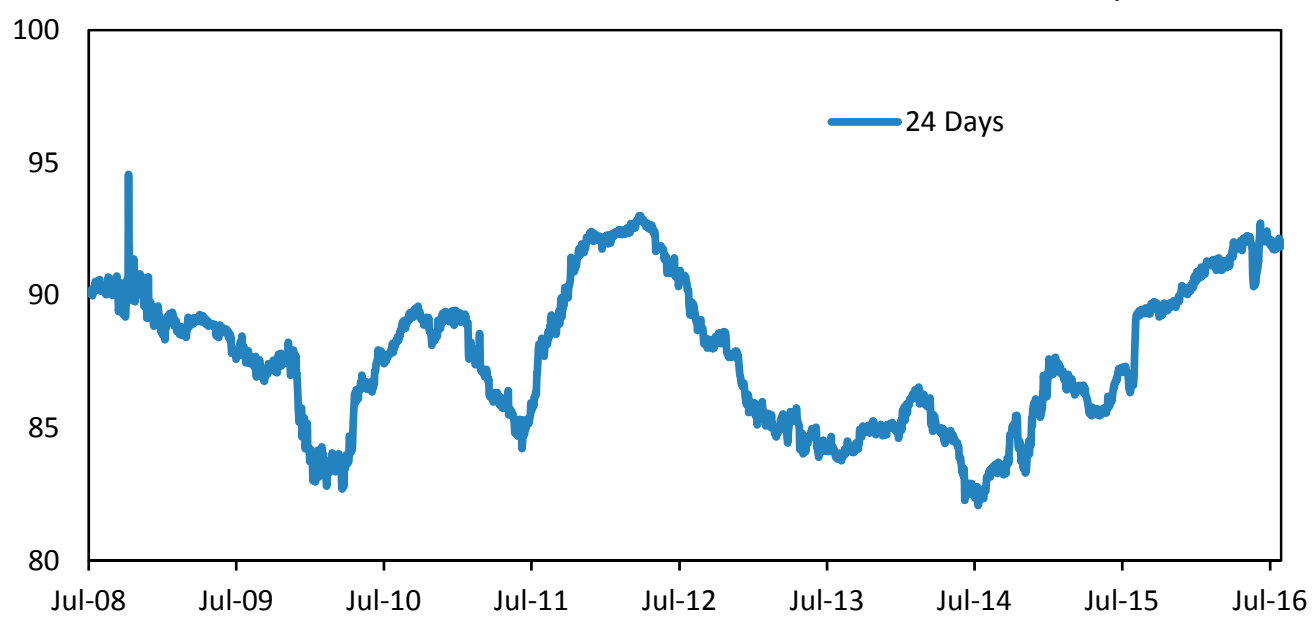

Appendix Table 1. Global Connectedness Pair-Wise Correlations

\begin{tabular}{ccccccc}
\hline GPU & SLOPE & US10 & VIX & US3 & MOVE & DXY \\
0.57 & -0.40 & -0.38 & 0.29 & 0.22 & 0.21 & 0.15 \\
\hline
\end{tabular}

Source: Bloomberg, Bankscope, FRED, IMF Staff estimates Note: Sample: July 2008-August 2016. 


\section{Appendix Figure 9. Global Connectedness vs. Three-Month Yields}

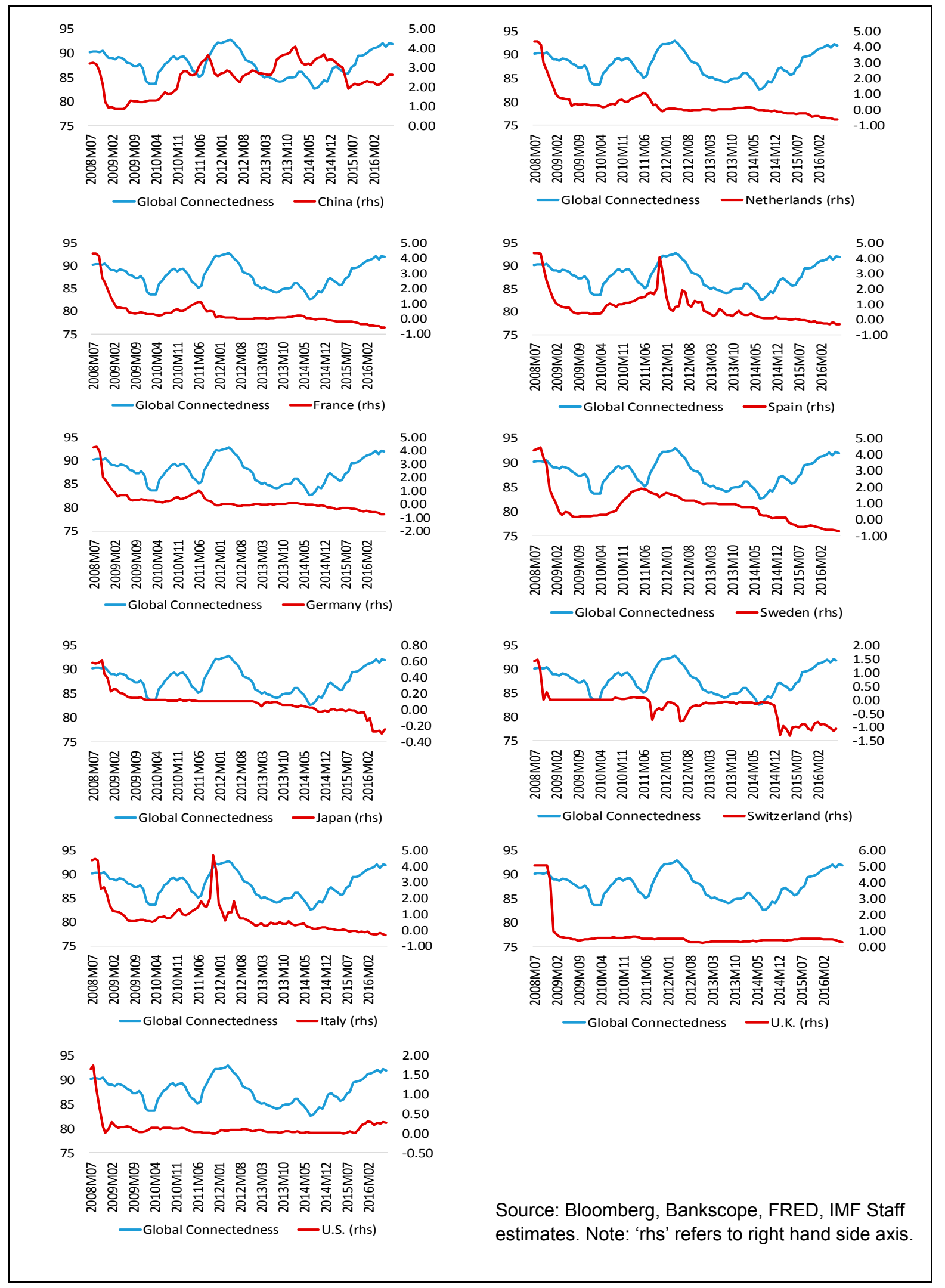


Appendix Figure 10. Global Connectedness vs. Ten-Year Yields

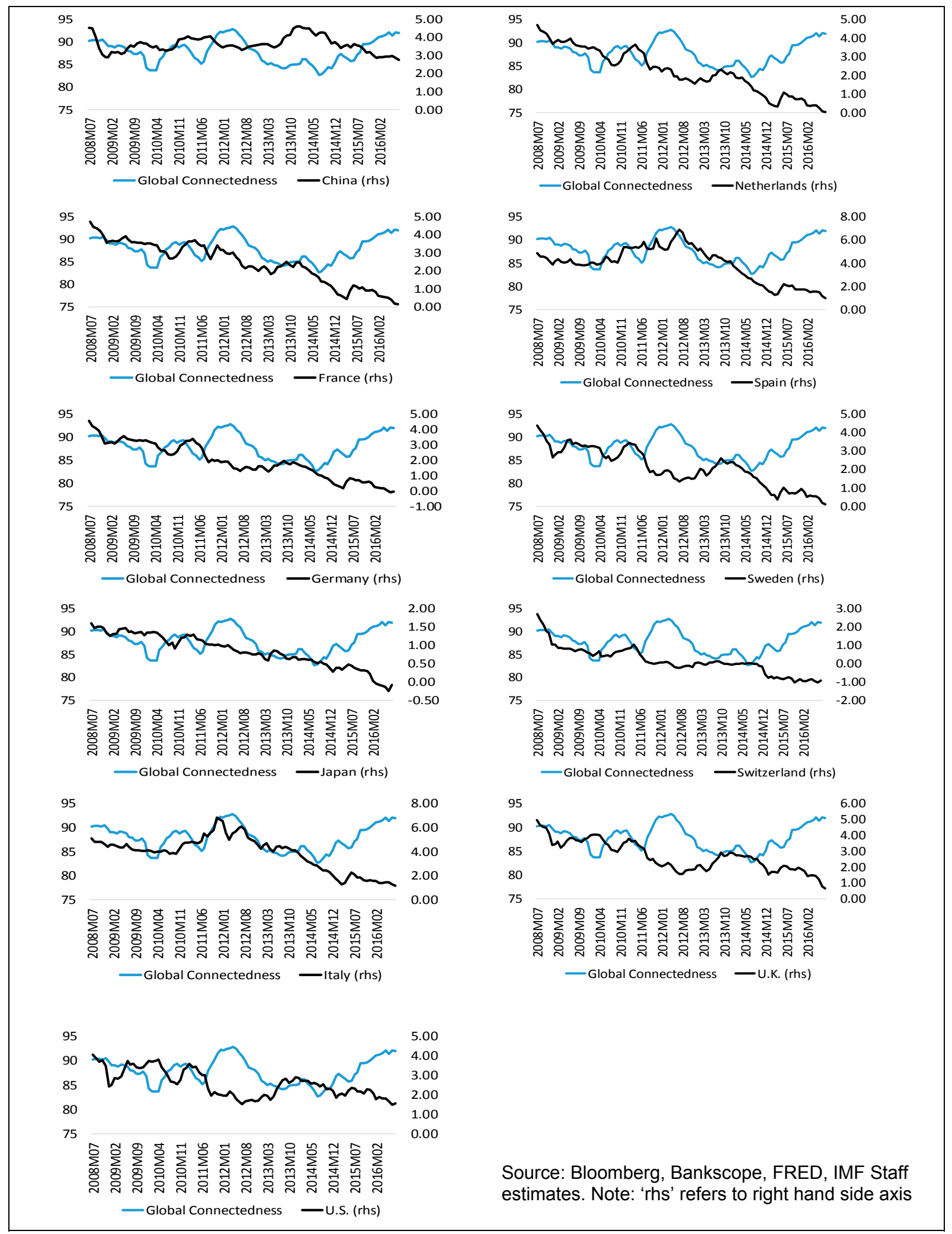

